\title{
TRANSPORTATION ENERGY FUTURES SERIES
}

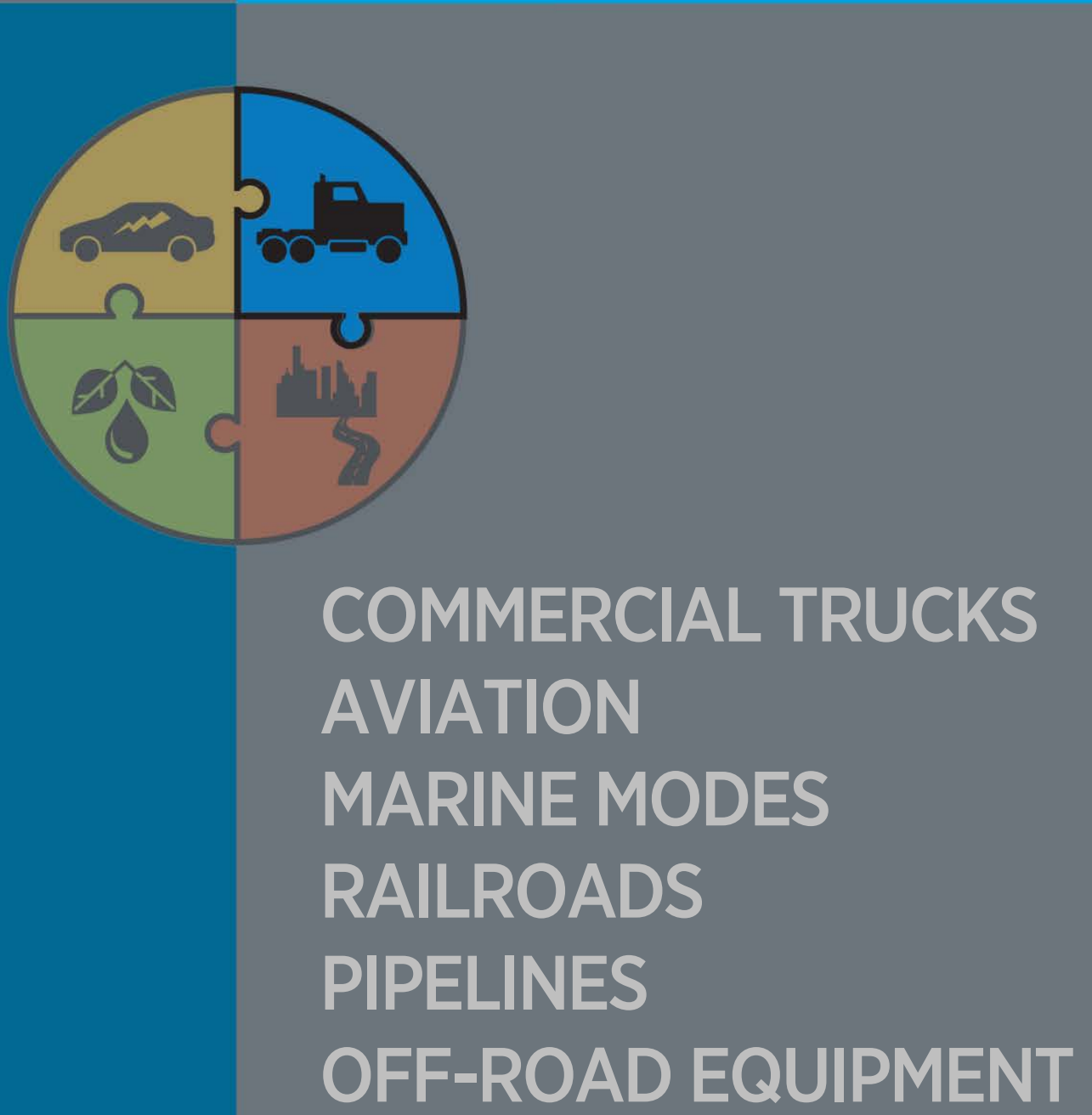

Potential for Energy Efficiency Improvement Beyond the Light-Duty-Vehicle Sector 



\title{
TRANSPORTATION ENERGY FUTURES SERIES: \\ Potential for Energy Efficiency Improvement Beyond the \\ Light-Duty-Vehicle Sector
}

\author{
A Study Sponsored by \\ U.S. Department of Energy \\ Office of Energy Efficiency and Renewable Energy
}

February 2013

Prepared by

ARGONNE NATIONAL LABORATORY

Argonne, IL 60439

managed by

U Chicago Argonne, LLC

for the

U.S. DEPARTMENT OF ENERGY

under contract DE-AC02-06CH11357

This report was prepared as an account of work sponsored by an agency of the United States Government. Neither the United States Government nor any agency thereof, nor any of their employees, makes any warranty, expressed or implied, or assumes any legal liability or responsibility for the accuracy, completeness, or usefulness of any information, apparatus, product, or process disclosed, or represents that its use would not infringe privately owned rights. Reference herein to any specific commercial product, process, or service by trade name, trademark, manufacturer, or otherwise, does not necessarily constitute or imply its endorsement, recommendation, or favoring by the United States Government or any agency thereof. The views and opinions of authors expressed herein do not necessarily state or reflect those of the United States Government or any agency thereof. 


\section{About the Transportation Energy futures Project}

This is one of a series of reports produced as a result of the Transportation Energy Futures (TEF) project, a U.S. Department of Energy (DOE)-sponsored multi-agency project initiated to identify underexplored strategies for abating greenhouse gases and reducing petroleum dependence related to transportation. The project was designed to consolidate existing transportation energy knowledge, advance analytic capacity-building, and uncover opportunities for sound strategic action.

Transportation currently accounts for $71 \%$ of total U.S. petroleum use and $33 \%$ of the nation's total carbon emissions. The TEF project explores how combining multiple strategies could reduce GHG emissions and petroleum use by $80 \%$. Researchers examined four key areas - lightduty vehicles, non-light-duty vehicles, fuels, and transportation demand - in the context of the marketplace, consumer behavior, industry capabilities, technology and the energy and transportation infrastructure. The TEF reports support DOE long-term planning. The reports provide analysis to inform decisions about transportation energy research investments, as well as the role of advanced transportation energy technologies and systems in the development of new physical, strategic, and policy alternatives.

In addition to the DOE and its Office of Energy Efficiency and Renewable Energy, TEF benefitted from the collaboration of experts from the National Renewable Energy Laboratory and Argonne National Laboratory, along with steering committee members from the Environmental Protection Agency, the Department of Transportation, academic institutions and industry associations. More detail on the project, as well as the full series of reports, can be found at http://www.eere.energy.gov/analysis/transportationenergyfutures.

Contract Nos.

DC-A36-08GO28308 and DE-AC02-06CH11357 


\section{AVAILABILITY}

This report is available electronically at http://www.osti.gov/bridge

Available for a processing fee to U.S. Department of Energy and its contractors, in paper form, from:

U.S. Department of Energy

Office of Scientific and Technical

Information

P.O. Box 62

Oak Ridge, TN 37831-0062

phone: 865.576 .8401

fax: 865.576 .5728

email: reports@adonis.osti
Available for sale to the public, in paper form, from:

U.S. Department of Commerce

National Technical Information Service 5285 Port Royal Road

Springfield, VA 22161

phone: 800.553 .6847

fax: 703.605 .6900

email: orders@ntis.fedworld.gov

online

ordering: http://www.ntis.gov/help/ordermet hods.

\section{Citation}

Please cite as follows:

Vyas, A. D.; Patel, D. M.; Bertram, K. M. (February 2013). Potential for Energy Efficiency Improvement Beyond the Light-Duty-Vehicle Sector. Transportation Energy Futures Series. Prepared for the U.S. Department of Energy by Argonne National Laboratory, Argonne, IL. DOE/GO-102013-3706. 82 pp. 


\section{REPORT CONTRIBUTORS AND ROLES}

Argonne National Laboratory

Anant D. Vyas

Lead and primary author

Deena M. Patel

Primary researcher and contributing author

Kenneth M. Bertram

Contributing author 


\section{ACKNOWLEDGMENTS}

We are grateful to colleagues who reviewed portions or the entirety of this report in draft form, including:

Dr. James Corbett, Professor, Marine Policy, University of Delaware

Don Kopinski, Senior Program Manager, National Vehicle and Fuel Emissions Laboratory, U.S. Environmental Protection Agency

John Maples, Transportation Team Lead, Office of Energy Analysis, Energy Information Administration, U.S. Department of Energy

James Tamm, Chief, Fuel Economy Division, National Highway Traffic Safety Administration

Dr. Mazyar Zeinali, Researcher, International Council on Clean Transportation

Participants in an initial Transportation Energy Futures scoping meeting in June 2010 representing the U.S. Department of Energy and National Laboratories - assisted by formulating innovative and timely ideas to consider for the project. Steering Committee members and observers offered their thoughtful perspective on transportation analytic research needs as well as insightful comments on an initial Transportation Energy Futures work plan in a December 2010 meeting, and periodic teleconferences through the project.

Many analysts and managers at the U.S. Department of Energy played important roles in sponsoring this work and providing valuable guidance. From the Office of Energy Efficiency and Renewable Energy, Sam Baldwin and Carla Frisch provided leadership in conceptualizing the project. A core team of analysts collaborated closely with the national lab team throughout implementation of the project. These included:

Jacob Ward and Philip Patterson (now retired), Vehicle Technologies Office

Tien Nguyen and Fred Joseck, Fuel Cell Technologies Office

Zia Haq, Kristen Johnson, and Alicia Lindauer-Thompson, Bioenergy Technologies Office

The national lab project management team consisted of Austin Brown, Project Lead, and Laura Vimmerstedt, Project Manager, (from the National Renewable Energy Laboratory); and Tom Stephens, Argonne Lead (from Argonne National Laboratory). Data analysts, life cycle assessment analysts, managers, contract administrators, administrative staff, and editors at both labs offered their dedication and support to this effort. 



\section{TABLe Of Contents}

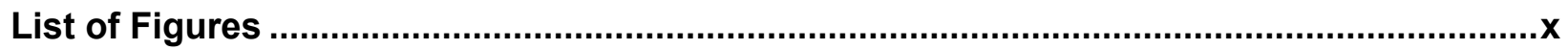

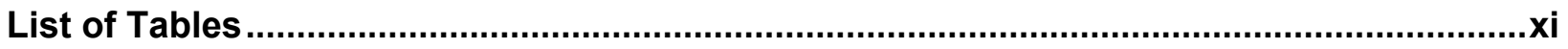

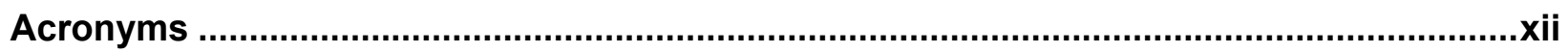

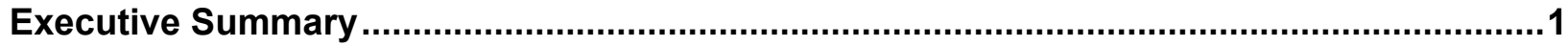

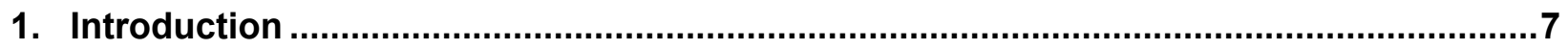

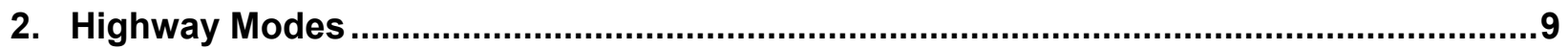

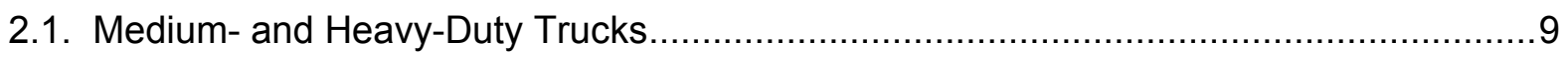

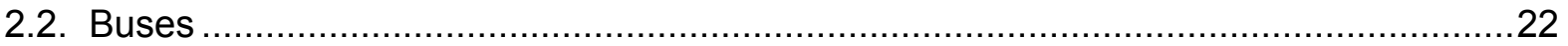

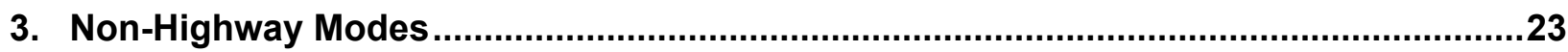

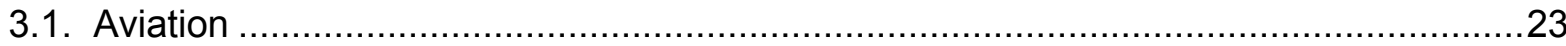

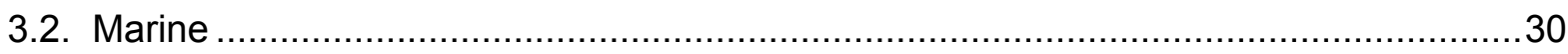

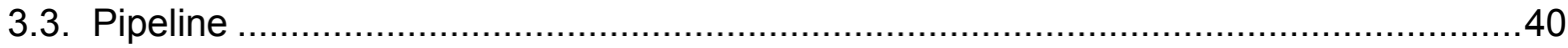

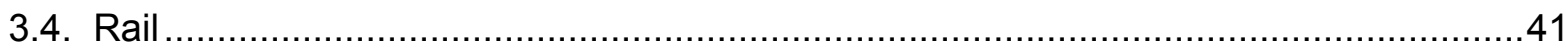

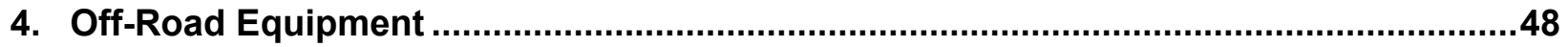

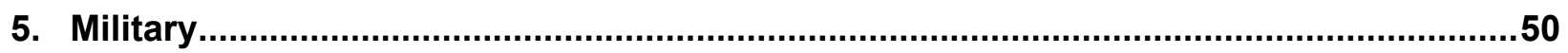

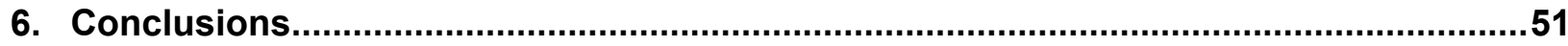

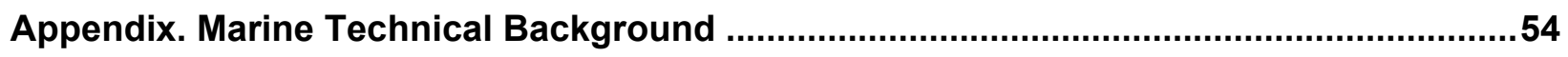

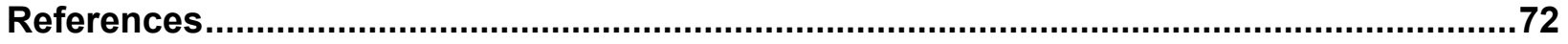

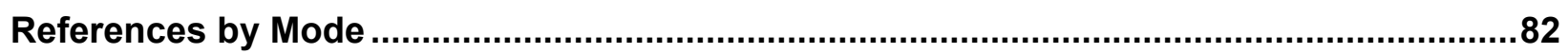




\section{LIST OF FIGURES}

Figure ES.1. Transportation energy, including off-road equipment .....................................

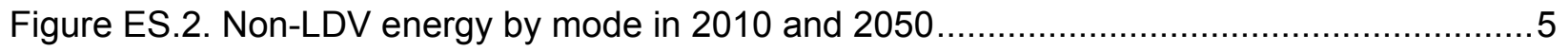

Figure ES.3. Non-LDV energy consumption by fuel type in 2010 and $2050 \ldots \ldots \ldots \ldots \ldots \ldots \ldots \ldots \ldots \ldots \ldots \ldots \ldots \ldots \ldots \ldots . . . .6 \ldots$

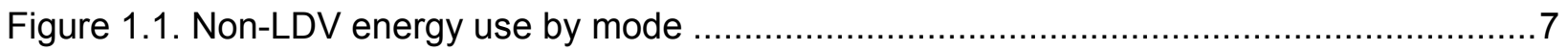

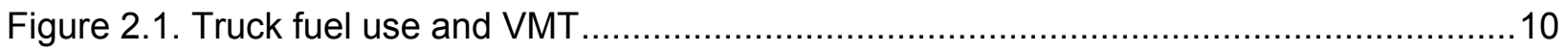

Figure 2.2. Average medium- and heavy-duty truck energy intensity .....................................11

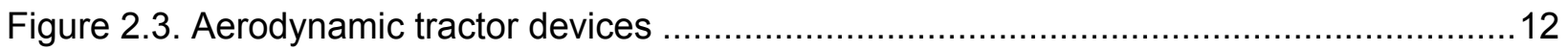

Figure 2.4. Air and rolling resistance as a function of velocity for a typical combination

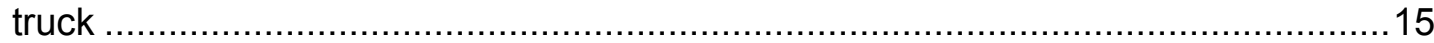

Figure 2.5. Aerodynamic devices on a tractor-trailer: side skirts and boat tail.........................16

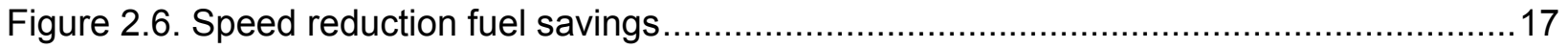

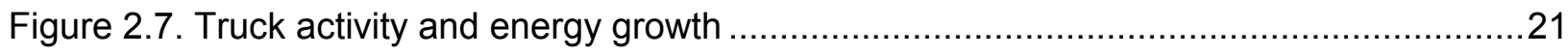

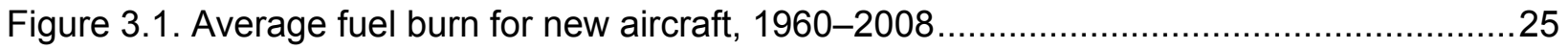

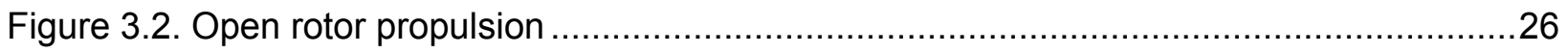

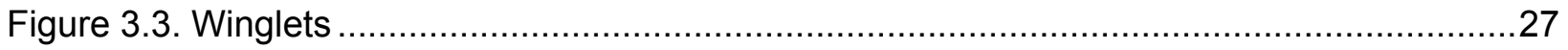

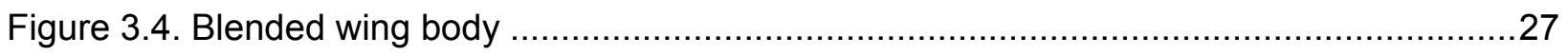

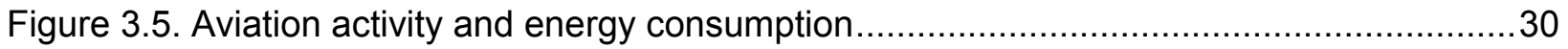

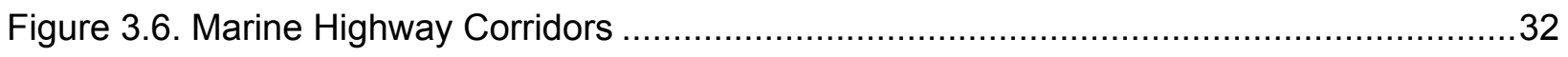

Figure 3.7. $\mathrm{CO}_{2}$ emissions intensity by ship type compared with rail and truck ........................33

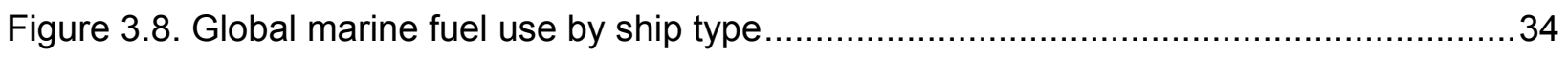

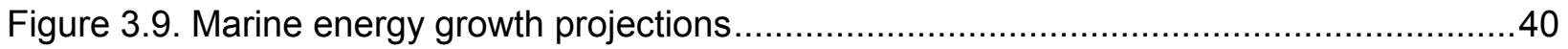

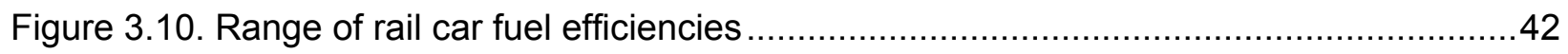

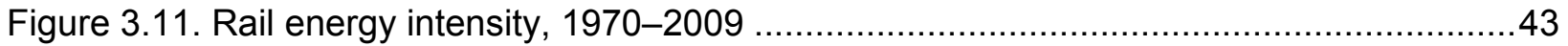

Figure 3.12. Railroad activity and energy consumption forecast .......................................... 47

Figure 5.1. Trend in Department of Defense energy consumption .....................................50 


\section{LIST OF TABLES}

Table ES.1. Energy Intensity Improvement Potential for Non-LDV Modes................................ 1

Table ES.2. Heavy-Duty Truck Efficiency Improvements Ranked by Cost Effectiveness ............ 3

Table ES.3. Medium-Duty Truck Efficiency Improvements Ranked by Cost Effectiveness.......... 3

Table ES.4. Energy Intensity Improvement Potential (\%), Activity Growth (\%), and Net

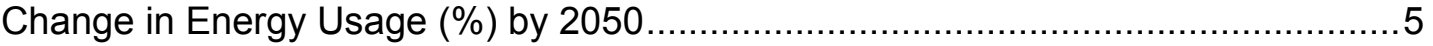

Table 2.1. Truck Categories and Gross Vehicle Weight Classes ........................................ 9

Table 2.2. Summary of Truck Energy Intensity Improvement Potential .................................19

Table 2.3. Truck Incremental Capital Cost for Energy Efficiency Improvements ......................20

Table 3.1. Summary of Aviation Energy-Intensity Improvement Potential ...............................29

Table 3.2. International Maritime Fuel and $\mathrm{CO}_{2}$ Savings Potential by 2050 ............................34

Table 3.3. Coastal Shipping Technology Options for Fuel and $\mathrm{CO}_{2}$ Reduction .......................36

Table 3.4. Inland Shipping Technology Options for Fuel and $\mathrm{CO}_{2}$ Reduction .........................38

Table 4.1. Off-Road Subsectors and Equipment Type .....................................................48

Table A.1. Estimated Annual OGV Port of Richmond Emissions by Operational Mode .............68

Table A.2. Estimated Annual Emissions (tons/year) for Selected California Ports ....................68

Table A.3. Port of Los Angeles $\mathrm{CO}_{2}$-equivalent Reductions by Source Type, 2005-2009 ........69 


\section{ACronyms}

\begin{tabular}{|c|c|}
\hline AAPN & American Apparel Producers Network \\
\hline AEO & Annual Energy Outlook \\
\hline AFL & American Feeder Lines \\
\hline AMP & alternative maritime power \\
\hline ASM & available seat miles \\
\hline ASTM & American Society for Testing and Materials \\
\hline ATA & American Trucking Associations \\
\hline ATM & air traffic management \\
\hline BAU & business as usual \\
\hline BNSF & Burlington Northern and Santa Fe (Railroad) \\
\hline BTS & Bureau of Transportation Statistics \\
\hline Btu & British thermal unit \\
\hline CAFE & Corporate Average Fuel Economy \\
\hline CANSO & Civil Air Navigation Services Organization \\
\hline CARB & California Air Resources Board \\
\hline CCPFR & capital cost per percent fuel reduction \\
\hline CNG & compressed natural gas \\
\hline CNS & communications, navigation, and surveillance \\
\hline $\mathrm{CO}_{2}$ & carbon dioxide \\
\hline $\mathrm{COB}$ & container on barge \\
\hline DOD & U.S. Department of Defense \\
\hline DOE & U.S. Department of Energy \\
\hline ECA & Emission Control Area \\
\hline $\mathrm{ECP}$ & electronically controlled pneumatic \\
\hline EGR & exhaust gas recirculation \\
\hline EIA & U.S. Energy Information Administration \\
\hline EPA & U.S. Environmental Protection Agency \\
\hline EU & European Union \\
\hline FAA & Federal Aviation Administration \\
\hline FERC & Federal Energy Regulatory Commission \\
\hline FHWA & Federal Highway Administration \\
\hline FRA & Federal Railroad Administration \\
\hline $\mathrm{GbD}$ & Greener by Design \\
\hline GDP & gross domestic product \\
\hline GHG & greenhouse gases \\
\hline GLIN & Great Lakes Information Network \\
\hline GPS & Global Positioning System \\
\hline GVW & gross vehicle weight \\
\hline HFO & heavy fuel oil (also known as residual fuel oil) \\
\hline HSC & Houston Ship Channel \\
\hline
\end{tabular}




\begin{tabular}{|c|c|}
\hline HVAC & heating, ventilation, and air conditioning \\
\hline ICAO & International Civil Aviation Organization \\
\hline ICCT & International Council for Clean Transportation \\
\hline IEA & International Energy Agency \\
\hline IMO & International Maritime Organization \\
\hline IPCC & International Panel on Climate Change \\
\hline LDV & light-duty vehicle \\
\hline LNG & liquid natural gas \\
\hline LPG & liquid petroleum gas \\
\hline MAC & marginal abatement costs \\
\hline MARAD & U.S. Maritime Administration \\
\hline MDO & marine diesel oil \\
\hline MGO & marine gas oil \\
\hline NAS & National Academy of Sciences \\
\hline NASA & National Aeronautics and Space Administration \\
\hline NBB & National Biodiesel Board \\
\hline NESCCAF & Northeast States Center for Clean Air Future \\
\hline NHTSA & National Highway Traffic Safety Administration \\
\hline $\mathrm{NO}_{\mathrm{x}}$ & nitrogen oxides \\
\hline OECD & Organization for Economic Cooperation and Development \\
\hline OGV & ocean-going vessel \\
\hline OPRF & Ocean Policy Research Foundation \\
\hline ORNL & Oak Ridge National Laboratory \\
\hline OSV & offshore support vessel \\
\hline PANYNJ & Port Authority of New York and New Jersey \\
\hline PHA & Port of Houston Authority \\
\hline PM & particulate matter \\
\hline PTC & positive train control \\
\hline quad & quadrillion Btu \\
\hline $\mathrm{RO} / \mathrm{RO}$ & roll-on/roll-off \\
\hline ROG & reactive organic gases \\
\hline RPM & revenue passenger miles \\
\hline SAE & Society of Automotive Engineers \\
\hline SCR & selective catalytic reduction \\
\hline $\mathrm{SO}_{\mathrm{x}}$ & sulfur oxides \\
\hline TAD & trackside acoustic detector \\
\hline TEU & Twenty-foot equivalent unit (container) \\
\hline TMT & ton-miles of travel \\
\hline U.S. DOT & U.S. Department of Transportation \\
\hline VIUS & Vehicle Inventory and Use Survey \\
\hline VMT & vehicle miles of travel \\
\hline VOC & volatile organic compounds \\
\hline VSR & vessel speed reduction \\
\hline
\end{tabular}





\section{EXECUTIVE SUMMARY}

The Transportation Energy Futures (TEF) Study evaluates various technological, fuel substitution, and policy options for reducing transportation-related greenhouse gas (GHG) emissions and petroleum use. In 2009, 30 quadrillion Btu of energy were used in the transportation sector. Light-duty vehicles (LDVs), cars and light trucks, account for 55\% of this energy use. The other $45 \%$ consists of freight and passenger transportation by way of medium- and heavy-duty trucks, buses, aircraft, marine vessels, trains, pipeline, and off-road equipment (Table ES.1). These are the non-light-duty vehicle (non-LDV) transportation modes.

\begin{tabular}{|c|c|c|}
\hline & 2030 & 2050 \\
\hline Medium- and Heavy-Duty Trucks & $15 \%-30 \%$ & $25 \%-50 \%$ \\
\hline Aviation & $30 \%-40 \%$ & $50 \%-65 \%$ \\
\hline Marine & $40 \%$ & $50 \%-75 \%$ \\
\hline Pipeline & $10 \%$ & $20 \%$ \\
\hline Rail & $15 \%-17 \%$ & $30 \%-35 \%$ \\
\hline Off-Road Equipment & & $15 \%-18 \%$ \\
\hline
\end{tabular}

While there has been considerable research focusing on energy efficiency and fuel substitution options for LDVs, much less attention has been given to non-LDV modes, even though they constitute close to half of the energy used in the transportation sector (Figure ES.1). We conducted an extensive literature review of the non-LDV modes, and in this report we bring together the salient findings concerning future energy efficiency options in the time period up to 2050 . The studies reviewed provided potential energy savings for individual technologies within each mode, as well as an overall energy savings representing the case where all possible improvements are implemented. The overall mode improvement estimate accounts for mutually exclusive technologies and the possibility that some technologies may counteract the effects of others. In addition, we discuss the projected activity increases in each of the modes and combine this with forecasts of overall energy efficiency improvement potential to estimate the total GHG emissions relative to current levels and to a "business as usual" case based on Annual Energy Outlook (AEO) 2011 projections.

We find that there is room for technological and operational improvements in energy efficiency for each non-LDV mode, as summarized in Table ES.2. However, energy savings due to these improvements are essentially nullified by projected increases in the volume of activity by the U.S. Energy Information Administration and the Federal Aviation Administration, leaving non-LDV energy use and GHG emissions unchanged from 2010 levels. Considerable improvements will be necessary just to maintain the energy consumption and emission status quo. In order to decrease GHG emissions below 2010 levels, levers such as activity reduction, mode shift, demand reduction, and fuel substitution would need to be implemented in parallel with technological and operational energy efficiency measures. Other reports in the TEF series address these areas.

\footnotetext{
${ }^{1}$ Authors' estimates based on literature review. Each publication listed energy efficiency improvement potential for individual technology and collective improvement for all technologies, accounting for mutually exclusive technologies and conflicting effects of a few. The values listed here represent ranges of these collective estimates. The potential for off-road equipment represents authors' estimates.
} 


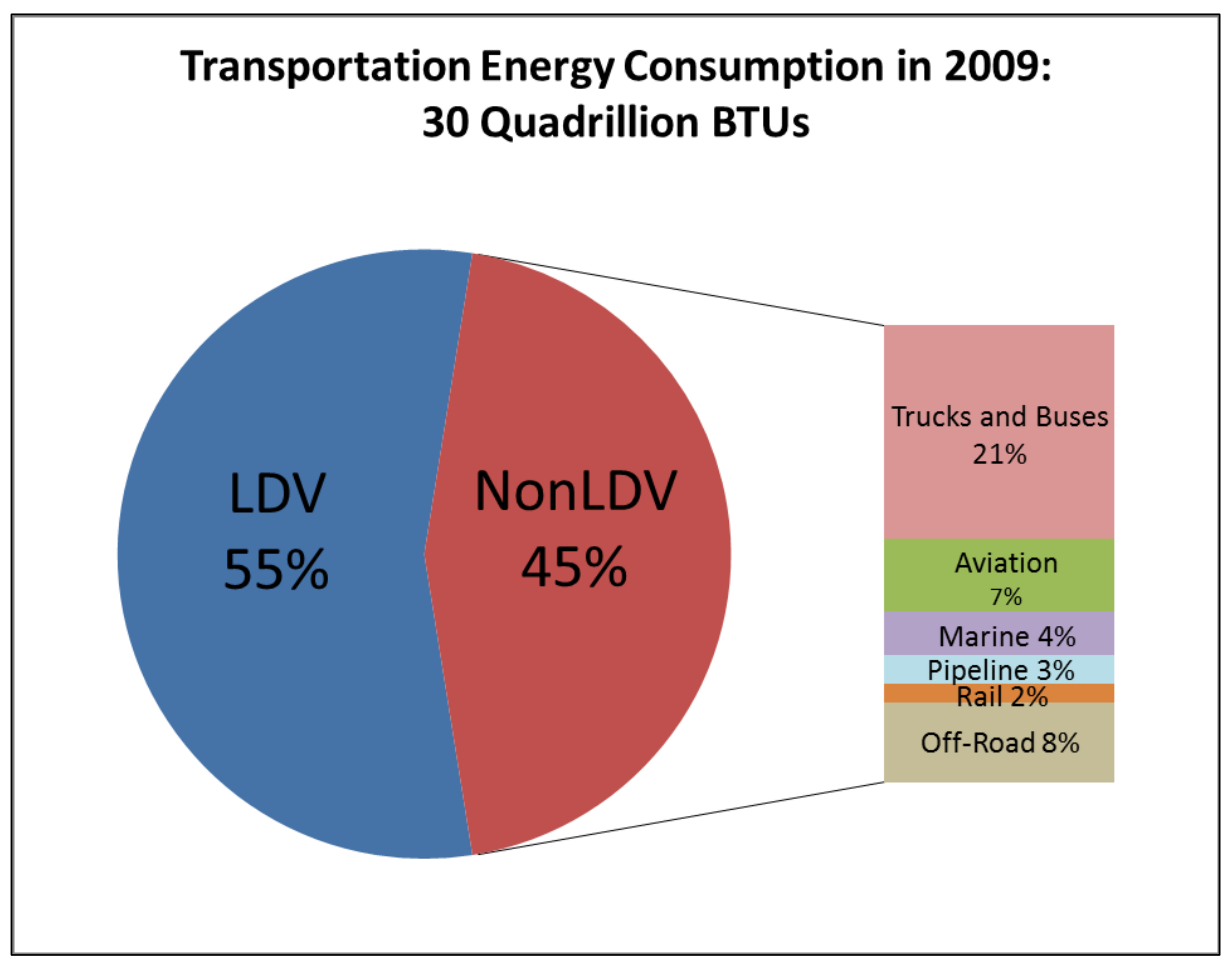

Figure ES.1. Transportation energy, including off-road equipment

(Source: Davis et al. 2011)

\section{Non-LDV Sector Potential Energy Intensity Improvement}

The non-LDV sector has three categories: highway, non-highway, and off-road equipment. The highway mode consists of medium- and heavy-duty trucks and buses. The non-highway modes consists of aviation, marine, pipeline, and rail. Off-road equipment includes construction, agriculture, forestry, industrial, and lawn equipment, among others.

\section{Trucks}

Of the non-LDV modes, medium-and heavy-duty trucks consume the most energy. Trucks accounted for nearly half of all non-LDV energy consumption and carried over $70 \%$ of the freight shipped in the United States in 2007 (Davis et al. 2011). While several studies were reviewed which evaluated technological options for improving energy efficiency in trucks, much of the information presented in this section draws on the 2010 National Academy of Sciences' study (NAS 2010).

A number of technological improvements can potentially decrease medium- and heavy-duty truck energy use enough to result in a $25-50 \%$ reduction in energy intensity by 2050 . The most cost-effective improvement, in terms of cost per percent decrease in energy intensity, is switching to low rollingresistance tires. Additionally, several engine improvements are possible. Waste heat recovery technologies, such as turbocompounding and bottoming cycles, provide the largest potential gains in engine energy efficiency. Improved aerodynamics present large efficiency gains for long-haul tractortrailers which travel long distances at high speed. Other technologies, such as hybrid systems and lightweighting, provide more limited gains at higher costs. These measures and their cost effectiveness relative to tire replacement are listed in Table ES.3). For instance, heavy-duty truck transmission and driveline improvement is expected to cost 2.5 times more for each percent decrease in energy intensity as compared to tire replacement. Because of the high usage level of heavy-duty trucks, the fuel savings of these measures add up quickly. Therefore, even including the more costly technologies such as 
hybridization and weight reduction, these measures are cost effective at a fuel price as low as $\$ 1.09 /$ gallon (Table ES.2). Medium-duty trucks have different duty cycles depending on their function. Refuse and delivery trucks, for example, have more stop-and-go driving, making a hybrid system more effective. A similar package of improvements to medium-duty trucks results in cost savings at fuel prices over \$4.17/gallon (Table ES.3).

Table ES.2. Heavy-Duty Truck Efficiency Improvements Ranked by Cost Effectiveness

\begin{tabular}{ll}
\multicolumn{1}{c}{ (Source: NAS 2010) } \\
\hline Improvements (ranked from most to least cost effective) & $\begin{array}{l}\text { Cost Effectiveness } \\
\text { (relative to tire } \\
\text { replacement) }\end{array}$ \\
\hline Low rolling-resistance wide-base single tires & 1.0 \\
Transmission and driveline improvement & 2.5 \\
Tractor and trailer aerodynamics improvement & 3.2 \\
Engine improvement, including bottoming cycle & 3.5 \\
Mild hybrid with idle reduction & 7.7 \\
Weight reduction through material substitution & 33.0 \\
\hline $\begin{array}{l}\text { Total package breakeven fuel price } \\
\text { (based on 7\% discount rate and 10-year life) }\end{array}$ & $\$ 1.09 / g a l l o n$ \\
\hline
\end{tabular}

Table ES.3. Medium-Duty Truck Efficiency Improvements Ranked by Cost Effectiveness

(Source: NAS 2010)

\begin{tabular}{ll}
\hline Improvements (ranked from most to least cost effective) & $\begin{array}{l}\text { Cost Effectiveness } \\
\text { (relative to tire } \\
\text { replacement) }\end{array}$ \\
\hline Low rolling resistance tires & 1.0 \\
Transmission and driveline improvement & 4.5 \\
Aerodynamics improvement & 5.4 \\
Parallel hybrid & 6.7 \\
Improved engine & 9.3 \\
Weight reduction through material substitution & 11.9 \\
\hline $\begin{array}{l}\text { Total package breakeven fuel price } \\
\text { (based on 7\% discount rate and 10 year life) }\end{array}$ & $\$ 4.17 /$ gallon \\
\hline
\end{tabular}

\section{Aviation}

Among the non-highway modes, aviation uses the most energy and was responsible for $16 \%$ of all nonLDV energy consumption in 2009. It is primarily comprised of commercial passenger transport, $80 \%$ of which is for domestic travel and $20 \%$ for international travel. Overall, aviation has the potential for an energy intensity reduction of $50-65 \%$ in the long term. Enhancements to turbofan engines, including improved compressors and "geared turbofans," as well as advanced open rotor engines are capable of delivering better fuel economy. Changes to the airframe include near-term possibilities, such as using winglets and riblets to reduce air friction. These improvements are already considered cost effective at oil prices of $\$ 73 /$ barrel. Longer term improvements include advanced airframe design, using elements such as a blended wing body or strut-braced wings. Operational improvements made possible by implementing satellite navigation systems can decrease congestion and reduce fuel use. 


\section{Marine}

Marine transportation covers domestic and international freight movements and recreational use. Recreational energy use has remained nearly constant over time, and has dropped only during periods of economic downturn. Marine mode transports the bulk of the international freight and international shipping accounts for nearly $80 \%$ of marine freight energy use. This transportation mode has the secondlowest energy intensity next to the rail mode. The United States is projected to increase its global trade by $263 \%$ between 2010 and 2035 and, if the trend continues, the increase could be $450 \%$ by 2050 .

Studies by several international and U.S. organizations were reviewed. These studies evaluated options to improve international marine energy intensity through better ship design, engine and driveline efficiency, waste heat recovery, and operational changes. These studies also examined wind and solar options to improve energy efficiency. The projected range of energy intensity reduction is $25 \%-75 \%$ by 2050 . Also evaluated were several reports on inland waterway transport that projected a potential for $15 \%$ improvement in energy intensity by 2030 and $30 \%$ by 2050 .

\section{Pipeline}

Although there are chemical, petroleum, and natural gas pipelines, only natural gas pipeline energy consumption is assigned to the transportation sector. Natural gas pipelines consumed $6 \%$ of non-LDV energy in 2009 to power compressors. Potential savings can be delivered through more efficient compressors and improved operations. An estimated $20 \%$ energy intensity improvement is possible by 2050.

\section{Rail}

Trains are already a very efficient way of moving freight. Railroads move an amount of ton-miles almost equivalent to that transported by heavy-duty trucks, but use just one-tenth of the energy. Further efficiency improvements are still possible, but more limited than for other modes. Locomotive diesel engine improvements will follow advances in engine technology by the trucking industry. Genset locomotives (utilizing multiple engines and generators) and hybrid locomotives provide improvements in switching and yard operations. Railcar aerodynamics can be improved by using streamlined loading patterns and matching railcars to container size to minimize gaps. Rail and wheel lubrication and steerable trucks can decrease rolling friction. Other improvements included electronically controlled pneumatic (ECP) brakes and positive train control (PTC) which can relieve congestion and decrease idling time, resulting in improved energy efficiency. Also, upgrading the rail system infrastructure has the potential to relieve congestion and reduce fuel usage. Overall, a potential $35 \%$ energy intensity improvement is possible by 2050 .

\section{Off-Road Equipment}

Off-road equipment used in agriculture, airport ground service, construction, forestry, industry, lawn and garden, mining, oil field, rail maintenance, and recreation consumed 2.4 quadrillion Btu, or $17 \%$ of nonLDV energy use in 2009. We estimate the potential for a 15-18\% energy intensity improvement by 2050 . Combining the upper end of the potential energy intensity improvement with a $20 \%$ activity increase expected in 2050 , total energy use is projected to stay close to the 2010 value.

\section{Conclusions}

Even if the most energy efficient technological improvements are implemented by 2050, the projected increases in activity will offset the non-LDV sector efficiency gains and result in an overall net energy use change of 1\% below the 2010 level. Table ES.4 summarizes the maximum projected energy intensity improvements, activity growth, and the resulting net change by mode. Figure ES.2 illustrates the 
maximum energy efficiency case (EE Case), where all the modes reduce energy intensity by the maximum amount possible, in comparison with 2010 values and AEO 2011 projections extended to 2050.

Figure ES.3 illustrates the same projections by fuel type. Shifting to low-carbon fuels can complement energy efficiency and activity reduction. Although we list potential alternative fuels that can reduce carbon intensity and petroleum consumption, it is not the primary focus of this paper, and our literature review is limited in that area. Other TEF research addresses the fuel substitution issue.

Table ES.4. Energy Intensity Improvement Potential (\%), Activity Growth (\%), and Net Change in Energy Usage (\%) by 2050

\begin{tabular}{l|c|c|c|c|c|c|c}
\hline & Trucks & Aviation & $\begin{array}{l}\text { Inland } \\
\text { Marine }\end{array}$ & $\begin{array}{l}\text { Ocean } \\
\text { Marine }\end{array}$ & Rail & Pipeline & Off-road \\
\hline $\begin{array}{l}\text { Energy intensity } \\
\text { improvement }\end{array}$ & 50 & 65 & 30 & 75 & 35 & 20 & 18 \\
Activity growth & $87^{\mathrm{a}}$ & $217^{\mathrm{b}}$ & $32^{\mathrm{a}}$ & $450^{\mathrm{c}}$ & $47^{\mathrm{a}}$ & $16^{\mathrm{a}}$ & $20^{\mathrm{d}}$ \\
\hline Net change & -7 & +11 & \multicolumn{2}{|c|}{+1} & -4 & -7 & -2 \\
\hline
\end{tabular}

${ }^{a}$ EIA projections extrapolated.

${ }^{b}$ FAA projections extrapolated.

${ }^{c}$ Growth in dollar value of trade (EIA).

${ }^{d}$ Projected at half the population growth.

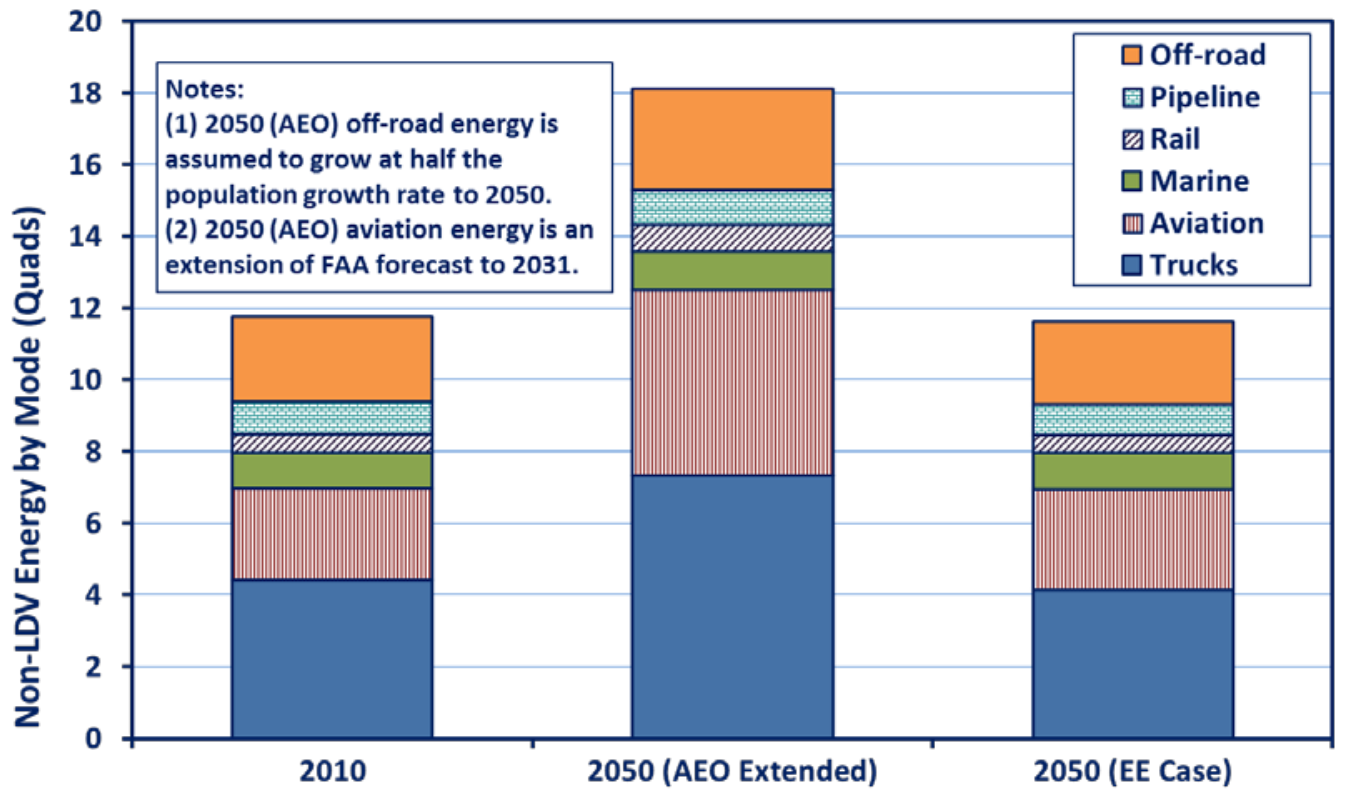

Figure ES.2. Non-LDV energy by mode in 2010 and 2050

After examining potential technological and operational options for energy efficiency improvements found in the non-LDV sector literature, we have concluded that even the most dramatic of these energy efficiency improvements will maintain but not decrease non-LDV GHG emissions, while not implementing these measures - continuing the trend represented by the AEO (Extended) - will increase GHG emissions by as much as $50 \%$. 


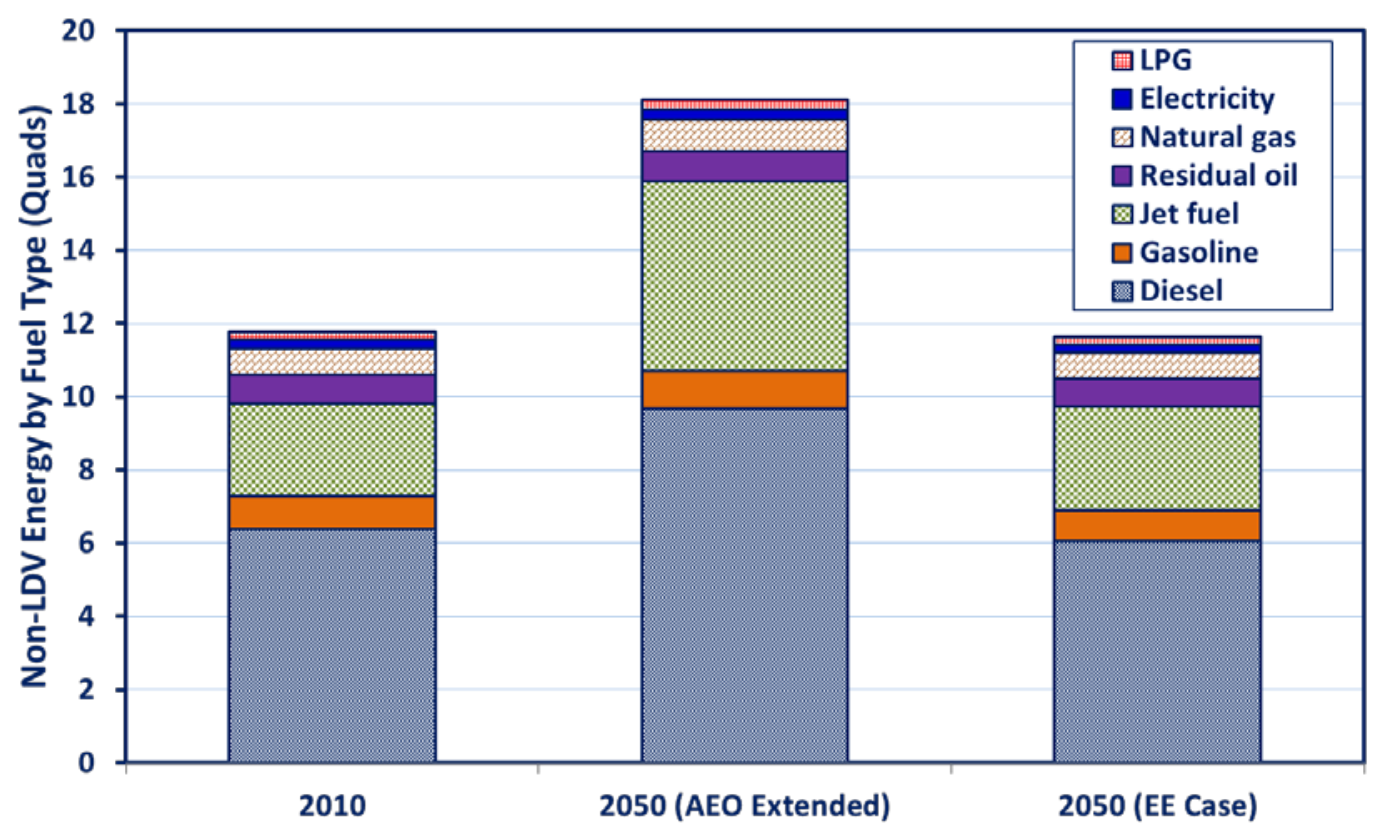

Figure ES.3. Non-LDV energy consumption by fuel type in 2010 and 2050 


\section{INTRODUCTION}

The Transportation Energy Futures Study examines technological, fuel substitution, and policy options for reducing transportation-related greenhouse gas (GHG) emissions and petroleum use. Since all transportation modes use fuels that contain carbon, and the production of these fuels requires processes that emit GHG, a literature review of the potential for improvement in the energy efficiency of transportation modes was undertaken.

The transportation sector consists of light-duty vehicles (LDVs) (such as cars and light trucks), heavyduty vehicles (such as medium- and heavy-duty trucks and buses), aircraft, marine vessels, pipelines, and trains. The LDVs make up a majority of the energy consumption within the transportation sector-almost $60 \%$ in 2009 , the latest year for which data by mode, sub-mode, and fuel type were available. This report focuses on the other $40 \%$, which we term non-LDV. Based on a comprehensive literature review, this report explores the potential for improvement in non-LDV energy efficiency. Other Transportation Energy Futures research focuses on the light-duty sector.

The non-LDV sector is broken down into highway modes and non-highway modes. Highway modes consist of trucks over 10,000-lb. gross vehicle weight (GVW) and buses and account for almost $60 \%$ of non-LDV energy consumption (see Figure 1.1). Aircraft, marine vessels, pipeline, and trains make up the non-highway modes.

Off-road equipment includes mobile sources, defined by the U.S. Environmental Protection Agency (EPA) as engine-powered devices moved at least once in a 12-month period, not already listed in the previous categories. This includes agricultural, construction, forestry, and lawn equipment. Since this type of equipment is not necessarily associated with the transportation of goods or people, it is not always included as part of the transportation sector. However, it is a mobile source that consumes a significant amount of energy (more than aviation) so we include it in this report. When off-road equipment is factored in, the non-LDV share of total transportation energy use increases to $45 \%$.

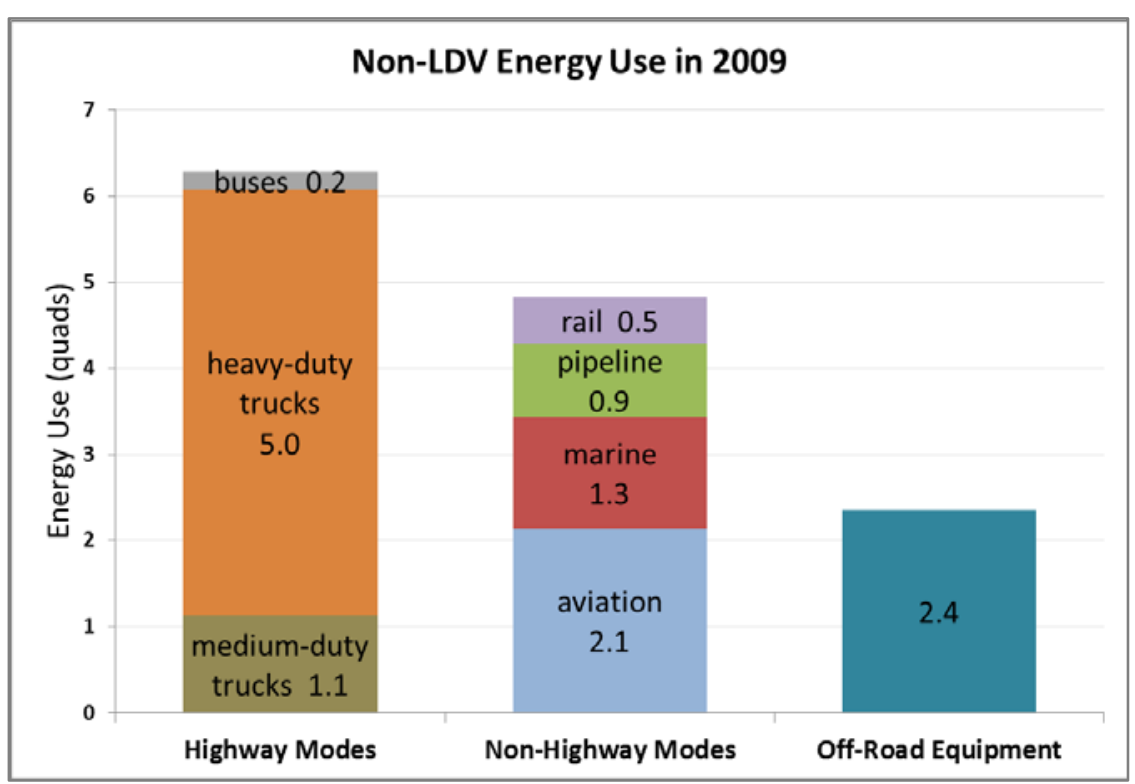

Figure 1.1. Non-LDV energy use by mode

(Source: Davis et al. 2011) 
The non-LDV sector consumed nearly 13,470 trillion Btu of energy in 2009 (Davis et al. 2011). Figure 1.1 shows the 2009 non-LDV energy consumption broken down by highway modes, non-highway modes, and off-road equipment. While there is a large body of literature examining energy efficiency and GHG reduction options for the light-duty component of the transportation sector, the non-LDV sector has not been studied as extensively. For this report, we reviewed the available literature on non-LDV modes to quantify the amount of energy efficiency improvement possible within each of the six modes and summarized our findings. Most of the emphasis here is on technological improvements, but some operational improvements also are addressed. When available, we include cost information about technological improvements, such as capital costs and maintenance costs. Little information is available on estimates of research and development costs for more advanced technologies beyond 2030 production.

The non-LDV and off-road modes use a variety of fuels. The non-LDV modes consume diesel (blended with bio-diesel), electricity, gasoline (blended with ethanol), jet fuel, liquid petroleum gas (LPG), natural gas, and residual fuel oil. Off-road equipment uses diesel (blended with bio-diesel), gasoline (blended with ethanol), LPG, and natural gas. Some off-road equipment is powered by electricity, but the amount of electric energy use is small and often gets reported with other electricity consumptions. Switching to fuels with lower net carbon emissions such as biodiesel, or less carbon-intensive fossil fuels such as natural gas, are also ways to decrease GHG emissions. While we do mention some of these fuel switching possibilities, it is not a focus of this report. Many of the technological improvements that we discuss are applicable to any fuel source (e.g., aerodynamic improvements on trucks and aircraft).

Each mode includes a discussion of anticipated demand growth, historical changes in energy efficiency, and a detailed look at the technological options available for improving energy efficiency out to 2050 . At the end of each section, we also include an energy consumption growth forecast scenario, where the more optimistic of the technological improvements are realized. While we see drastic reductions compared with a "business as usual" case, overall energy use is not changed by more than a few percentage points from 2010 levels.

The detailed breakdown of 2009 energy consumption by non-LDV modes and off-road equipment, excluding military non-LDV energy, is listed in Table 1.1. Although military modes are not typically considered part of the transportation sector, and access to information on military modal energy consumption, research, and technology implementation is limited, $74 \%$ of the military's energy use is non-light duty transportation-related. A brief overview of energy consumption by military trucks, tanks, off-highway ground transportation, navy vessels and aircraft is provided in Section 5.

Table 1.1. Energy Consumption by Mode in 2009

\begin{tabular}{lccc}
\hline & & \multicolumn{2}{c}{ Share (\%) } \\
\cline { 3 - 4 } \multicolumn{1}{c}{ Mode/Subsector } & $\begin{array}{c}\text { Energy Use } \\
\text { (Quadrillion Btu) }\end{array}$ & $\begin{array}{c}\text { Including } \\
\text { Off-road }\end{array}$ & $\begin{array}{c}\text { Excluding } \\
\text { Off-road }\end{array}$ \\
\hline Trucks and buses & 6.28 & 46.7 & 56.6 \\
Air & 2.14 & 15.9 & 19.2 \\
Marine & 1.29 & 9.6 & 11.6 \\
Pipeline & 0.86 & 6.4 & 7.7 \\
Rail & 0.54 & 4.0 & 4.9 \\
Subtotal (excluding off-road) & 11.11 & - & 100 \\
Off-road & 2.36 & 17.4 & - \\
Total (including off-road) & 13.47 & 100 & - \\
\hline
\end{tabular}

(Source: Davis et al. 2011) 


\section{HighWAY MODES}

The highway non-LDV vehicles are medium-duty trucks with GVW of 10,001-26,000 lb., heavy-duty trucks with GVW greater than 26,000 lb., and buses. This section describes energy use in highway modes and mechanisms for energy efficiency improvement in medium- and heavy-duty trucks.

The two GVW groups we use to categorize medium- and heavy-duty trucks correspond with the U.S. Energy Information Administration (EIA) in its Annual Energy Outlook (AEO) projections. In addition to these aggregate weight categories, non-LDV trucks are classified by GVW Class 3 through Class 8 . Table 2.1 lists these classes and gives typical examples of each.

Table 2.1. Truck Categories and Gross Vehicle Weight Classes

\begin{tabular}{lcll}
\hline EIA Category $^{\mathrm{a}}$ & GVW Class $^{\mathrm{b}}$ & \multicolumn{1}{c}{ GVW $(\mathrm{lb} .)^{\mathrm{b}}$} & \multicolumn{1}{c}{ Examples } \\
\hline 3 & 3 & $10,001-14,000$ & Utility van, minibus \\
\multirow{2}{*}{ Medium } & 4 & $14,001-16,000$ & Delivery, bucket, landscaping \\
& 5 & $16,001-19,500$ & Delivery, bucket \\
& 6 & $19,501-26,000$ & Delivery, school bus \\
\hline \multirow{2}{*}{ Heavy } & 7 & $26,001-33,000$ & Refuse, fire engine, tow \\
& 8 & 33,001 and over & Tractor-trailer, tanker, flatbed \\
\hline
\end{tabular}

a As in Annual Energy Outlook 2011.

${ }^{b}$ As specified by the National Highway Traffic Safety Administration for Vehicle Identification Number Requirements, 49CFR565.6 (NHTSA 2000).

Three sub-categories exist among the buses: transit buses, school buses, and intercity and/or charter buses.

\subsection{Medium- and Heavy-Duty Trucks}

Medium- and heavy-duty trucks consumed 6.09 quadrillion Btu of energy in 2009. Trucks are the largest category of energy consumers within the non-LDV sector. Their energy share in 2009 was $45 \%$ of combined non-LDV modes with off-road included and 55\% of non-LDV modes without off-road. The energy use share by fuel type was $90 \%$ diesel and $10 \%$ gasoline (Davis et al. 2011). Historically, truck activity increased on average by $2.7 \%$ per year and energy consumption by $4.7 \%$ per year from $1997-$ 2007 (Davis et al. 2011).

Medium-duty trucks typically are used for delivery and service operation, with some medium-duty trucks transporting freight over short distances. The highway statistics published by the Federal Highway Administration (FHWA) does not separate trucks by GVW class. Rather, they are classified as 1) singleunit trucks with two or more axles and six or more tires, and 2) combination trucks (tractor-trailers). In single-unit trucks the engine, cab, and body are inseparable, such as in a van, flat bed, or pickup truck. These trucks are used mainly in local service and made up 71\% in 2002 and $76 \%$ in 2009 of all on-road trucks (FHWA 2003, 2009). National Transportation Statistics, published by U.S. Department of Transportation's (U.S. DOT's) Bureau of Transportation Statistics, provides ton-miles of travel within the U.S. Aside from excluding international marine ton-miles, these data exclude local movement of freight - which is almost all by trucks - and travel by service, utility, retail trade, and contractor trucks. While computing ton-mile shares by mode, we excluded ton-miles by oil and oil products pipelines because they are not included in estimating transportation energy consumption. In 2009, trucks accounted for 1,321 billion ton-miles of travel out of 3,734 billion ton-miles, a 35.4\% share (BTS 2012). If we 
assume $70 \%$ of truck energy consumption by intercity freight trucks, the 2009 truck energy intensity works out to 3,224 Btu per ton-mile.

The Vehicle Inventory and Use Survey (VIUS), which was discontinued after 2002, put the medium-duty truck share of combined medium- and heavy-duty truck energy use at 19\%, and that for heavy-duty trucks at $81 \%$ (VIUS02 2004). Medium-duty trucks accounted for $26 \%$ of the combined medium- and heavyduty truck vehicle miles of travel (VMT), averaging 13,970 annual miles per truck. Nearly $46 \%$ of all heavy-duty trucks (GVW Class 7 and 8) were single-unit trucks, according to the 2002 VIUS. The singleunit heavy-duty trucks accounted for $12 \%$ of the total non-LDV truck VMT, averaging 15,440 annual miles per truck, and they consumed $13 \%$ of the energy. Combination trucks, mostly Class 8 line-haul trucks, comprised the rest (54\%) of the heavy-duty trucks. The combination trucks accounted for $62 \%$ of medium- and heavy-duty truck VMT, averaging 65,280 annual miles per truck, and they consumed 68\% of energy. Figure 2.1 shows energy use and VMT by these truck types. Because the Class 8 long-haul combination trucks consume a large fraction of truck energy use, we focus on their energy efficiency improvement potential in this report.

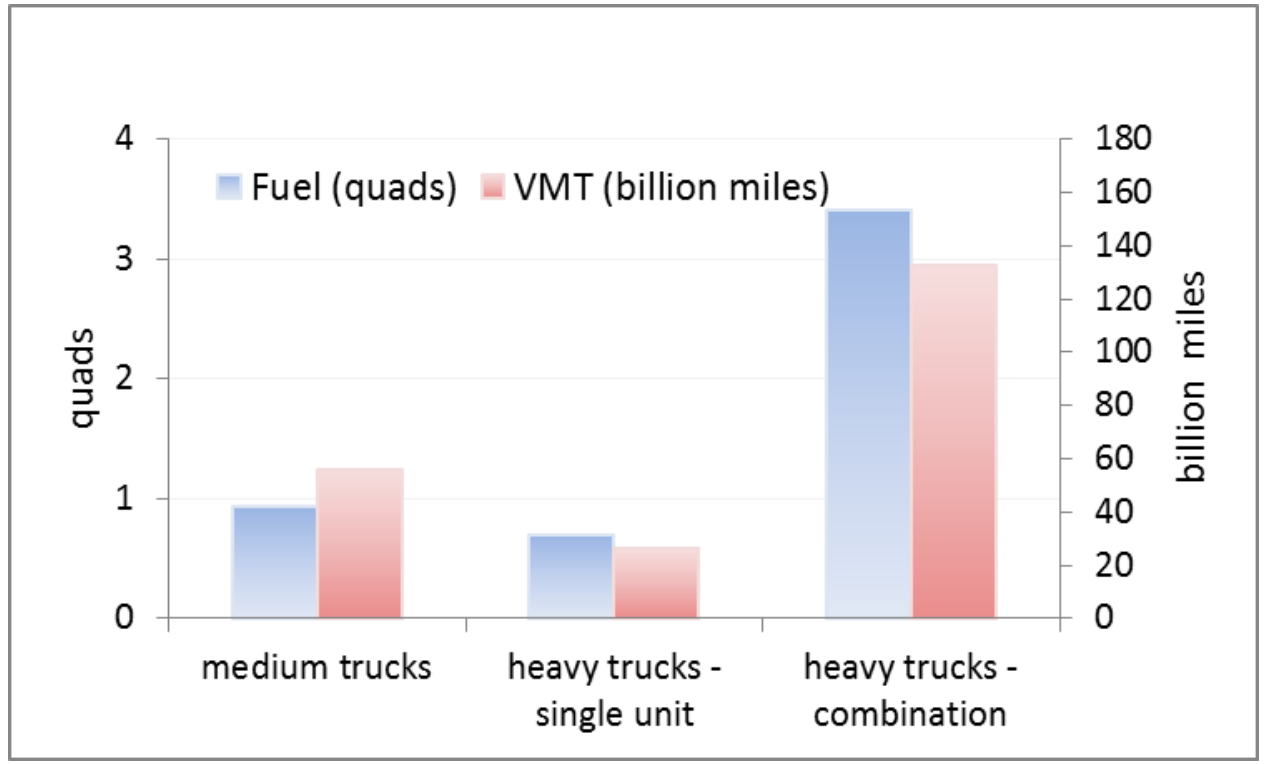

Figure 2.1. Truck fuel use and VMT

(Sources: VIUS 2004; Davis et al. 2011)

According to the 2007 Commodity Flow Survey, combination trucks transported $70 \%$ of the domestic tons shipped by a single mode (CFS07 2010). Aside from transporting $70 \%$ of single-mode tonnage, the trucks also were used in multiple-mode shipments that accounted for $4.6 \%$ of tonnage.

Medium- and heavy-duty trucks, unlike LDVs, are primarily load-bearing vehicles. Therefore, any energy-use metric should include a measure of how much freight, or payload, is carried. The relevant energy intensity metric commonly used is gallons of fuel per ton-mile. This metric is dependent on a number of factors, including the duty cycle and the amount of payload carried. A city delivery truck that makes frequent stops will have higher energy intensity than a long-haul delivery truck. Similarly, a halfloaded truck will have higher energy intensity than a fully loaded truck. For this report, we define truck energy efficiency as the inverse of energy intensity, measured in ton-miles per gallon.

Until recently, there have not been any fuel economy standards in the United States for medium- and heavy-duty trucks. The first set of energy efficiency standards, put forward as a final rule in September 2011, applies to vocational trucks, pickup trucks and vans, and combination tractors (EPA and NHTSA 2011b). This ruling covers all on-road vehicles over 8,500-lb. GVW, except those vehicles already 
covered by the LDV Corporate Average Fuel Economy (CAFE) regulation. The energy intensity of pickup trucks and vans will be measured in gallons of fuel per 100 miles. The energy intensity of vocational trucks and combination tractors will be measured in gallons of fuel per 1,000 ton-miles, thereby reflecting their role as cargo-carrying vehicles. Initially, in 2014 and 2015, the NHTSA fuel consumption standards will be voluntary, and will become mandatory beginning in 2016. The proposed standards aim to reduce combination truck-tractor fuel use by up to $20 \%$, pickup and van fuel use by $15 \%$, and vocational truck fuel use by up to $10 \%$ by model-year 2018, relative to 2010 baseline models.

\subsubsection{Future Medium- and Heavy-Duty Truck Demand}

Projections by the EIA in the 2011 AEO represent the most recent truck energy and activity projections (EIA 2011b). The EIA projects a 56\% increase in medium- and heavy-duty truck VMT between 2010 and 2035 , representing an average annual increase of $1.8 \%$. The VMT increase during the 25 -year period for medium-duty trucks is projected to be slightly higher (59\%) than for heavy-duty trucks $(55 \%)$.

\subsubsection{Historical Energy Efficiency Improvements}

Since 1975, the energy intensity for trucks has decreased more than $60 \%$, with most of the reduction happening before 1995 (see Figure 2.2). This trend is the result of better engine efficiency, aerodynamics and tire rolling resistance, along with regulatory changes that increased the maximum weight and length of trailers in the early 1980 s.

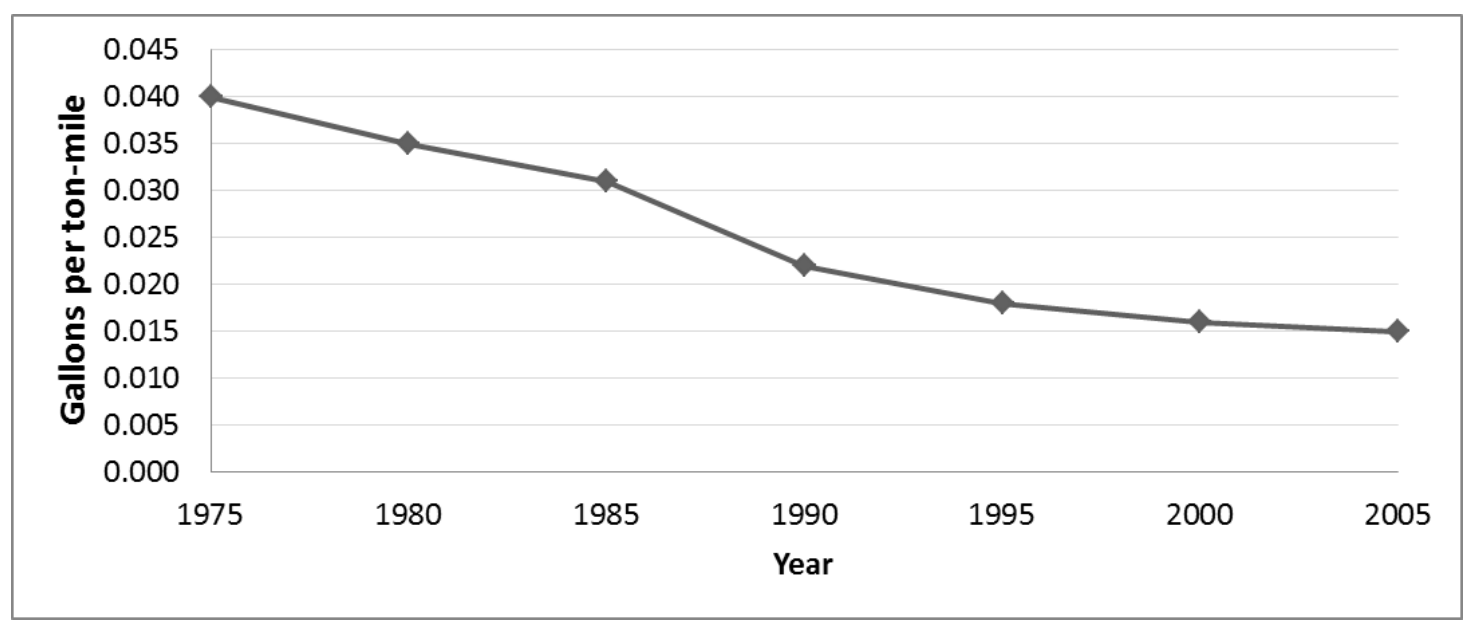

Figure 2.2. Average medium- and heavy-duty truck energy intensity

[Source: National Academy of Sciences (NAS) 2010]

The drop in energy intensity that occurred in the early 1990s was largely due to improved engine technologies, including electronic fuel injection, air-to-air after-cooling, and turbocharging [National Academy of Science (NAS) 2010]. Electronic fuel injection allows for better control over timing and amount of fuel, thus leading to improved energy efficiency while allowing emissions standards to be met.

The slowing energy intensity improvements in more recent years have been partially due to emissions regulations. Emissions standards for nitrogen oxides $\left(\mathrm{NO}_{\mathrm{x}}\right)$ and particulate matter $(\mathrm{PM})$ have impacted energy intensity. In-cylinder controls for $\mathrm{NO}_{\mathrm{x}}$ work by lowering the maximum temperature in the combustion chamber, which in turn makes combustion less efficient. Exhaust gas recirculation (EGR) is one of these technologies, and it was widely implemented in trucks to meet the 2004 emissions requirements.

Selective catalytic reduction (SCR) is an aftertreatment technology for reducing $\mathrm{NO}_{\mathrm{x}}$ that uses urea as a reducing agent. Because it allows for a higher engine-out $\mathrm{NO}_{\mathrm{x}}$ level, energy efficiency is not as compromised. However, the energy cost to make urea from natural gas also should be accounted for when 
evaluating full-fuel-cycle energy use. Most 2010 trucks use SCR to meet emissions standards, and they have less of an energy efficiency penalty than trucks that use only in-cylinder technologies to meet the $\mathrm{NO}_{\mathrm{x}}$ requirement. It is estimated that emissions controls have increased fuel consumption by $10 \%$ relative to energy efficiency trends pre-2000, before emission standards were implemented (NAS 2010; Greszler 2010).

Non-engine technology improvements include aerodynamics and tire rolling resistance. Aerodynamic devices for tractors had a long-haul fleet penetration of 78\% of VMT in 2007 (ICF International 2009a). Tractor aerodynamic devices include cab extenders, roof fairing, aero side mirrors, aero hoods, aero bumpers, chassis fairing, and full-side fairing (see Figure 2.3). Trailer aerodynamic devices have been slower to catch on. Aerodynamic devices are more effective for long-haul trucks, which spend a significant amount of time at highway speeds. For short-haul trucks, air friction is less of an issue, and aerodynamic devices can be counterproductive because of the added weight. Devices such as gap reducers can be a further hindrance in city driving, since they decrease maneuverability and can make turns difficult.

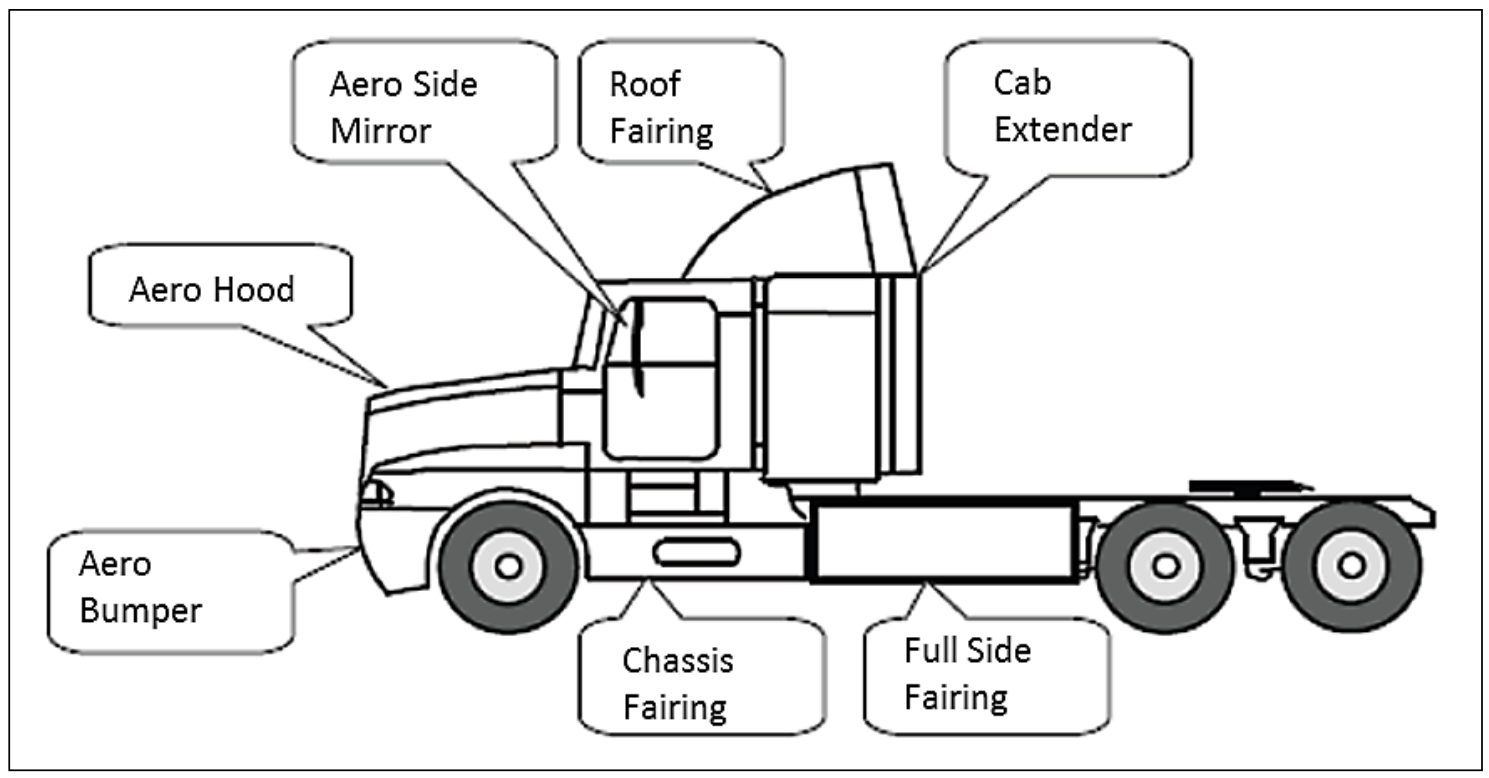

Figure 2.3. Aerodynamic tractor devices

(Source NAS 2010)

Since the 1990s, the coefficient of rolling friction for tires has decreased by $50 \%$. Single wide tires offer even lower rolling resistance than conventional double tires. They have been available since the 1980s, but have been slow to catch on- only $0.5 \%$ of tires currently sold are single wide [American Trucking Associations (ATA) 2008; ICF International 2009a]. The main barriers have been lack of redundancy in case of failure, safety concerns, and limited availability. Studies have shown the performance and safety of the "New Generation Wide Single" tires to be similar to duals (ATA 2008; NAS 2010).

Operational factors also affect energy efficiency. As more companies use "just-in-time" systems to decrease the cost of maintaining large inventories, shipments become more frequent with less cargo per truck. With this type of system, the timing of the delivery schedule is more important than utilizing maximum truck capacity. This trend has a negative impact on energy efficiency. Another operational consideration is the number of miles driven with no cargo, or empty miles. Empty miles result in additional fuel use without moving cargo, thereby increasing the overall average energy intensity. According to the most recent VIUS 2002, about 20\% of long-haul truck miles and $40 \%$ of short-haul truck miles are driven without cargo, and these "empty" miles increased over the period from 1997 to 
2002 (ICF International 2009a). Although more recent data are not available, some speculate that improved logistics may have reduced empty miles.

\subsubsection{Future Energy Efficiency Improvements}

This section covers future energy efficiency improvements in trucks. Technologies that are likely to be improved upon and new emerging technologies are reviewed.

\subsubsection{Diesel Engine Technologies}

Diesel is by far the dominant fuel of medium- and heavy-duty trucks, and it constitutes $90 \%$ of the fuel used by these vehicles (Davis et al. 2011). Almost all heavy-duty trucks and the majority of medium-duty trucks $(60 \%$ sold in 2008$)$ have diesel engines.

All new on-highway diesel engines are turbocharged. Turbochargers work by using exhaust energy to drive a compressor that increases the pressure at the intake manifold, forcing more air into the engine. Improvements to compressor or turbine efficiency can reduce fuel consumption. High-pressure-ratio radial compressors, or axial compressors, are emerging technologies with the potential to further improve fuel economy.

Currently, diesel truck engines run at $42 \%$ peak thermal efficiency, which means $58 \%$ or more of the input energy is ejected as waste heat (NAS 2010). The biggest potential engine efficiency gain is from waste heat recovery. Two ways of recovering this energy are turbocompounding and bottoming cycles.

Mechanical and electrical turbocompound systems use a power turbine to extract additional energy from the exhaust stream, converting it into either mechanical energy to turn the crankshaft or electrical energy to power a motor or accessories, or to charge a battery. Mechanical turbocompound systems are currently in production and offer a 3-5\% fuel consumption benefit. Electrical turbocompound systems are not commercially available, but they are estimated to reduce fuel consumption by $3-10 \%$ [NAS 2010 ; Northeast States Center for Clean Air Future (NESCCAF)/International Council for Clean Transportation (ICCT) 2009].

A bottoming cycle uses a secondary engine that utilizes exhaust energy or other waste heat from the primary engine to develop additional power. Up to a $10 \%$ fuel consumption reduction is possible (NAS 2010; NESCCAF et al. 2009).

Decreasing engine friction by using lower viscosity oil and a temperature controller can lead to a $1-2 \%$ decrease in fuel consumption. Fuel injection improvements can lead to a $1-4 \%$ fuel consumption decrease. Real-time combustion control can result in a 1-4\% fuel consumption reduction. Electrification of accessories allows them to be turned off and on as needed instead of imposing a constant parasitic demand on the engine. Such electrification can reduce fuel consumption by $2-5 \%$, and it has more of an effect in short-haul urban applications (NAS 2010).

Alternative combustion cycles, such as low-temperature combustion, homogeneous charge compression ignition, and premix charge compression ignition, are useful for lowering emissions. However, they do not have an inherent advantage for fuel consumption.

Any or all of the above technologies can be employed to increase the engine system efficiency. The DOE goals for heavy-duty truck diesel engines are to increase the engine thermal efficiency from $42 \%$ in the baseline MY 2009 engine to $50 \%$ efficiency by 2015 and to $55 \%$ efficiency by 2018 . These goals correspond to an energy intensity improvement of $17 \%$ by 2015 and $23 \%$ by 2018 . These targets are for prototype engines, but not for engines expected to be commercially available in those years (Gravel 2011).

Overall, it is estimated that improved diesel engine technologies in new trucks can reduce fuel consumption 15-20\% in the 2020-2030 timeframe (NAS 2010; Greszler 2010). The expected incremental capital cost for a tractor-trailer with an advanced 11- to 15-liter engine with a bottoming cycle is $\$ 23,000$ 
(NAS 2010). This does not include the cost of emissions aftertreatment hardware or particulate filters. This expense is a significant investment relative to the price of a new tractor- $\$ 80,000$ to $\$ 120,000$. Maintenance costs also will rise due to the increased engine complexity.

\subsubsection{Transmission and Driveline}

A truck's transmission and driveline are the components that connect the engine to the wheels. Reducing friction in the transmission and axles by using improved synthetic lubricants can help reduce fuel consumption by about $1 \%$. Efficiency also can be improved by using a system optimization strategy that is dependent on the driving cycle. The simplest strategy is to match the top gear and rear axle ratio to the typical cruise speed. Automated manual transmissions have been gaining market share in long-haul trucks - $20 \%$ in 2008. In automated manual transmissions, a computer optimizes the shifting schedule based on the engine efficiency map and takes into account load, vehicle speed, and acceleration. The automated manual transmissions tend to be slightly more fuel efficient than the typical manual transmission driver.

In the 2015-2020 timeframe, tractor-trailer transmission and driveline fuel consumption can potentially be reduced by $7 \%$. However, most tractor-trailers already are well specified for their application and will not see as high a reduction (NAS 2010).

\subsubsection{Hybrid Power Trains}

The two major types of hybrid trucks are electrical and hydraulic. Hybrid electric vehicles are used in all vehicle weight classes, while hydraulic hybrid vehicles are used mainly in medium and heavy vehicles that operate with high-power, low-energy requirements. This includes the stop-and-go driving profiles associated with refuse vehicles, city buses, and delivery vans.

There are many different ways to configure a hybrid vehicle. The different architectures usually are grouped into three general categories: series, parallel, and power split. In series hybrids, the internal combustion engine (ICE) is connected in series with an electric or hydraulic motor that powers the wheels. In parallel hybrids, both the internal combustion engine and motor are able to power the wheels directly. The power-split hybrid has a power-split device that allows the vehicle to operate in either a parallel or series configuration, thus combining the benefits of both. Between series and parallel hybrids, the series hybrid has higher capital costs because it requires a full-size motor, a generator, and an internal combustion engine. Among the parallel hybrids, the power-split hybrid is a more complicated system, which adds to the increased capital and maintenance costs.

Advantages of hybridization include regenerative braking, which captures energy and saves wear on the brakes; reduced idling; improved torque characteristics of electric motors with high torque at low speeds; and the possibility for internal combustion engine downsizing. Disadvantages include increased complexity, weight, and cost.

Fuel savings for hybrid trucks strongly depend on the driving cycle and hybrid configuration. Hybrid technology is better suited to vehicles that operate with frequent stops in an urban environment, such as refuse trucks and city buses. Medium-duty trucks (Class 3-6) have a fuel consumption benefit of 20$45 \%$. Hybridization has a smaller impact on heavy-duty trucks. There are limited gains for regenerative braking in long-haul trucks. For these trucks, the main benefits occur when the driver is resting and engine is idling to operate heat, air conditioning, or appliances. This type of "hotel load" can be completely operated with grid electricity via truck-stop electrification (electrified parking spaces) for plug-in vehicles. The overall fuel consumption benefit for the hybridization of long-haul trucks is estimated at 5-10\% (NAS 2010; NESCCAF et al. 2009).

The capital cost for truck hybridization is a significant factor. For long-haul trucks, the incremental capital cost for a mild parallel hybrid system is currently estimated at $\$ 25,000$. For Class $3-6$ straight or single-unit (i.e., non-trailer) trucks, the cost for a parallel hybrid system is estimated at $\$ 20,000$ (NAS 2010). 
Power management strategies are important in determining the fuel consumption savings in hybrids. These should be optimized based on driving cycles that reflect real-world driving based on the vehicle function.

\subsubsection{Aerodynamics}

Air drag can account for as much as $20 \%$ of fuel use for trucks that travel at highway speeds. The power required to overcome aerodynamic drag is given by the following equation (Equation 2.1):

$$
P_{a}=1 / 2 \rho A C_{d} v^{3}
$$

$$
\begin{aligned}
& \text { where } \rho=\text { air density, } \\
& A=\text { truck frontal area, } \\
& C_{d}=\text { coefficient of aerodynamic drag, and } \\
& v=\text { truck velocity. }
\end{aligned}
$$

The cube of velocity shown in Equation 2.1 indicates that aerodynamic resistance increases quickly at high speeds. For a typical combination truck, aerodynamic drag overtakes rolling resistance at around 50 $\mathrm{mph}$, as illustrated in Figure 2.4. This explains why aerodynamic devices are most effective on long-haul trucks that spend more time at high speeds.

The drag coefficient, $\mathrm{C}_{\mathrm{d}}$, depends on the shape of the truck. One fifth of tractors have a "classic," boxy body type (ICF International 2009a). This type of tractor has a typical drag coefficient of $\mathrm{C}_{\mathrm{d}}=0.80$. A more aerodynamic tractor outfitted with full aerodynamic devices currently on the market has $\mathrm{C}_{\mathrm{d}}=0.58$, a 28\% difference (EPA and NHTSA 2011a). Since the vast majority of tractors are already aerodynamically equipped, further improvements are estimated to improve overall energy efficiency by $2-4 \%$.

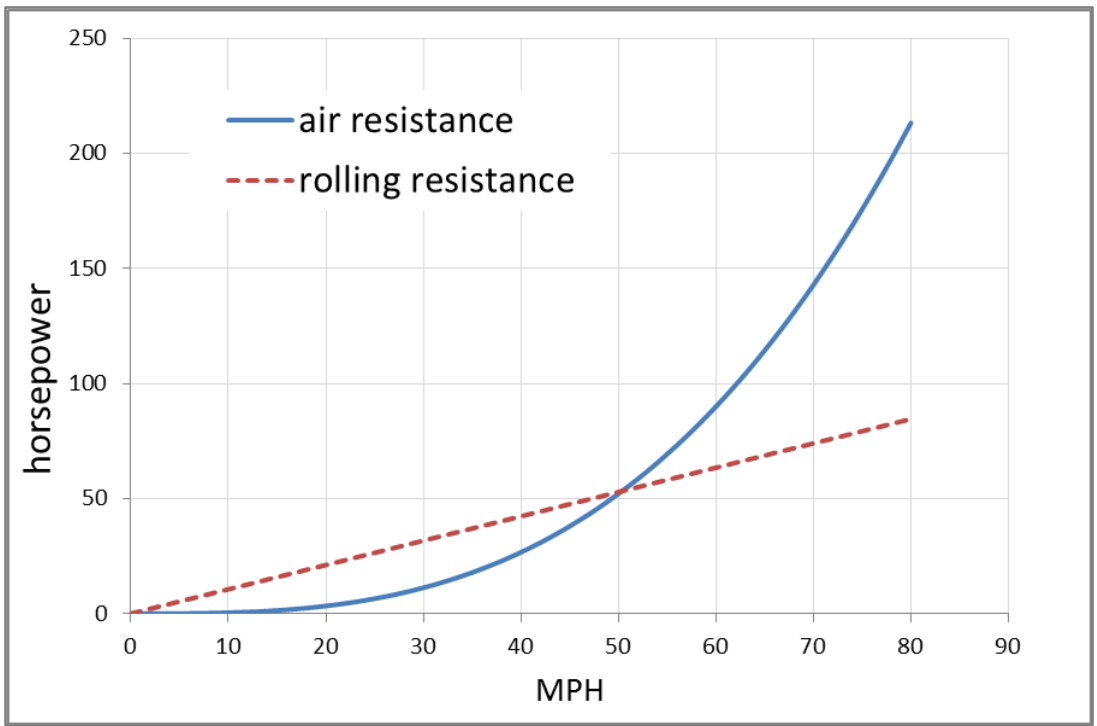

Figure 2.4. Air and rolling resistance as a function of velocity for a typical combination truck

There is more room for improvement on the trailer side. Devices such as side skirts, boat tails, and gap reducers currently are available, but not widely implemented (see Figure 2.5). Pneumatic blowing, where compressed air is blown over the trailer to smooth the airflow, is a promising technology. 


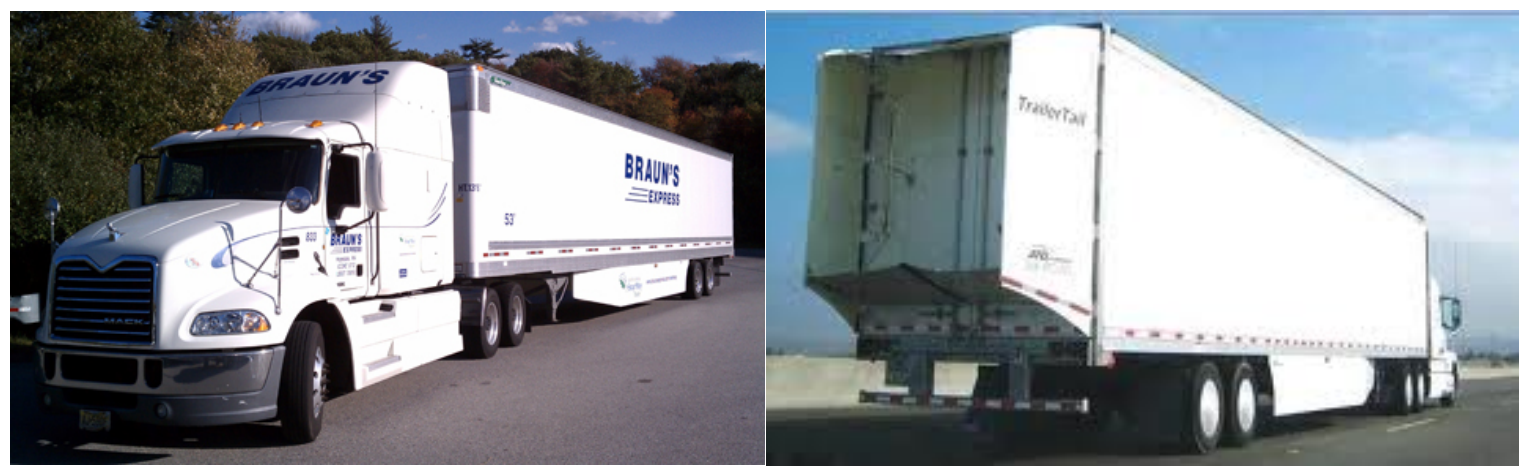

Figure 2.5. Aerodynamic devices on a tractor-trailer: side skirts and boat tail

(Source: Braun's Express and ATDynamics)

Because trailers tend to be used for temporary storage, they do not put on as many miles per year, so investing in their improvement is not as cost effective. Although there are three times as many trailers as tractors, their less frequent use results in a longer lifetime (20-25 years compared with about 10-12 for tractors) and slower turnover rate. In addition, because the trailer owners usually are not the tractor owners, they do not necessarily reap the benefit of investing in aerodynamic trailers. The additional capital cost for implementing full aerodynamic features on a trailer is $\$ 3,000$ (NAS 2010), about 5-10\% of the cost of a new trailer. If these impediments can be overcome, aerodynamic tractor-trailer devices overall can offer a fuel consumption decrease of $9-12 \%$ in the 2015-2020 timeframe (NAS 2010; Greszler 2010).

\subsubsection{Trailer Height}

Trucks usually carry low density consumer goods. Even a fully packed 53-foot long trailer (the longest allowed in most states), may not reach the federal weight limit of 80,000 lbs. Double-deck trailers have been gaining market share in recent years in the U.K. where there are no trailer height restrictions and bridge and tunnels clearances are sufficiently high. Although the higher trailers (15.7-16.5 feet) have more significant air drag and are heavier when empty than single-deck trailers, the increase in payload makes it more energy efficient on a ton-mile basis. It is estimated that double-deck trailers have a $15 \%$ reduction in energy intensity compared to single-deck (Holter et al. 2010). These taller trailers will have limited use in the United States where most bridge clearances are 15 feet or less and many states have trailer height restrictions of 13.5 to 14.5 feet.

\subsubsection{Speed Reduction}

Air drag increases significantly with speed, so limiting the top cruising speed of trucks has a large effect on reducing fuel consumption. Figure 2.6 illustrates the power loss due to air resistance in a typical tractor-trailer. The red arrow indicates the amount of power saved by reducing speed from $70 \mathrm{mph}$ to 65 $\mathrm{mph}$. For a truck cruising at $65 \mathrm{mph}$, this is equivalent to a savings of a half-gallon per hour, or about $6 \%$ of fuel consumption. According to a 2008 Oak Ridge National Laboratory (ORNL) study, potentially half of all fuel used in Class 8 trucks occurs at speeds over $65 \mathrm{mph}$ (Davis et al. 2011, Figure 5.4). A speed cap of $65 \mathrm{mph}$ can reduce overall fuel use by $3-5 \%$ in long-haul combination trucks. 


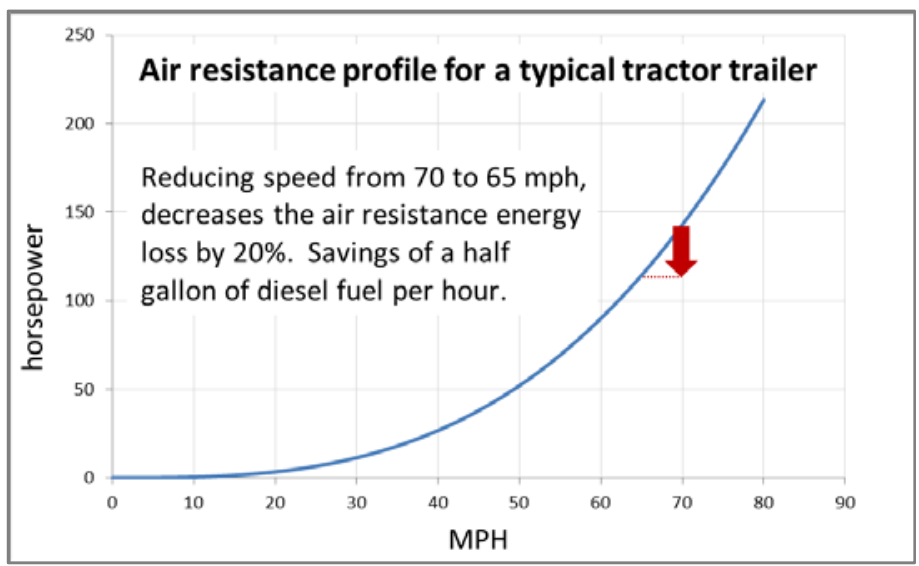

Figure 2.6. Speed reduction fuel savings

\subsubsection{Rolling Resistance}

At lower truck speeds, the energy required to overcome rolling resistance is greater than that to overcome aerodynamic drag. Because its magnitude is linear to truck speed as well as weight, rolling resistance also contributes substantially to energy consumption by long-haul trucks. The power required to overcome rolling resistance is given by the following equation (Equation 2.2):

$$
P_{r}=C_{r} g M v
$$

where $C_{r}=$ composite coefficient of rolling resistance,

$g=$ acceleration due to gravity,

$M=$ truck mass, and

$v=$ truck velocity.

Rolling resistance reduction measures have a potentially large impact on Class 8 long-haul trucks. Other truck applications with less mass and more frequent stops will have less efficiency gain. Replacing conventional dual tires with wide-base single tires can decrease fuel consumption by $1-11 \%$ in the nearterm 2015-2020 timeframe (NAS 2010; Franzese et al. 2010; Bachman et al. 2005; ATA 2008). Other strategies to reduce rolling resistance involve ensuring that tires are always properly inflated through the use of tire pressure monitoring systems automated tire inflation systems, and nitrogen tire inflation.

\subsubsection{Weight Reduction}

The energy required to accelerate and overcome rolling resistance is proportional to the vehicle's total mass (including payload), so weight reduction, or lightweighting, is a useful strategy to decrease fuel consumption. Emissions controls, aerodynamic devices, waste heat recovery systems, batteries, and hybrid components all impose additional mass, increasing the empty weight of a truck. Energy efficiency in heavy-duty trucks is not as sensitive to empty vehicle weight as it is in LDVs, since the empty vehicle weight in trucks is a fraction of payload. However, the use of lightweight materials, such as aluminum and carbon composites, has a beneficial impact on energy efficiency. If the truck is filled to volume capacity, the decreased mass will require less energy per ton-mile of cargo. In this situation, it is estimated that every 1,000-lb. decrease in mass results in about a $1 \%$ fuel reduction (NAS 2010). Hilly terrain or more frequent stop-and-go driving increases the potential fuel savings. If the truck is filled to weight capacity (as is the case for about $20 \%$ of truck VMT), the greater amount of cargo will result in fewer trips. In this case, the effective fuel savings is about $2 \%$ per 1,000-lb. mass reduction (NAS 2010). For long-haul trucks, a fuel consumption decrease of $1-5 \%$ due to lightweighting is possible by 2020 (ICF international 2009a; NAS 2010). 


\subsubsection{Idle Reduction}

Long-haul trucks can spend a significant amount of time parked with the engine running to power trailer refrigeration, air conditioning, heating, and onboard appliances. Federal law requires truck drivers to spend no more than 11 hours a day driving. Much of the rest of the day may be spent with the truck idling. There is a lack of good data on how much fuel is used annually through truck idling, but Gaines et al. estimate that drivers of Class 8 sleeper trucks spend from 0.5 to 6 hours per day and $7 \%$ of their fuel on overnight idling (Gaines et al. 2006). Another study by ORNL collected data on six Class 8 trucks and found that $7 \%$ of fuel use takes place during idling - half of which occurs during overnight idling (Capps 2008). Much related energy use can be eliminated by idle reduction systems. These include automated shutdown/startup systems, battery power, fuel heaters, auxiliary power units, and truck-stop electrification. A fuel consumption benefit of 5-9\% is possible (NAS 2010; ICF International 2009a).

Many states, counties, and cities have enacted regulations that prohibit truck idling beyond a fixed duration, generally 5-20 minutes. The violators are subject to a fine. Some fleets even track the amount of time their drivers idle and reward or punish them accordingly. A compendium of idling regulations is available on the website of American Transportation Research Institute (http://www.atrionline.org/research/idling/ATRI_Idling_Compendium.pdf).

\subsubsection{Future Truck Energy Efficiency Summary}

Estimates for future energy intensity improvements for trucks range from 25-50\% (Greszler 2010; NAS 2010; NESCCAF et al. 2009). These estimates are for new vehicles relative to 2008-2010 model-year vehicles and include technology improvements to engines and vehicle designs, as well as operational improvements such as speed reduction. Table 2.2 summarizes these improvements. Not all improvements are independent, some may lessen the effects of others, hence the overall improvement is less than the combination of individual improvements.

This summary does not include the possibility of taller trailers and longer combination trucks. Because these items would require legislative approval, changes to state regulations, and increases in bridge and tunnel clearances, they have been excluded.

The Super Truck Program was initiated by the U.S. Department of Energy (DOE) in 2010, with the focus of reducing fuel consumption in Class 8 long-haul trucks while maintaining current emissions standards. Truck and engine manufacturers were asked to develop demonstration vehicles by 2015 that will increase fuel economy by $50 \%$, which translates into a $33 \%$ reduction in energy intensity (in gallons per ton-mile). This is a comprehensive reduction, encompassing all areas of truck technology discussed above, including waste heat recovery, aerodynamics, rolling resistance, hybridization, and idling technologies (Stanton 2011; Rotz 2011). The Super Truck goal is within the estimates of future energy efficiency improvement potential. 
Table 2.2. Summary of Truck Energy Intensity Improvement Potential

\begin{tabular}{|c|c|c|}
\hline Item & $\begin{array}{l}\text { Energy Intensit } \\
\text { Reduction }\end{array}$ & $\begin{array}{l}\text { r ton-mile) } \\
2050\end{array}$ \\
\hline \multicolumn{3}{|l|}{ Engine Improvements } \\
\hline \multicolumn{3}{|l|}{ Turbocompounding } \\
\hline \multicolumn{3}{|l|}{ Decreasing friction } \\
\hline Electric auxiliaries & $15-20 \%$ & \\
\hline \multicolumn{3}{|l|}{ Improved fuel injection } \\
\hline \multicolumn{3}{|l|}{ Real-time combustion control } \\
\hline \multicolumn{3}{|l|}{ Bottoming cycle } \\
\hline \multicolumn{3}{|l|}{ Transmission and Driveline Improvements } \\
\hline Decreasing friction & $4-7 \%$ & \\
\hline \multicolumn{2}{|l|}{ Automated manual transmission } & $25-50 \%$ \\
\hline \multicolumn{3}{|l|}{ Hybrid Powertrain } \\
\hline $\begin{array}{l}\text { For trucks operating in congested conditions and for vocational } \\
\text { trucks that require stop-and-go operation and/or engine power } \\
\text { take-off }\end{array}$ & $5-10 \%$ & \\
\hline \multicolumn{3}{|l|}{ Other } \\
\hline \multicolumn{3}{|l|}{ Aerodynamics } \\
\hline \multicolumn{3}{|l|}{ Low rolling resistance tires } \\
\hline \multicolumn{3}{|l|}{ Weight reduction } \\
\hline \multicolumn{3}{|l|}{ Idle reduction } \\
\hline Operational improvements - speed reduction & & \\
\hline
\end{tabular}

Note: Energy intensity improvements are not additive. Independent improvements are combined by using the formula: $(1-a)^{*}(1-b)=(1-c)$, where $a$ and $b$ are independent improvements, and $c$ is the total combined improvement. Not all improvements are independent.

Table 2.3 summarizes the cost of energy efficiency improvements to medium- and heavy-duty trucks in the 2020 timeframe based on the NAS report (NAS 2010). Also included is the capital cost per percent fuel reduction (CCPFR) measure of cost effectiveness. The CCPFR is calculated by dividing the average capital cost of the improvement by the estimated percent of fuel reduction. This is a useful measure to compare the cost effectiveness of different technologies within a particular type of vehicle. For both types of trucks reviewed in Table 2.3, replacing tires with lower rolling resistance tires is the most cost effective technology option, followed by transmission and driveline improvements. For tractor-trailers, aerodynamics and engine improvements provide the next most cost effective solutions. Both offer substantial energy savings but also carry a higher initial cost. For the medium box truck, hybridization is about as cost effective as aerodynamics. However, for tractor-trailers, hybridization is more than twice as costly per fuel saved as aerodynamics. Weight reduction through the use of lightweight materials is the least cost effective measure, especially in tractor-trailers, compared with the other technologies.

The CCPFR is not useful for comparing improvements across different types of vehicles. For such a comparison, a better metric is the breakeven fuel price, which is the minimum fuel price needed to ensure that the amount saved in fuel costs covers the total capital cost of energy efficiency improvements. (This is over a 10 -year period at a discount rate of $7 \%$ per year.) For the complete energy efficiency package in tractor-trailers the breakeven price is $\$ 1.09$ per gallon-much lower than the current cost of diesel fuel. Making these changes to heavy-duty trucks not only will help to reduce GHG, but actually will save money as well. 
Table 2.3. Truck Incremental Capital Cost for Energy Efficiency Improvements

(Source: NAS 2010)

\begin{tabular}{|c|c|c|c|c|c|c|}
\hline & \multirow{2}{*}{\multicolumn{3}{|c|}{$\begin{array}{l}\text { Heavy-Duty Truck } \\
\text { Class } 8 \text { tractor-trailer }\end{array}$}} & \multirow{2}{*}{\multicolumn{3}{|c|}{$\begin{array}{l}\text { Medium-Duty Truck } \\
\text { Class 3-6 straight box truck }\end{array}$}} \\
\hline & & & & & & \\
\hline & Description & Cost & $\mathrm{CCPFR}^{\mathrm{a}}$ & Description & Cost & CCPFR \\
\hline Engine & $\begin{array}{l}\text { Advanced } 11-\text { to } 15-\mathrm{L} \text { engine with } \\
\text { bottoming cycle }\end{array}$ & $\$ 23,000$ & $\$ 1,150$ & Advanced 6- to 9-L engine & $\$ 13,000$ & $\$ 929$ \\
\hline $\begin{array}{l}\text { Transmission and } \\
\text { driveline }\end{array}$ & $\begin{array}{l}\text { Automated manual transmissions, } \\
\text { reduced driveline friction }\end{array}$ & $\$ 5,800$ & $\$ 829$ & $\begin{array}{l}\text { 8-speed automatic, } \\
\text { reduced driveline friction, } \\
\text { and aggressive shift logic }\end{array}$ & $\$ 1,800$ & $\$ 450$ \\
\hline Hybrid & Mild parallel hybrid with idle reduction & $\$ 25,000$ & $\$ 2,500$ & Parallel hybrid & $\$ 20,000$ & $\$ 667$ \\
\hline Aerodynamics & Tractor plus three trailers & $\$ 12,000$ & $\$ 1,043$ & $\begin{array}{l}\text { Aero cab, skirts, and } \\
\text { round corners }\end{array}$ & $\$ 3,250$ & $\$ 542$ \\
\hline Tires & $\begin{array}{l}\text { Wide-base single tires on tractor plus } \\
\text { three trailers }\end{array}$ & $\$ 3,600$ & $\$ 327$ & $\begin{array}{l}\text { Low rolling resistance } \\
\text { duals }\end{array}$ & $\$ 300$ & $\$ 100$ \\
\hline Weight & Material substitution: $2,500 \mathrm{lb}$. & $\$ 13,500$ & $\$ 10,800$ & $\begin{array}{l}\text { Material substitution: } \\
1,000 \mathrm{lb} \text {. }\end{array}$ & $\$ 4,770$ & $\$ 1,193$ \\
\hline \multicolumn{2}{|l|}{ Total capital cost } & $\$ 84,600$ & & & $\$ 43,120$ & \\
\hline \multicolumn{2}{|c|}{$\begin{array}{l}\text { Breakeven fuel price } \\
\text { (based on } 7 \% \text { discount rate and } 10 \text {-year life) }\end{array}$} & $\$ 1.09 / \mathrm{gal}$ & & & $\$ 4.17 / \mathrm{gal}$ & \\
\hline
\end{tabular}

${ }^{a}$ CCPFR is the capital cost per percent fuel reduction.

\subsubsection{Truck Alternative Fuels}

Diesel is the primary fuel of medium- and heavy-duty trucks, and it constitutes $90 \%$ of truck energy use. Alternative fuels capable of reducing carbon emissions and petroleum dependence include natural gas and biodiesel. Heavy-duty trucks have higher power requirements than passenger cars, making electric battery power less practical in most applications. While some full-electric medium-duty trucks are being built, their limited range makes them better suited as urban delivery trucks (LaMonica 2010; Pepsico 2011).

Natural gas, in the form of compressed natural gas (CNG) or liquid natural gas (LNG), has been gaining attention as a substitute to diesel fuel in trucking operations. Natural gas vehicles emit about $25 \%$ less carbon dioxide $\left(\mathrm{CO}_{2}\right)$ than diesel and also show a significant decrease in non- $\mathrm{CO}_{2}$ emissions, such as $\mathrm{NO}_{\mathrm{x}}$ and PM (EERE 2011). However, the energy required to cool down LNG to liquid temperatures also has a carbon penalty, rendering LNG trucks at about $18 \%$ less carbon emitting than diesel (ATA 2010). Methane, the primary component of natural gas, is a powerful GHG, and leaks can nullify the carbon advantage of natural gas over diesel.

CNG tends to be used in local applications, with an estimated $15 \%$ refuse trucks and city buses running on natural gas. Because LNG has a higher energy density than CNG (although a significantly lower density than diesel) it can be more readily used in long-haul trucking operations. However, the lack of LNG refueling infrastructure presents a significant challenge for long-haul operations. A few long-haul trucks run on natural gas. To date, a total of about 1,000 natural gas tractors have been sold in the United States (Ball 2011). United Parcel Service, with one of the largest truck fleets, ordered 48 LNG long-haul tractors at twice the cost of diesel tractors. With the current low price of natural gas, the anticipated standard payback time is 10 years, but has been shortened to 3 years by government subsidies (Ball 2011; Wald 2011). 
Most natural gas engines are spark ignition, like gasoline engines, so they tend to be $7-10 \%$ less efficient than compression-ignition diesel engines (ATA 2010). Compression-ignition natural gas engines that rely on a pilot injection of diesel to ignite have a $1 \%$ energy efficiency penalty compared with diesel (ATA 2010). Drawbacks to natural gas trucks include decreased power, decreased range, increased capital cost, and lack of adequate fueling infrastructure. A possibility that addresses at least three of the above issues is a dual-fuel engine, which uses natural gas as a supplement to diesel fuel (Straight 2011).

Biodiesel blends can be used in diesel engines with little or no modifications and takes advantage of the improved efficiency of compression-ignition engines. In addition, biodiesel has a higher cetane rating, improved lubricating properties, and almost no sulfur content compared with diesel (National Renewable Energy Laboratory 2009).

\subsubsection{Truck Summary and Energy Growth Forecast}

Energy consumption depends on energy intensity as well as activity. Future reductions in either or both can reduce total energy use. The 2011 AEO (EIA 2011b) extended truck energy and VMT growth are shown in blue in Figure 2.7. Based on the literature review, if we take the maximum energy efficiency case where the truck-fleet energy intensity is reduced $30 \%$ by 2030 compared with the 2010 fleet, and $50 \%$ by 2050 , the total energy demand remains very close to the 2010 value. This is assuming the same VMT growth as in AEO (about 1.6\%/year) and a constant average tonnage per truck (i.e., ton-miles growth is also about $1.6 \%$ year).

In order to bring energy consumption below 2010 levels, VMT reduction must occur simultaneously with vehicle efficiency improvements. This can be accomplished in part by transferring freight activity to less energy-intensive modes, such as rail and marine. Reducing truck VMT by $3 \%$ in $2020,10 \%$ in 2030 , and $15 \%$ in 2050 results in energy consumption that is $20 \%$ lower in 2050 than in 2010 . This is shown by the lower dotted orange line in Figure 2.7.

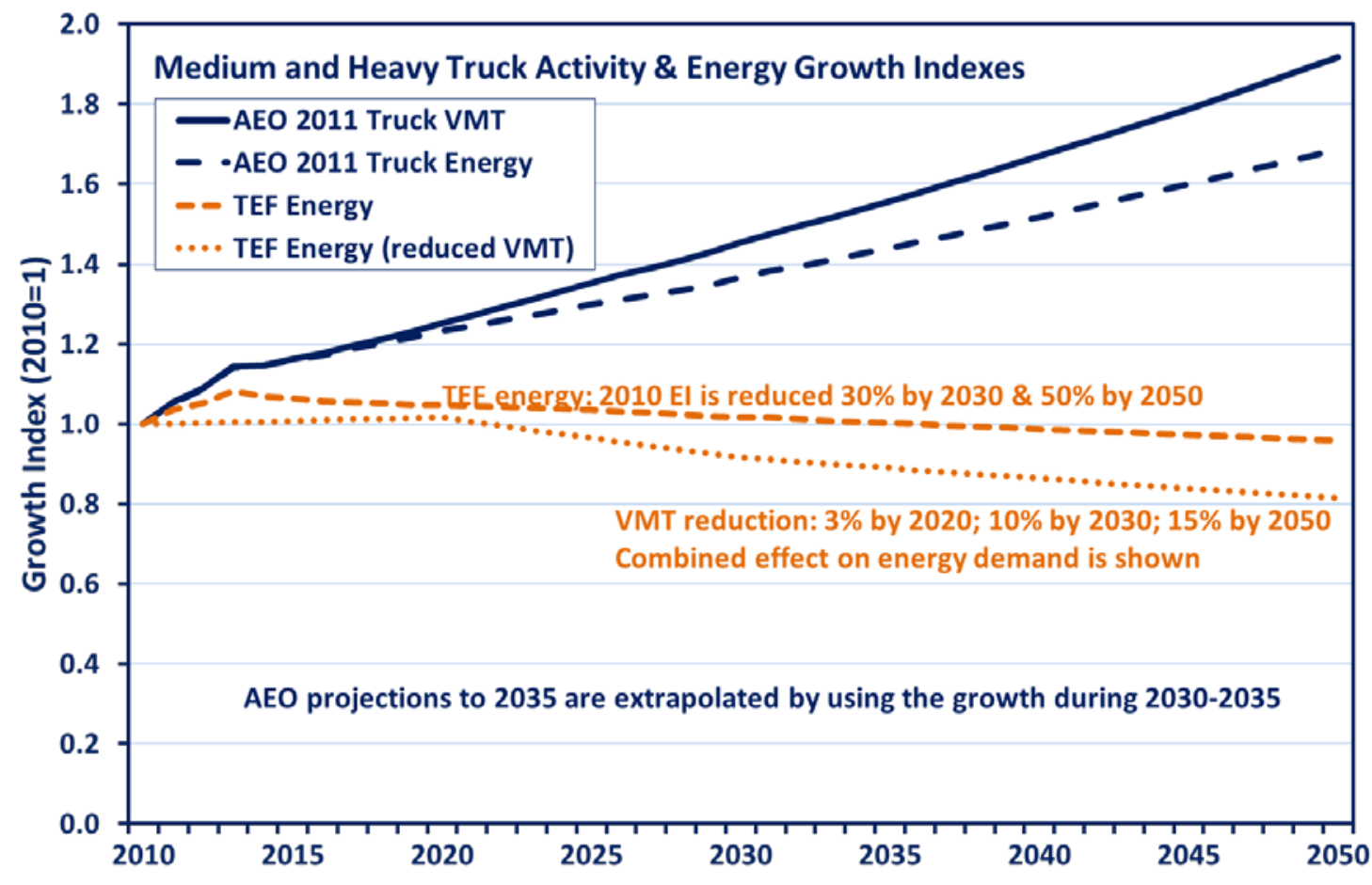

Figure 2.7. Truck activity and energy growth 


\subsection{Buses}

In aggregate, buses consume relatively little energy. During 2009, buses consumed 200 trillion Btu of energy (Davis et al. 2011). This constitutes $1.5 \%$ of total non-LDV and off-road energy and $1.8 \%$ of nonLDV energy, excluding off-road equipment.

In 2009, transit buses consumed 46\% (92 trillion Btu) of total bus energy. These buses usually travel at low speeds with frequent stops and starts. New technologies, such as hybrid electric and CNG powertrains, are aimed at reducing transit bus petroleum energy consumption and emissions. School buses were second in energy consumption, at nearly 39\% (77 trillion Btu), and intercity/charter buses consumed 15\% (31 trillion Btu) of total bus energy in 2009 (Davis et al. 2011).

Most buses have diesel engines that also are used in trucks. As such, they would benefit from improvements that result from ongoing diesel engine energy-efficiency research. 


\section{NON-HighwaY MOdes}

Non-highway modes include aviation, marine, pipeline, and rail. Combined these modes consumed 4.8 quadrillion Btu of energy in 2009, 36\% of combined non-LDV modes and off-road energy.

\subsection{Aviation}

Aviation has the highest energy use among the non-highway modes. Aviation consumes $16 \%$ of combined non-LDV modes and off-road energy and 19\% of non-LDV modes energy without off-road. Of the 2.14 quadrillion Btu of aviation energy in 2009, about $10 \%$ was used in general aviation, $72 \%$ in domestic commercial aviation, and the remaining $18 \%$ for international commercial aviation (Davis et al. 2011).

The aviation mode is used primarily for passenger transport. While there are some dedicated cargo planes, most air freight tends to be carried in the bellies of passenger planes in the course of normal passenger service. For this report, we focus on aircraft energy efficiency in terms of passenger service in the United States for both domestic and international flights. We use energy efficiency and energy intensity metrics in terms of passenger- or seat-miles, rather than ton-miles.

Aircraft energy intensity typically is measured in gallons of fuel per revenue passenger mile (gal/RPM) or gallons per available seat mile [gal/available seat miles (ASM)]. The former measure depends on the passenger load factor, while the latter is a more direct measure of the technology improvement. Aircraft energy efficiency is the inverse of energy intensity, measured in passenger- or seat-miles per gallon (RPM/gal or ASM/gal).

\section{Non-CO $\mathrm{O}_{2} \mathrm{GHG}$ Emissions from Aviation}

In other non-LDV modes, we focus on $\mathrm{CO}_{2}$ emissions as a measure of greenhouse gases. However, because aircraft emissions occur at a high altitude, non- $\mathrm{CO}_{2}$ aviation emissions play a significant, though often times scientifically less well understood, role. Radiative forcing (a measure of the warming tendency) for all aircraft emissions is 2-4 times as high as that due to $\mathrm{CO}_{2}$ alone (Lee 2001, Lee 2009).

Aircrafts produce the same types of emissions as on-road vehicles, but high altitude increases the global warming potential of some types of emissions. For example, about $30 \%$ of aviation emissions consist of $\mathrm{H}_{2} \mathrm{O}$, which when emitted at high altitude produces contrails, or vapor trails, that can lead to cirrus cloudiness (FAA 2005, Macintosh 2009). Contrails and cloudiness may contribute to global warming, but the level of scientific understanding of their effect is poor (Lee 2001). $\mathrm{NO}_{\mathrm{x}}$ is also an important contributor to global warming. $\mathrm{NO}_{\mathrm{x}}$ emitted in the troposphere and lower stratosphere (altitude of 5 to 8 miles) produces ozone, which has positive radiative forcing, but it also depletes methane and causes negative radiative forcing. The effects do not completely cancel out, but they lead to a reduced net positive radiative forcing (Lee 2009, IPCC 2007, Macintosh 2009). Also, ozone has a much shorter lifetime (months) compared with methane, which can be present in the atmosphere for 8 to 10 years. Because the chemistry is complex, the global warming effects of $\mathrm{NO}_{\mathrm{x}}$ and $\mathrm{H}_{2} \mathrm{O}$ emissions are dependent on many variables, such as latitude, time of year, and exhaust temperature (Akerman 2005).

\subsubsection{Future Aviation Demand}

\subsubsection{U.S. Aviation Demand Projections}

Projections by the EIA in the 2011 AEO (EIA 2011b) and by the FAA in its Aerospace Forecast 20112031 (FAA 2011) are among the most recent U.S. aviation demand projections. The AEO 2011 projections show a 1.1\% average annual growth in revenue passenger miles during $2010-2035$ and a $1 \%$ 
annual growth in seat miles. The smaller increase in seat miles results from a $0.1 \%$ increase in the load factor. A higher average annual growth of $1.3 \%$ is projected in international revenue passenger miles compared with a $1.1 \%$ annual growth in domestic revenue passenger miles. The Aerospace Forecast 2011-2031 by the FAA projects a 3.8\% annual increase in revenue passenger miles between 2010 and 2030 and a $3.7 \%$ annual increase in seat miles. The $0.1 \%$ difference in the two annual rates is again due to a $0.1 \%$ annual increase in the load factor. A much higher average annual growth of $5 \%$ is projected in international revenue passenger miles compared with a 3.2\% annual growth in domestic revenue passenger miles.

Based on a city-pair model, Jamin et al. (2004) estimate a 2.4\% average annual growth rate for domestic U.S. air travel out to 2030. In the projections used by the Pew Center, the authors cite EIA predicting a $0.8 \%$ annual growth rate for U.S. domestic passenger aviation and a $2.7 \%$ annual growth rate for U.S. international travel (McCollum et al. 2009).

\subsubsection{Global Aviation Demand Projections}

Among the recent projections for global aviation demand, Macintosh (Macintosh and Wallace 2009) and Owen (Owen et al. 2010) cite 5\% and 4.1\% average annual growth in passenger miles (McIntosh) and seat miles (Owen).

\subsubsection{Historical Improvements in Aircraft Efficiency}

New commercial aircraft energy intensity, in terms of energy use per seat-mile, has decreased by more than 50\% since 1960 (see Figure 3.1) [Rutherford and Zeinali 2009; Lee et al. 2001; Greener by Design (GbD) 2005]. The majority of this trend is attributed to improved engine efficiency. Jet engine efficiency, as measured by fuel burn per hour at cruising speed, has improved more than 40\% since 1960 (Lee et al. 2001). Most of this improvement is due to the introduction of high-bypass turbofan engines in the 1970s. Because of their higher thermal efficiency and reduced noise compared with the earlier low-bypass-ratio engines, almost all commercial jet aircraft in operation today use high-bypass turbofans.

Aerodynamic efficiency, as measured by the lift-to-drag ratio, has improved by over $15 \%$ since 1960 (Lee et al. 2001). Most of this improvement happened pre-1970 because of better wing design, improved propulsion/airframe integration, and enhanced computational and experimental design tools.

The overall rate of decrease in aircraft energy intensity has been falling over time. The 1960s and 1980s showed the most improvement, while the post-2000 period showed almost no improvement (Rutherford and Zeinali 2009; Peeters et al. 2005). Part of this trend of slowing improvement in energy intensity also may be due to the increased use of regional jets, which have less than 100 seats and are used for flights under 600 miles. Hub-and-spoke operations have widely replaced point-to-point service. Regional jets are used to expand hub service and to replace the more fuel-efficient turboprops. These jets tend to be 1.5 to 2 times more fuel intensive than large aircraft, primarily because of operational differences (Babikian 2001). Shorter travel distances mean a higher fraction of fuel is used in takeoff, landing, and ground taxiing.

Another factor that affects energy intensity (fuel use per passenger- or seat-mile) is the number of passengers per aircraft. The number of seats per aircraft increased dramatically in the $1970 \mathrm{~s}$ - by over $50 \%$. At the same time, passenger load factors increased from about 50\% in 1970 to over $70 \%$ in 1998 (Lee et al. 2001) and is currently over 80\% (BTS 2011). 


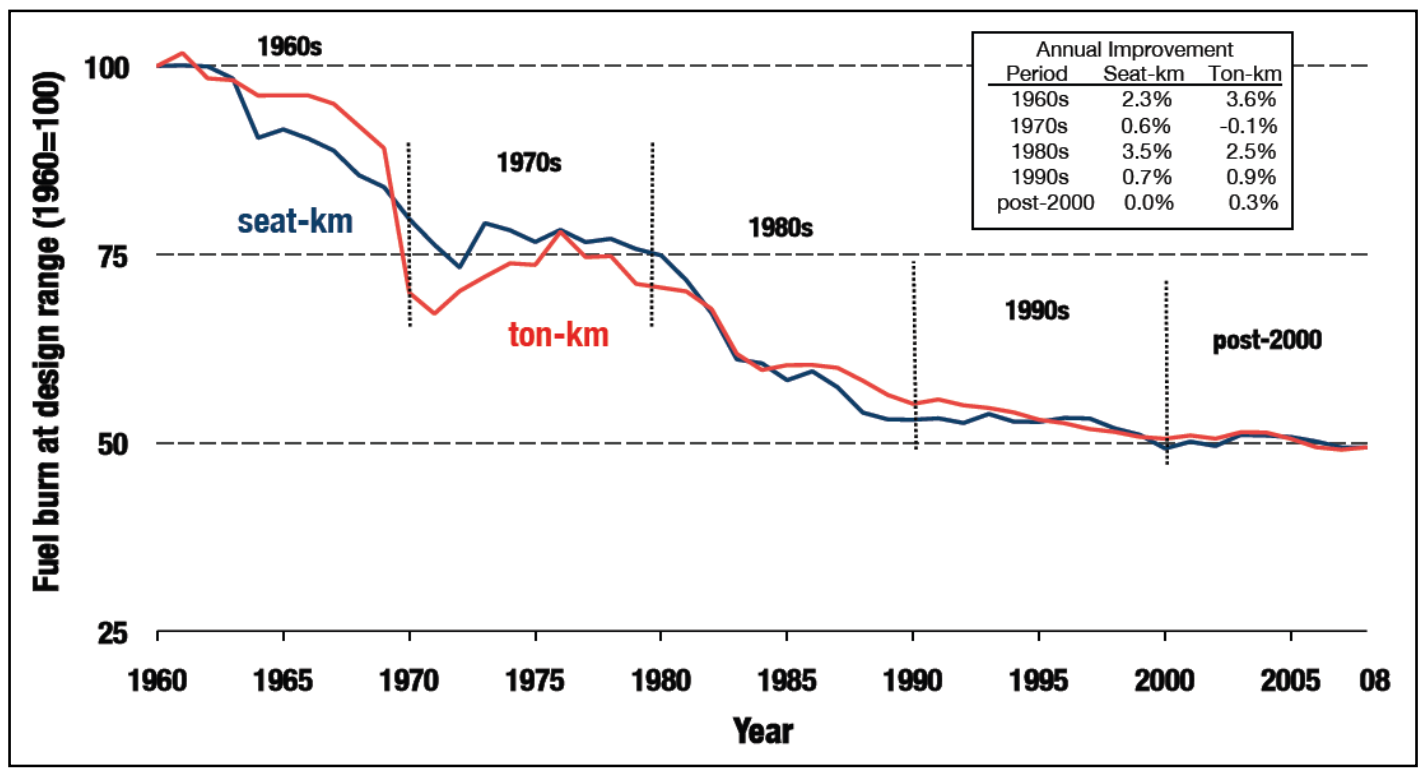

Figure 3.1. Average fuel burn for new aircraft, 1960-2008

(Source: Rutherford and Zeinali 2009)

\subsubsection{Future Improvements in Aircraft Efficiency}

Future aircraft energy efficiency improvements will depend on how long it takes for new technology to enter the fleet. U.S. passenger aircraft lifespan is typically 20-25, but it can be as long as 35 years (Lee et al. 2001). It takes 10-15 years for the average fleet energy efficiency to catch up to the energy efficiency of new aircrafts (Lee et al. 2001; FAA 2005). New aircraft development programs take 7-10 years (Lee et al. 2001). Pre-commercial aircraft research and development is conducted by NASA. The time it takes for NASA research to reach fleet average performance is 20 to 40 years (FAA 2005).

In the rest of this section, we discuss possibilities for future technological improvements in new aircrafts, as well as improvements on the operational side.

\subsubsection{Engine Improvements}

Today's commercial aircraft use high-bypass-ratio turbofan engines. Currently, the bypass ratio for these engines is already optimized for minimizing fuel burn. Increasing the bypass ratio will decrease noise and ground $\mathrm{NO}_{\mathrm{x}}$ emissions, but it will increase energy intensity and $\mathrm{NO}_{\mathrm{x}}$ emissions at cruise (GbD 2005). The thermal efficiency of turbofan engines can be improved by increasing the pressure ratio. However, this will increase $\mathrm{NO}_{\mathrm{x}}$ emissions nine times faster than the reduction of $\mathrm{CO}_{2}$ emissions.

Improved propulsion technology presents an opportunity to achieve better engine energy efficiency. Open rotor propulsion systems which have fan blades on the outside of the engine nacelle (see Figure 3.2) can reduce energy intensity by $10 \%$ compared with new turbofans [International Civil Aviation Organization (ICAO) 2010]. Open rotor engines are also sometimes referred to as unducted fans, propfans, and ultrahigh bypass engines. Speeds are limited compared to those of typical passenger jets because of air drag acting on the propeller blade tips at high speeds. This limits their use to short- and medium-range flights, where an increase in flight time may not be as much of a concern (Akerman 2005; GbD 2005; Lee et al. 2009; McCollum et al. 2009). Open rotor engines are also noisier than turbofans. This technology first appeared in the 1980s, but noise requirements and low fuel costs have kept it from coming to market. However more recent research suggests international noise regulations can be met without compromising energy efficiency (Croft 2012). 


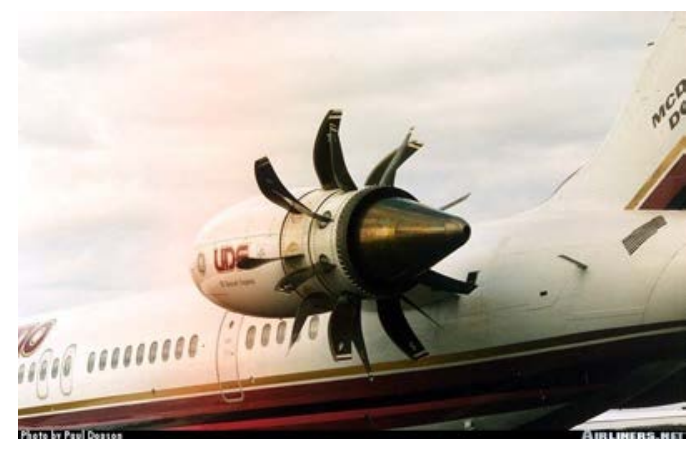

Figure 3.2. Open rotor propulsion

(Source: GE Aviation) ${ }^{2}$

Near-term technologies capable of reducing fuel burn and $\mathrm{NO}_{\mathrm{x}}$ include improved compressor operation and improved engine efficiency at slower speeds. This technology is used in the Rolls Royce Trent 1000 engine, which has a fuel savings of $15 \%$ (McCollum et al. 2009). Pratt \& Whitney, along with NASA, have developed a demonstration geared turbofan engine, where the fan and compressor run at different speeds, thus allowing for optimal operation of each with fuel savings of $12-15 \%$. It is expected to begin production in 2013 (Hughes 2010; Sabnis 2010; The Economist 2011).

In 2001, the Advisory Council for Aeronautics Research in Europe (ACARE) set targets to reduce noise, $\mathrm{NO}_{\mathrm{x}}$, and $\mathrm{CO}_{2}$ emission intensities in aviation. The energy intensity, or $\mathrm{CO}_{2}$ emission, reduction target is $50 \%$ by 2020 compared with 2000 energy intensity. They estimate that improved engine technologies can reduce energy intensity by $15-20 \%$ for new aircraft in 2020 (ACARE 2010). These targets are challenging but attainable goals (GbD 2005).

\subsubsection{Weight Reduction}

Substituting lightweight, high-strength materials for aluminum in aircraft construction offers a way to decrease aircraft weight and reduce fuel consumption. Increase use of titanium would provide greater structural strength and also some weight reduction. Composite carbon-fiber-reinforced plastic currently accounts for only $15 \%$ of material by weight in large aircraft, such as the A330 and B777. Greener by Design (GbD 2005) estimates that this can be increased to $65 \%$ composites by 2020 , thereby reducing fuel burn by an estimated $10-15 \%$. Up to $25 \%$ fuel reduction, is possible if more advanced, lighter composite materials are used.

\subsubsection{Aerodynamic Improvements}

Winglets and riblets are near-term options for improving aerodynamics. Wingtip vortices occur because of the pressure difference on the upper and lower surfaces of the aircraft wing. These vortices and the air drag associated with them can be reduced through the use of winglets, or vertical extensions of wingtips (see Figure 3.3). Winglets were developed by NASA in the 1970s and are now more common on newer aircraft. They have logistical advantage at airports because they reduce the time between successive takeoffs needed for turbulence to disperse (Andersen et al. 2003). They can reduce fuel consumption in longrange flights by up to 7\%, but the increased weight associated with them makes them ineffective for short-range flights (McCollum et al. 2009). Other wingtip devices also are possible, including a blended winglet, where the sharp angle is rounded out, and a spiroid, where the winglet loops back on itself

\footnotetext{
${ }^{2}$ In the mid-1980s, GE Aviation introduced the unique, highly fuel-efficient unducted fan (UDF) engine, in which two counter rotating stages of open rotors produced thrust to propel an aircraft. The UDF was successfully flight-tested as one of two engines powering a McDonnell Douglas MD-80 twinjet aircraft. The technology, which was not pursued as a result of a significant reduction in fuel prices, is now being reevaluated and enhanced in today's open rotor engine at GE Aviation. UDF is a trademark of General Electric.
} 
(Jahanmiri 2011). Riblets are small, raised grooves on airframes that reduce air turbulence and friction drag. An air drag reduction of 1-3\% is likely (Viswanath 2002; Jahanmiri 2011).

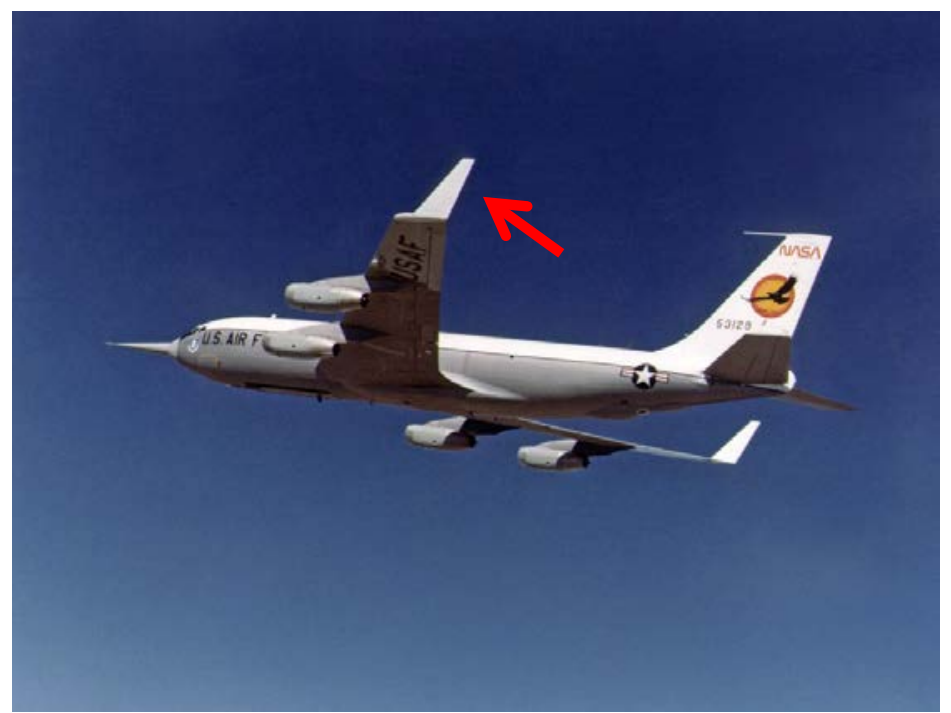

Figure 3.3. Winglets

(Source: NASA)

\subsubsection{Long-Term Technologies and NASA Studies}

Longer term aircraft designs to achieve better energy efficiencies include moving away from the tubeand-wing design of conventional aircraft. In the blended wing body, the wings, fuselage, and engines are smoothly blended together to resemble a flying wing, as shown in Figure 3.4. This design improves aerodynamics by enabling the entire aircraft to contribute to lift generation. The body shape and lack of a tail result in much less drag than the conventional tube-and-wing aircraft. The blended wing body design has an estimated 20-30\% reduction in fuel burn (McCollum et al. 2009; IPCC 2007). This is a long-term option and is unlikely to be seen in commercial aircraft before 2030 .

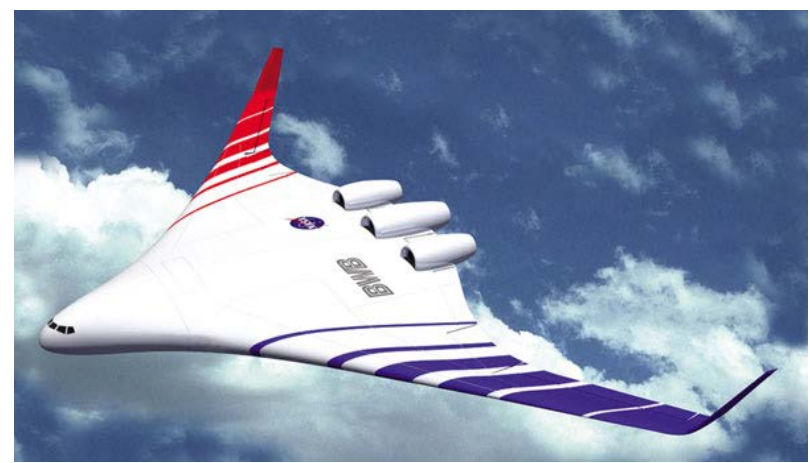

Figure 3.4. Blended wing body

(Source: NASA)

Increasing wingspan is another way to improve aircraft aerodynamics. The longer wingspan increases the lift-to-drag ratio. Wingspan has been optimized to be as long as possible, while keeping the wing weight low enough to manage the bending moment. The use of advanced composite material for the wing skins leaves the possibility of increasing span without increasing weight. A strut-braced, or truss-braced, wing design allows for a longer, thinner wing. This design improves the lift-to-drag ratio by up to $28 \%$ and has a $15 \%$ decrease in takeoff gross weight compared with a conventional wing (Ko et al. 2002). A design 
constraint on longer wingspans is the 80 -meter box at airports, which currently limits the aircraft wingspan to a maximum of 80 meters (GbD 2005). The 80 -meter limit is set by ICAO and FAA. Any change in this limit will require extensive airport improvements.

Laminar flow control aims to maintain smooth flow of air adjacent to the surface of the aircraft. This reduces viscous drag and decreases fuel burn. This technology includes passive control, which addresses the problem solely through reshaping the wing. Passive control is limited to small- and medium-sized aircraft. Active control, also called hybrid laminar flow control includes surface cooling and suctioning through porous surfaces to reduce turbulence at the boundary layer. This technology is practical for medium- to long-range aircraft, and it has a possible 10-20\% fuel reduction potential (IPCC 2007; Brashlow 1999; GbD 2005; Jahanmiri 2011).

In 2008, NASA commissioned four 18-month studies led by industry and academic teams to design future passenger aircraft capable of meeting environmental targets. The targets include a simultaneous reduction of noise, $\mathrm{NO}_{\mathrm{x}}$, and fuel burn. The most stringent of these is the "N+3 generation," with a target entry date of 2030 and a fuel reduction of $70 \%$ compared with 2008 aircraft. Trends that were seen across all the studies were lower cruise speeds at higher altitudes to reduce drag; high-bypass-ratio turbofan engines with a small, high-efficiency core; high-aspect-ratio wings; and laminar flow control (Dryer 2010). Final designs included a truss-braced wing with hybrid electric propulsion, a hybrid wing body with turboelectric distributed propulsion, and a double-bubble fuselage in the shape of two combined cylinders placed side by side with high bypass ratio and boundary layer ingestion propulsion (Wahls 2010).

Marginal abatement costs (MAC) were estimated by Morris (Morris 2009) for the UK and European fleets. The MAC is the cost of abating one unit of $\mathrm{CO}_{2}$ after taking into account capital cost, maintenance cost, fuel savings, and a discount factor. A negative MAC indicates that the fuel savings outweighs the intervention cost. The MAC is useful for ranking technology options based on economic feasibility. In 2025 , the order of technological intervention, from the most- to least-feasible, will be: winglets, riblets, aircraft lightweighting, blended wing design, and open rotor engines. In 2025, at an average oil price of \$73/barrel, winglets, riblets, and lightweighting all will have negative MAC (Morris et al. 2009).

\subsubsection{Operational Improvements}

Near-term aviation operational improvements will involve the communications, navigation, and surveillance (CNS) and air traffic management (ATM) systems. In the U. S., these improvements are part of the Next Generation Air Transportation System (NextGen) initiative, which aims to improve efficiency by shortening travel distances and decreasing congestion. This initiative includes implementing satellite navigation systems, which allow more precise control of the aircraft and facilitate closer flying distances, continuous descent arrivals, and in-flight route updating based on weather conditions (McCollum et al. 2009).

The Civil Air Navigation Services Organization (CANSO) is an international group of ATM companies. They estimate that, on average, the aircraft in the United States burn 7-8\% more fuel than the optimum trajectory. Some of this is due to unavoidable interactions, such as weather, safety, noise, and capacity issues. However, they claim that a $2-6 \%$ fuel savings is possible through ATM efficiency improvements. As air traffic congestion increases in the future, improving the ATM system will be even more effective in reducing fuel consumption (Stollery 2008).

The International Civil Aviation Organization (ICAO) expects a 5\% fuel savings by 2015 in the United States and Europe. Savings of 8-10\% are expected in the longer term (McCollum et al. 2009; GbD 2005).

\subsubsection{Aviation Alternative Fuels}

Biojet fuel is the prevalent alternative fuel available in the aviation sector. In July 2011, the American Society for Testing and Materials (ASTM) International, a technical standards organization, approved blends of up to $50 \%$ biojet fuel. The fuel is referred to as hydroprocessed esters and fatty acids (HEFA) fuel or hydroprocessed renewable jet (HRJ) fuel. Feedstocks can include jatropha, algae, tallows, waste 
oil, and camelina (Millikin 2011a). This type of biofuel meeting ASTM specifications can be used without modification to the aircraft.

In November 2011, blends of 20\% biofuel were first used on commercial airlines. Fuel cost is currently an impediment to more widespread use, with biojet fuel costing over five times the price of jet fuel (Paur 2011). The 2009 Pew study estimated that $30 \%$ of petroleum jet fuel could be replaced by biofuel by 2050. Based on the assumption that the lifecycle $\mathrm{CO}_{2}$ emissions of biofuels are $80 \%$ lower than jet fuel, this would result in a $24 \%$ reduction in $\mathrm{CO}_{2}$ emissions (McCollum et al. 2009).

\subsubsection{Aviation Summary and Energy Growth Forecast}

Table 3.1 summarizes various estimates of the future energy-intensity improvement potential in the aviation sector, as derived from this literature search.

Table 3.1. Summary of Aviation Energy-Intensity Improvement Potential

\begin{tabular}{|c|c|c|c|c|}
\hline Study & Technology & $\begin{array}{l}\text { Base } \\
\text { Year }\end{array}$ & $\begin{array}{l}\text { Projection } \\
\text { Year }\end{array}$ & $\begin{array}{l}\text { Energy Intensity } \\
\text { Reduction }\end{array}$ \\
\hline \multirow[t]{3}{*}{ Pew 2009} & Operations improvements & 2005 & 2050 & $5 \%$ \\
\hline & $\begin{array}{l}\text { BAU scenario: turbofans with lightweight materials and } \\
\text { improved aerodynamics }\end{array}$ & 2005 & 2050 & $30 \%$ \\
\hline & $\begin{array}{l}\text { Open rotors, lightweight materials, lamellar flow control, and } \\
\text { blended wing body (fleet reduction potential) }\end{array}$ & 2005 & 2050 & $50-65 \%$ \\
\hline \multirow{6}{*}{$\begin{array}{l}\text { Greener by } \\
\text { Design } 2005\end{array}$} & Operations improvements & 2005 & 2020 & $8 \%$ \\
\hline & Open rotors & 2005 & & $12 \%$ \\
\hline & Light-weight material substitution & 2005 & & $25 \%$ \\
\hline & Blended wing body & 2005 & & $20 \%$ \\
\hline & Laminar flying wing & 2005 & 2030 & $50-60 \%$ \\
\hline & Laminar flying wing with open rotors and weight reduction & 2005 & 2030 & $65 \%$ \\
\hline Owen 2010 & $\begin{array}{l}\text { Fleet rollover model with a } 1 \% / y e a r \text { decline in fleet energy } \\
\text { intensity to } 2020 \text {; then a } 0.2-1.3 \% / y \text { r decline out to } 2050\end{array}$ & 2000 & 2050 & $23-45 \%$ \\
\hline Lee 2001 & $\begin{array}{l}\text { Based on the historical trend of a } 1-2 \% / y r \text { decline in fleet } \\
\text { energy intensity }\end{array}$ & 2000 & 2025 & $22-40 \%$ \\
\hline IPCC 2007 & $\begin{array}{l}\text { Aircrafts in production. This is a BAU estimate and does not } \\
\text { include advanced technologies, such as an open rotor engine } \\
\text { and blended wing design. }\end{array}$ & 1997 & 2050 & $29-33 \%$ \\
\hline ICAO 2010 & Open rotor engine, lamellar flow control, and weight reduction & 2000 & 2030 & $41-48 \%$ \\
\hline ATA & Goal for new aircraft & 2005 & 2025 & $23 \%$ \\
\hline \multirow{4}{*}{$\begin{array}{l}\text { ACARE research } \\
\text { target for new } \\
\text { aircraft }\end{array}$} & Airframes & 2000 & 2020 & $20-25 \%$ \\
\hline & Engines & 2000 & 2020 & $15-20 \%$ \\
\hline & Operations & 2000 & 2020 & $5-10 \%$ \\
\hline & Total & 2000 & 2020 & $50 \%$ \\
\hline \multirow[t]{3}{*}{ NASA } & $\mathrm{N}+1$ goal for new aircrafts & 2010 & 2015 & $33 \%$ \\
\hline & $\mathrm{N}+2$ goal for new aircrafts & 2010 & 2020 & $50 \%$ \\
\hline & $\begin{array}{l}\mathrm{N}+3 \text { goal: truss-braced wing with hybrid electric propulsion, } \\
\text { hybrid wing body with turbo electric distributed propulsion, } \\
\text { and double bubble with high BPR BLI propulsion }\end{array}$ & 2010 & 2030 & $70 \%$ \\
\hline
\end{tabular}


Figure 3.5 shows the projected growth of aviation energy consumption out to 2050. The FAA forecast, when extended at gradually decreasing growth rates, shows passenger miles increasing to more than three times the 2010 value by 2050 . Even with the most optimistic energy intensity reductions (65\% fleetwide reduction by 2050), the overall aviation energy usage in 2050 will be $11 \%$ above the 2010 levels. In order for further reduction goals to be met, the implementation of low-carbon fuels and a reduction in air travel demand would need to be pursued in addition to the energy efficiency improvements.

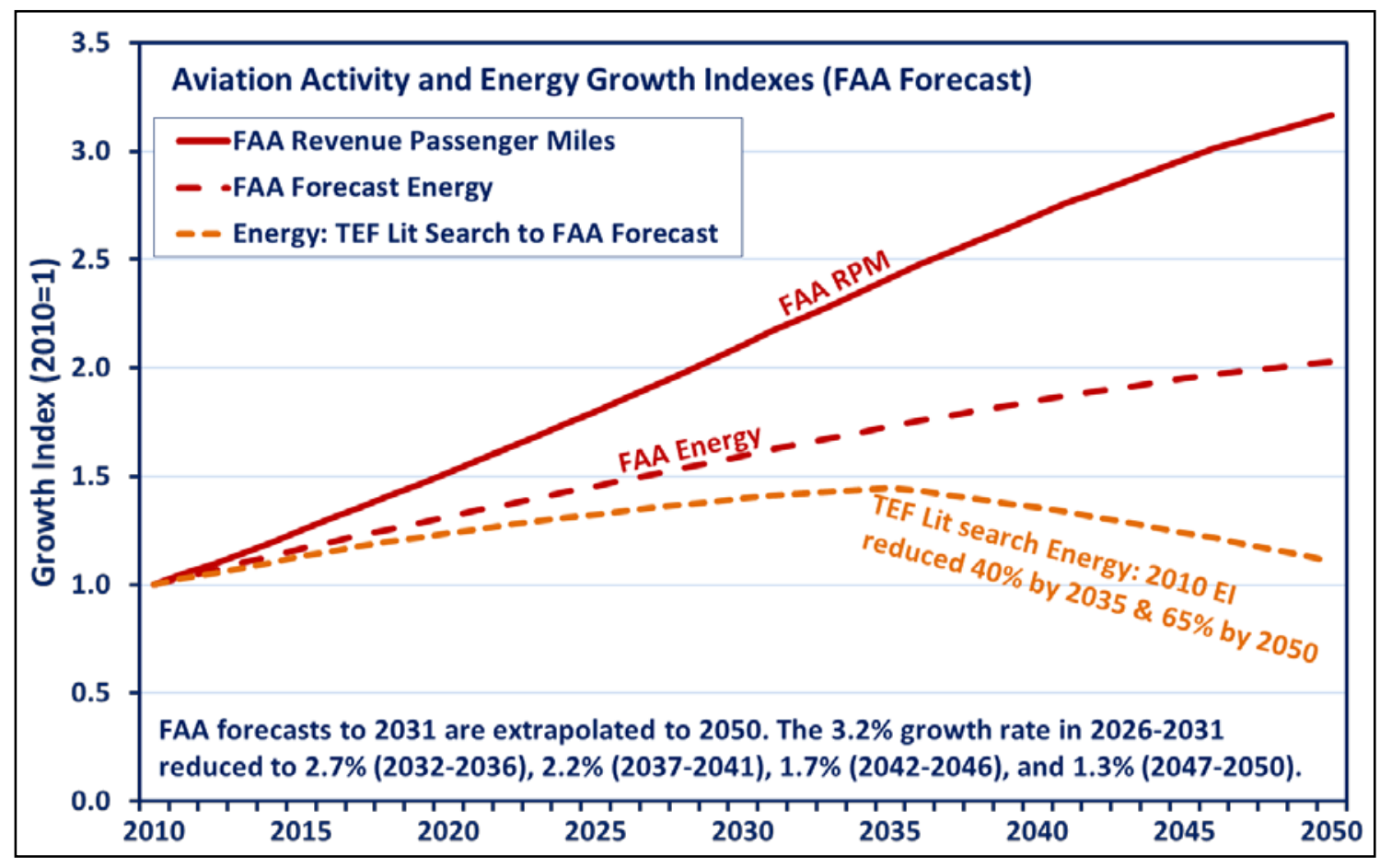

Figure 3.5. Aviation activity and energy consumption

\subsection{Marine}

The marine mode consumed 1.22 quadrillion Btu of energy in 2009. The mode is used for freight movement and recreation. The freight component used $80 \%$ of the energy, with $81 \%$ in the form of residual fuel oil, and $19 \%$ as marine diesel. In terms of ton-miles, U.S. DOT provides only the domestic marine ton-miles. In 2009, domestic marine accounted for 471 billion ton-miles, a $12.8 \%$ share of total ton-miles (BTS 2012). If we assume 20\% share of total marine energy by domestic marine (EIA 2011b), the domestic marine energy intensity works out to $438 \mathrm{Btu}$ per ton-mile. The domestic marine mode is being used less and less, carrying fewer ton-miles over time. The mode accounted for 922 billion tonmiles in 1980, 834 billion ton-miles in 1990, and 646 billion ton-miles in 2000.The recreational energy use has remained in the range of 200-250 trillion Btu/year over the past two decades. Within the recreation use, a majority of energy consumption is by recreational boats that operate in inland and coastal waters. A majority of recreational energy use $(82 \%)$ is in the form of gasoline, while marine diesel is used by large boats, passenger ferries, and cruise ships. In the rest of the review, we focus on fuel use in the marine freight component.

Because the United States imports and exports a large amount of goods, EIA subdivides marine freight as domestic and international (EIA 2011b). According to EIA, international marine freight transport accounts for $80 \%$ of marine freight energy use. The international marine trade, in terms of 2005 dollars, is projected to grow at an average annual rate of 5.3\% between 2010 and 2035 (EIA 2011b). This makes international marine transport [or ocean-going vessels (OGVs)] a major contributor of transportation energy consumption and GHG emissions. 
Sections 3.2.1 and 3.2.2 provide overviews of the international and domestic marine sectors. Section 3.2.3 discusses fuel use and efficiency by ship type. Section 3.2.4 covers potential fuel and $\mathrm{CO}_{2}$ reduction measures for international and domestic shipping, with domestic shipping consisting of coastal, inland, and Great Lakes. Finally, Section 3.2.5 summarizes efficiency estimates, discusses predictions for future growth in shipping activity, and projects future $\mathrm{CO}_{2}$ shipping emissions.

\subsubsection{International Marine Overview}

Approximately 50\% of global freight trade occurs between locations more than 1,800 miles apart, and about $90 \%$ of that trade (by weight) is maritime (Rodrigue 2011; Breitling 2010). The Pew Center on Climate Change estimates that world merchandise exports increased an average of $5.5 \%$ per year [double the growth rate of global gross domestic product (GDP)] from 2000 to 2007 (McCollum et al. 2009). A German Technical Cooperation paper on port development disclosed that the fastest growing part of world trade, container shipments, had port throughputs of 506 million Twenty-foot equivalent units (TEUs) in 2008, versus 100 million in 1990, with Chinese ports accounting for about $23 \%$ of shipment volume (Breitling 2010). Although transpacific trade has been growing at a faster pace than transatlantic trade, the United States, Germany, and Japan have maintained their combined one-third share (Rodrigue 2011).

In the United States, more than $60 \%$ of all waterborne commerce, by tonnage, is composed of international shipments. Furthermore, trade tonnage to and from the United States increased 2\% per year from 2003 to 2008, but declined 10\% in 2009 (Davis et al. 2011).

\subsubsection{Estimated Increases in Potential International Maritime Emissions}

By using a range of business-as-usual (BAU) rapid ton-mile growth scenarios, a 2009 International Maritime Organization (IMO) study projects that by 2050 the baseline world international maritime $\mathrm{CO}_{2}$ growth will range from $220-310 \%$, with a $265 \%$ average (IMO 2009). Without technology improvements, the high end estimate is a $723 \% \mathrm{CO}_{2}$ increase, providing a major incentive for improvement (IMO 2009). These projected emission growths use the IMO's 2007 base-year estimate of 1,050 million metric tonnes for worldwide maritime shipping, with the international and domestic shares of 870 million tonnes $(2.7 \%)$ and 180 million tonnes $(0.6 \%)$ of global $\mathrm{CO}_{2}$ emissions, respectively (IMO 2009). The share of world $\mathrm{CO}_{2}$ emissions coming from international maritime sources in 2050 could range from $5.9 \%$ (based on $220 \%$ growth) to $19.5 \%$ share (based on $723 \%$ growth).

Although no estimates are available for the U.S. share of international global maritime GHG emissions, a reasonable estimate of the U.S. share of these emissions is in the range of $1-12 \%$. The U.S. contribution to international maritime GHG emissions is either the world's largest or one of the world's largest. ${ }^{3}$

The U.S. DOT defines U.S. domestic shipping as comprising inland rivers (62\% of tonnage; 622 million tons); domestic ocean/coastwise, including St. Lawrence Seaway facilities and movements (27\%; 267 million tons); and the Great Lakes (11\%; 115 million tons) as shown in Figure 3.. These add up to about 1 billion tons, which in 2006 was $6 \%$ of domestic tons shipped and represented $9 \%$ of domestic freight ton-miles. The U.S. international waterborne foreign trade tons shipped (more than 1.5 billion in 2006) now exceeds domestic waterborne tons by 50\%. Furthermore, from 1986 through 2006, overall domestic waterborne ton-miles decreased from 873 billion to 591 billion, with inland waterway and Great Lakes ton-miles increasing less than $10 \%$, and coastwise ton-miles decreasing by about $55 \%$.

\footnotetext{
${ }^{3}$ The 2009 IMO study indicates that the U.S. shares of 2008 world trade in terms of dollar value, overall worldwide fleet deadweight tonnage, and U.S.-owned fleet deadweight tonnage are $11.38 \%, 1.09 \%$, and 3.84\%, respectively. Since the percentage trade dollar value shares of Germany, China, Japan, France, and the United Kingdom were 8.51, 7.81, 4.77, 4.16, and 3.76, respectively (IMO 2009), and these are the world's major trading nations, the more likely U.S. share is near the upper end of the parametric range. However, since one-third of the world's 53,000 ships are general cargo ships with unknown emissions (Breitling 2010), the lower end of the parametric range cannot be ignored.
} 


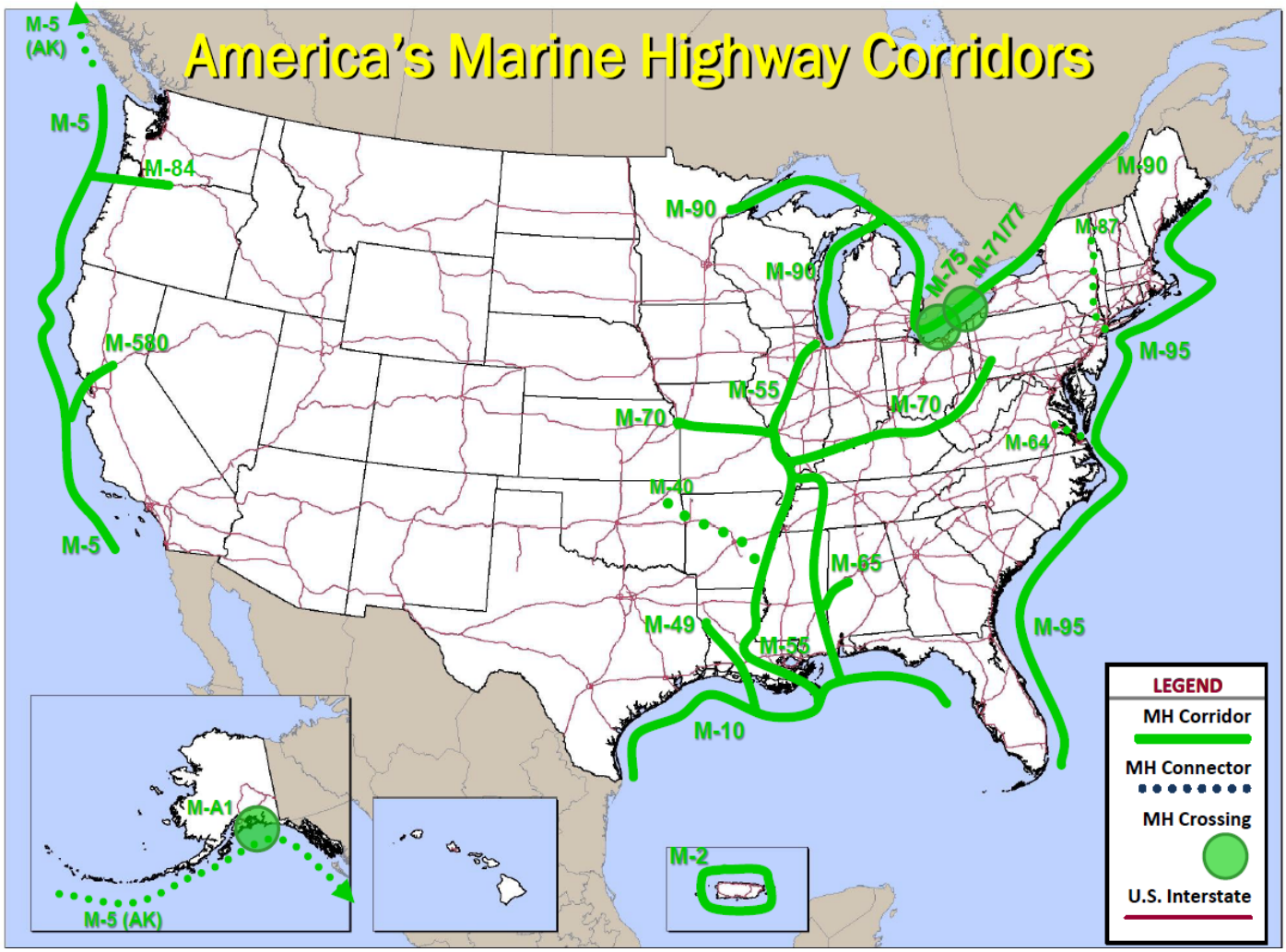

Figure 3.6. Marine Highway Corridors

(Source: U.S. DOT, Maritime Administration)

\subsubsection{Domestic Marine Overview: Coastal and Inland}

The water mode's infrastructure-related reasons for this trend were cited in the U.S. DOT Volpe Center report as channel depth restrictions on the Upper Mississippi, Illinois, and Ohio Rivers, which have restricted throughput capacities. In addition, three related competitive market forces have diminished the waterborne domestic freight share: increased demand for high-value, just-in-time shipments; competition with major rail corridors that excel at shipping large volume, high-density imports from East to West; and truck shipment networks that serve distribution and consolidation centers near major ports (Barami and Dyer 2009).

This underutilization of the highly energy-efficient marine mode share of domestic freight movements, plus the U.S. and worldwide need to reduce GHG emissions, led to the U.S. DOT/U.S. Maritime Administration (MARAD) Marine Highway Program. Triggered by the Energy Act of 2007, this program has been designed to increase the nation's use of domestic waterborne shipping, especially coastal shipping, via Intracoastal Waterway systems and coastal Domestic Ocean waters. These domestic waterborne shipping systems are analyzed in this report with a view toward identifying measures that can help further reduce fuel use and GHG emissions and enhance marine modes' already considerable energy efficiency advantage over domestic trucking. Appendix A.1 offers additional information about the U.S. DOT/MARAD Marine Highway Program and related shipping opportunities.

\subsubsection{Energy Intensities and Fuel Use by Ship Type}

Figure 3.7 illustrates the range in GHG emissions (and fuel intensities) for various ship types and includes a comparison to rail and truck energy intensities Large bulk and crude oil carriers are the least fuel intensive, ranging from 4 to 13 grams of $\mathrm{CO}_{2}$ emissions per ton-mile traveled and they have no overlap with rail intensities, which range from 25 to 100 grams of $\mathrm{CO}_{2}$ per ton-mile. General cargo and ocean- 
going container vessels tend to be more fuel intensive than the bulk and crude oil carriers. Smaller coastal container vessels are twice as fuel intensive as their larger ocean-going counterparts, but still compare favorably with trucks.

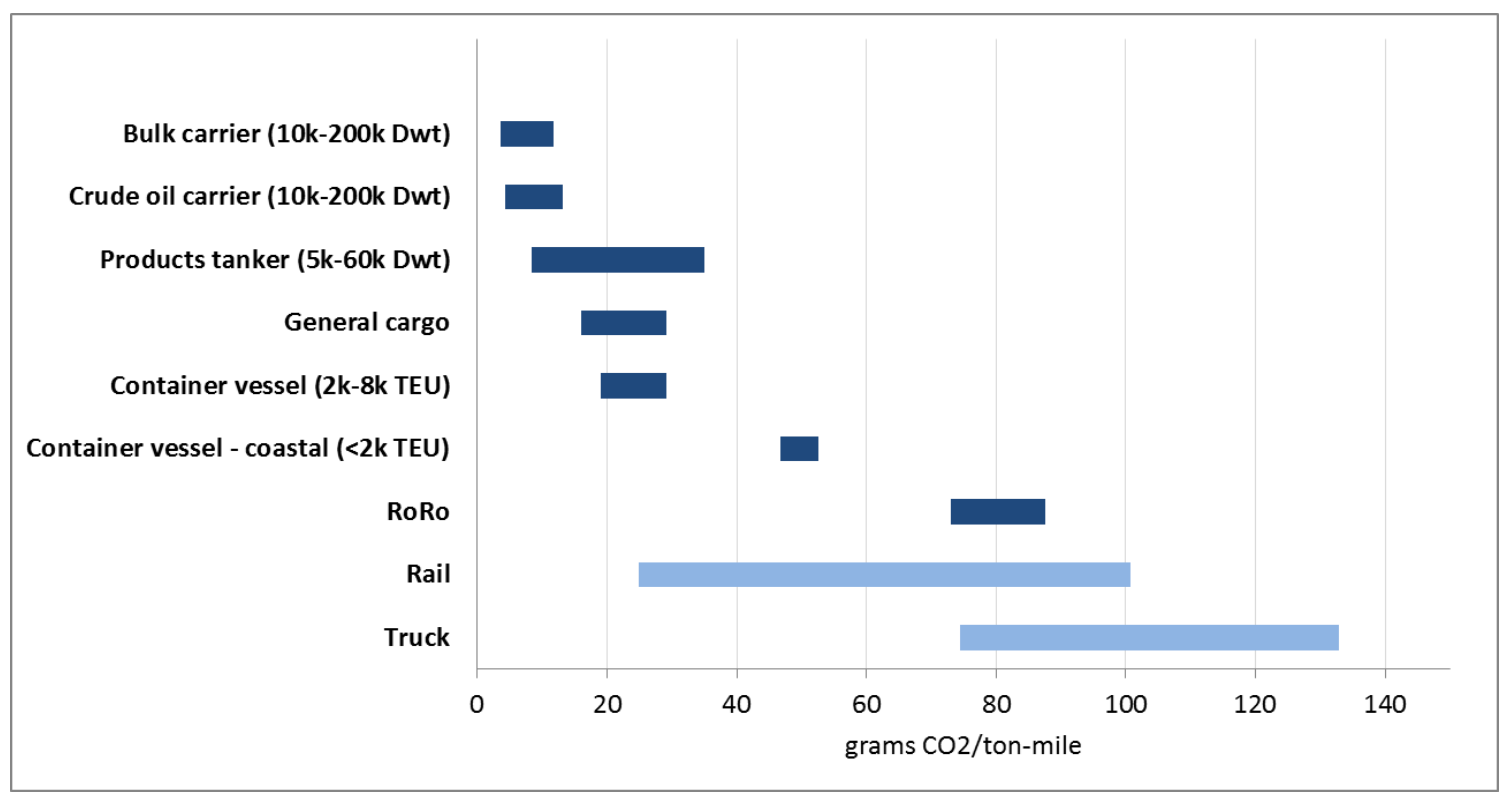

Figure 3.7. $\mathrm{CO}_{2}$ emissions intensity by ship type compared with rail and truck

(Sources: Crist 2009; IMO 2009)

There is limited data addressing fuel use by ship type. Studies estimate that general cargo ships-a category covering varied types of cargo ships - consume $12-13 \%$ of total international maritime fuel (IMO 2009; IEA 2009). Their share of international shipping fuel use and $\mathrm{CO}_{2}$ emissions is unlikely to be measurable, now or in the future, ${ }^{4}$ and accuracy of estimates may decline over time as trade with developing nations, where data quality is worse, increases. ${ }^{5}$ General cargo vessels are estimated at $32 \%$ of the total 2009 world merchant fleet of 53,005 ships, as indicated by the following listing:

- General cargo ships $(17,104)$,

- Bulk carriers $(7,787)$,

- Container ships $(4,678)$,

- Tankers $(14,095)$,

- Passenger ships $(6,839)$, and

- Other (2,502). (Breitling 2010 citing Lloyd's Register 2009)

Figure 3.8 illustrates global fuel use by vessel type, but we did not find similar estimates of U.S. domestic marine fuel use by vessel type.

\footnotetext{
${ }^{4}$ Since the 2009 IEA study indicates that "data on international bunkers for major non-OECD (Organization for Economic Cooperation and Development) countries, such as Russia, are missing..." (IEA 2009).

5 “...the importance of non-OECD countries in international bunkering may have been increasing. So, any gap between actual and reported bunker use may be growing over time (IEA 2009).”
} 


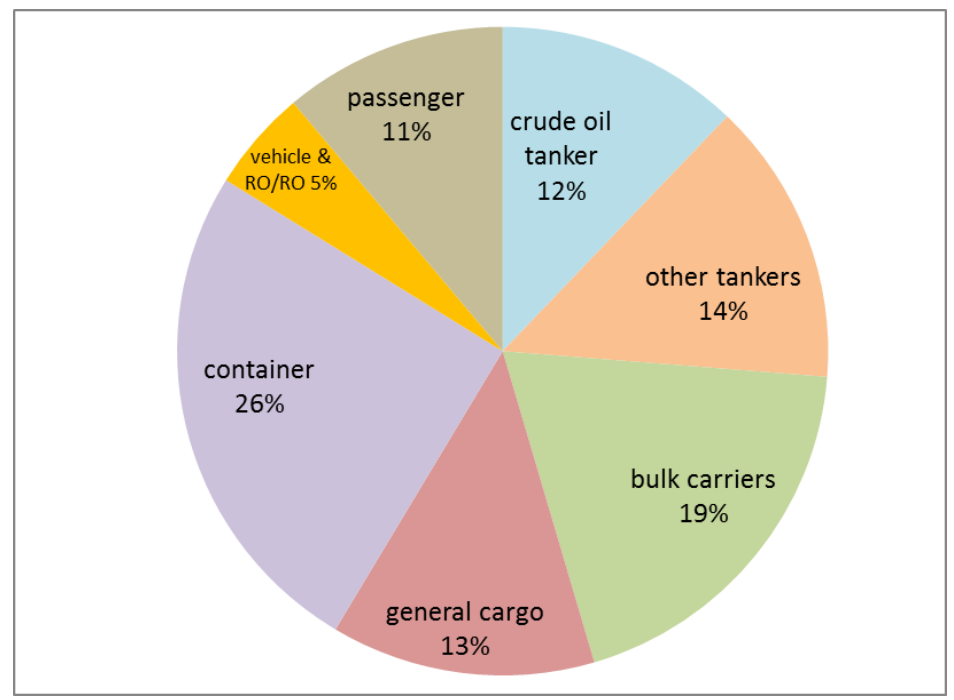

Figure 3.8. Global marine fuel use by ship type

(Source: IEA 2009)

\subsubsection{International Maritime Fuel Reduction Measures}

International maritime studies identify numerous potential fuel and GHG emissions savings. Estimates of these opportunities are summarized in Table 3.2 and presented in more detail in Appendix A.2.

\section{Table 3.2. International Maritime Fuel and $\mathrm{CO}_{2}$ Savings Potential by 2050}

\begin{tabular}{|c|c|c|c|}
\hline Study & Technology & $\begin{array}{l}\text { Savings per } \\
\text { Ton-Mile }\end{array}$ & $\begin{array}{l}\text { Combined Savings per } \\
\text { Ton-Mile }\end{array}$ \\
\hline \multirow{3}{*}{ Pew 2009} & $\begin{array}{l}\text { Operations: speed reduction, optimized routing, and reduced } \\
\text { port turnaround }\end{array}$ & $20-47 \%$ & \multirow{3}{*}{$37-80 \%$} \\
\hline & $\begin{array}{l}\text { New ship design: increased size, bulbous bow, novel hull } \\
\text { coatings, and improved propellers and engines, including } \\
\text { combined-cycle diesel engines }\end{array}$ & $20-37 \%$ & \\
\hline & $\begin{array}{l}\text { Low carbon fuels (marine diesel or LNG) and wind power } \\
\text { (sails) }^{6}\end{array}$ & $2-40 \%$ & \\
\hline \multirow{4}{*}{ IMO 2009} & $\begin{array}{l}\text { Operations: speed reduction, voyage optimization, and energy } \\
\text { management }\end{array}$ & $10-50 \%$ & \multirow{4}{*}{$25-75 \%$} \\
\hline & $\begin{array}{l}\text { New ship: hull and superstructure optimization, bulbous bow } \\
\text { and lightweight materials }\end{array}$ & $2-20 \%$ & \\
\hline & $\begin{array}{l}\text { New ship: power and propulsion systems-waste heat } \\
\text { recovery, diesel-electric propulsion, and propeller rotational } \\
\text { energy recovery (vanes, fins, ducts, and contra-rotating) }\end{array}$ & $5-15 \%$ & \\
\hline & Low carbon fuels (LNG) and renewable energy (wind)6 & $5-25 \%$ & \\
\hline \multirow{3}{*}{ IEA 2009} & $\begin{array}{l}\text { Operations: speed reduction, port time reduction, voyage } \\
\text { optimization, and energy management }\end{array}$ & $40 \%$ & \multirow{3}{*}{$50-60 \%$} \\
\hline & $\begin{array}{l}\text { New ship design (lightweight, optimal hull, bulbous bow, after } \\
\text { waterline extension, air lubrication, and more) }\end{array}$ & $30 \%$ & \\
\hline & Retrofits and maintenance & $20 \%$ & \\
\hline
\end{tabular}

\footnotetext{
${ }^{6}$ Estimate is for $\mathrm{CO}_{2}$ savings.
} 
The 2009 Pew study provides estimates of future international marine $\mathrm{CO}_{2}$ emissions intensity reductions in three areas: operations, ship design and propulsion, and alternative fuels. The lower end of these estimates is the improvement expected in their BAU scenario. The upper end of the range includes additional reduction measures that are possible in the 2050 timeframe. Freight companies have already reduced ship speeds due to high fuel prices, a continuation of this leads to a $20 \%$ fuel reduction in their BAU scenario. Aggressively combining slow steaming with increased port efficiency and optimized complementary land-side intermodal transport systems to reduce ship turnaround time, plus additional optimization of weather- and ocean-current-based routing, ship utilization (load factors), and maintenance, can achieve an emissions reduction of $27 \%$ beyond expected 2050 BAU improvements, producing a total reduction of $47 \%$ relative to 2007 levels. Similarly, improving new ship design, including improved engines and propellers, has the potential for up to $37 \%$ fuel savings over 2007 levels. Switching to low carbon fuel, such as LNG and wind power (sails) can reach up to a $40 \%$ reduction in $\mathrm{CO}_{2}$ emissions while keeping vessel performance unchanged. Combining the reductions in all three categories (operations, new ship design, and low carbon fuels) results in an overall $\mathrm{CO}_{2}$ intensity reduction of $37-80 \%$ compared with 2007 values. ${ }^{7}$ This is a combined $62 \%$ decrease from the $2050 \mathrm{BAU}$ case (McCollum et al. 2009).

The 2009 IMO study arrives at a range of potential savings, noting that the savings realized by the recommended measures will depend on the extent to which they are adopted on the various ship types and international routes traveled. The emissions savings are based on known technology and operational practices, and they range from $25 \%$ to $75 \%$ (IMO 2009 ).

Additional confirmation of this estimated potential range of $\mathrm{CO}_{2}$ emission savings is provided in the 2009 IEA study, which estimates an aggregate $\mathrm{CO}_{2}$ savings of up to $40 \%$ in 2030 , and from $50 \%$ to $60 \%$ in 2050 (IEA 2009).

Appendix A.2 presents potential improvements to reduce maritime fuel use and GHG emissions. These include operational measures such as ship speed reduction, steady power, cargo handling, anchoring and mooring, maintenance, ship routing, cargo pooling, trim, ballast, propeller pitch, optimal rudder, and energy management. Technological ship improvements such as enhancement of ship concept design, hull and superstructure design, power and propulsion improvements, and retrofits are also discussed. Marine vessels have a life span of 40 to 50 years. It will take at least 20 years after new technologies are deployed before it is seen in over half of the fleet.

\subsubsection{Domestic Coastal Vessels Fuel Reduction Measures}

Table 3.3 offers a summary of reduction measures.

This research found no aggregate 2050 projections of potential fuel and GHG savings for the domestic ships and harbor vessels (tugs and tow boats) involved in U.S. coastal shipping. However, one researcher's presentation to a July 2009 European Commission Stakeholder Meeting outlined potential percentage fuel savings for both European ship and inland waterway vessel technical equipment options. The presentation noted many similar options for both the marine and inland vessels, particularly with respect to hulls, propellers, and engines (Skinner 2009). Many of the measures listed in Table 3.3 were also included in the 2009 IMO study, which concentrated on OGV, but also can apply to smaller coastal and harbor vessels.

\footnotetext{
${ }^{7}$ Estimated using the formula $(1-a) *(1-b)=1-c$ (where $\mathrm{c}$ is the combined reduction of $\mathrm{a}$ and $\mathrm{b}$ ) to avoid double counting.
} 
Table 3.3. Coastal Shipping Technology Options for Fuel and $\mathrm{CO}_{2}$ Reduction

(Sources: Skinner 2009; Hazeldine et al. 2009)

\begin{tabular}{|c|c|c|}
\hline Technology & $\begin{array}{c}\text { Fuel and } \mathrm{CO}_{2} \text { Reduction } \\
\text { per Ship }\end{array}$ & Payback Time \\
\hline \multicolumn{3}{|l|}{ Hull } \\
\hline Design optimization (new ships) & $5-20 \%$ & Long \\
\hline Weight reduction (new ships) & $<7 \%$ & Short \\
\hline Transverse thruster opening (grids and flow optimization) & $1-5 \%$ & Very short \\
\hline Coatings & $5-15 \%$ & Very short \\
\hline Air lubrication & $5-15 \%$ & Very long \\
\hline \multicolumn{3}{|l|}{ Propeller } \\
\hline Energy recovery (fins, thrusters, and contra-rotating) & $5-10 \%$ & Short-to-medium \\
\hline Upgrade & $2-10 \%$ & Short-to-medium \\
\hline \multicolumn{3}{|l|}{ Engine } \\
\hline Upgrade (common rail technology) & $1 \%$ & Short \\
\hline Waste heat recovery & $10 \%$ & Medium \\
\hline \multicolumn{3}{|l|}{ Alternative energy } \\
\hline Sails and kites & $5-25 \%$ & Medium-to-long \\
\hline Flettner rotors & $12-30 \%$ & Medium-to-long \\
\hline LNG fuel & $15 \%$ & Medium-to-long \\
\hline
\end{tabular}

For example, American Feeder Line (AFL) is eligible to receive $\$ 7$ million from the U.S. DOT/MARAD America's Marine Highway Program as it builds 10 1,300-TEU capacity containerships (with 30-40 ships planned in the future) to provide coastal feeder and domestic containership services on the U.S. East and Gulf Coasts (Safe Seas 2010). The new ships will operate on low-sulfur fuel, including LNG and biodiesel fuel (waste fats), complying with IMO ECA regulations (Mack and Haines 2011) and illustrating how these vessels are smaller versions of the much larger China and Maersk containerships $(10,000$ - and 18,000-TEU). Fuel and GHG reduction measures (e.g., larger diameter propellers) apply to these vessels as well, albeit smaller in scale. This expanded service is timed to coincide with the Panama Canal expansion, which is expected to generate new demand for coastal ship services and increase cargo flow to the ports of PANYNJ, Norfolk, Miami, and Houston. ${ }^{8}$

\footnotetext{
${ }^{8}$ The business model of the feeder containership line for the East and Gulf Coasts is to facilitate the deployment of the "Super Ships" of the international containership lines being built and delivered now and in the future (AFL, undated). For example, AFL recently has begun weekly short sea feeder service that connects Boston, Massachusetts; Portland, Maine; and Halifax, Canada, for the Hapag Lloyd Line (Hapag-Lloyd 2011). In addition, a very important aspect of AFL's business model is that, as planned, it is up and running before the expansion of the Panama Canal is completed in 2014, and it generates new demand for coastal ship services (Safe Seas 2010). The \$5.25 billion canal expansion includes a deepening from the current 39.5-foot draft depth to a 50foot draft depth, thus increasing the maximum containership size that can traverse the canal from 4,400 TEUs to 12,600 TEUs. This will allow the seven new Chinese 10,000 TEU containerships (Hoifodt 2011) to go through the canal to the East Coast all the way from China. This is a major reason why the PANYNJ and Port of Miami have projects under way to increase draft depths and raise bridges to compete with Norfolk, which already has a 50-foot draft depth. The Port of Houston also is expected to have its cargo flows increased greatly, since it could become a major gateway port and intermodal transfer point for Asian container shipments to the Midwest (Thornton 2011).
} 
Domestic coastal shipping faces competitive pressure from trucking, which has driven many operations out of business. Private investment in fuel-saving technology is likely to be limited to those investments with very near-term payback. An improved competitive position of domestic coastal shipping would be necessary to expand the set of technologies financially attractive to private investors. Trends that could make domestic coastal shipping more competitive relative to trucking include increased highway truck traffic congestion and successful completion of the Panama Canal Expansion.

\subsubsection{Coastal Harbor Tugboats and Towboats}

Tug and towboat operators in U.S. seaport harbors and on U.S. inland waterways consume major amounts of bunker petroleum products annually. For example, a typical tugboat's tankage is between 10,000 and 30,000 gallons for local ship assist work, and up to 100,000 or more gallons if used for coastwise or offshore towing. The largest 150-foot tug under construction has a 250,000-gallon fuel tank capacity. Rising bunker fuel prices in recent years have spurred strong efforts by tug and towboat operators to conserve fuel while, for instance, pushing against a ship and consuming 100-200 gallons per hour, or towing an ocean barge and consuming 3,000-5,000 gallons of bunker fuel daily (Walsh 2007). However, we did not find estimates of total tugboat fuel use in our review.

Seaports have encouraged and facilitated the fuel use and consequent emission reduction efforts of companies building and operating these harbor and coastal vessels in recent years, in some cases with financial incentives and/or specialized facilities. In 2007, a maritime industry professional journal website (professionalmariner.com) provided a useful list of strategies that vessel operators can and have since taken, in some cases with the provision of facilities, funding, and/or accommodative policies from port authorities to reduce fuel use and emissions. The list includes operational as well as a few technical measures, but it does not include fuel reduction estimates for most measures or any overall fuel savings (Walsh 2007).

Since 2007, motivated by rising fuel prices, newly implemented or mandated (pending implementation dates) regulations of local, state, federal, or international authorities, harbor and coastal vessel operators, their equipment suppliers, and in some cases their ports of operation have executed or helped execute these strategies. Appendix A.4 discusses coastal harbor tugboat and towboat fuel reduction strategies in detail.

\subsubsection{Inland Shipping Fuel Reduction Measures}

Inland shipping consists primarily of the Mississippi River system and its major tributaries. Inland rivers account for $62 \%$ of U.S. domestic water freight tonnage. As with coastal shipping, we did not find any U.S. projections of fuel savings for inland shipping. However, European studies provide some projections and are cited here.

In the short term, through 2020, improved hull design retrofit (with a 5\% potential fuel savings estimated in Table 3.4) for existing ships can include such things as hull openings with scalloped rear ends and streamlined support brackets for propellers that minimize underwater resistance (Wartsila 2008). In addition, replacing existing conventional propellers with, for example, flattened ducted propellers are estimated to have a fuel savings potential of $20-30 \%$. Similarly, the same engine replacement strategy recommended in the harbor tug and towboat subsection also is estimated to have a possible $15-20 \%$ fuel savings, but with a payback period of greater than 10 years (Hazeldine et al. 2009).

In the long term, improved hull designs, which lengthen the front and back ends of the tug or towboat, were estimated to have 5-20\% savings. Regarding lightweight hulls, the use of composite materials was estimated to have the potential for up to a 5-15\% fuel savings, although the number of inland tugs and towboats that can use aluminum and other lightweight steel materials is limited (Wartsila 2008; Hazeldine 2009). Air lubrication with compressed air is expensive and requires energy to produce compressed air, and it is not yet a proven technology. Therefore, any potential savings, estimated at possibly $17 \%$, would be achieved many years out. Air lubrication does have the potential to reduce the viscous water resistance 
that is so damaging to the energy efficiency of inland vessels traveling at low speeds. Similarly, revolutionary new propeller designs are not a proven technology, but the experimental whale-tail wheel has an estimated fuel savings of up to $25 \%$ over conventional propeller designs.

The last long-term measure, larger barges (efficiency of scale) on large waterways, has been estimated to have a $4-5 \%$ energy efficiency improvement for a $10 \%$ increase in barge size (Perry 2008). The AEADutch study estimates a maximum $75 \%$ fuel savings, depending on the difference in scale, but it does not have a payback period estimate. The study also provides a more likely scenario of a doubling of wideriver barge sizes by 2050 , with a probable fuel savings of 50\% (Hazeldine et al. 2009). It also should be noted that increasing barge size must be done in step with inland waterway infrastructure development.

The AEA-Dutch study, in a manner similar to that for analysis of the coastal shipping technologies in the last section, also included where possible the estimated payback period of the inland tug and towboat technologies. Implementation and widespread use is unlikely unless payback times are attractive, even though these inland barge movers have better financial situations than coastal vessel operators. However, a few viable operational measures (e.g., reducing idling, reducing speed, and using shore-side power) set forth in the harbor barge and tug section are not included in the technology-focused Table 3.3 and Table 3.4. Of course, as with most unproven transportation technologies, and with the likelihood of a major increase in oil prices, much can happen to the payback periods of fuel savings measures in the nearly 40 years between 2009 and 2050 .

Table 3.4. Inland Shipping Technology Options for Fuel and $\mathrm{CO}_{2}$ Reduction

\begin{tabular}{|c|c|c|}
\hline Option & Reduction Potential per Ship & Payback Time \\
\hline \multirow[t]{2}{*}{ Larger units (economy of scale) } & $5 \%$ (for $10 \%$ increase) & \\
\hline & Up to $75 \%$, depending on scale & \\
\hline Computer-assisted trip planning and speed management & $5-10 \%$ & \\
\hline \multicolumn{3}{|l|}{ Hull } \\
\hline Improved design (existing ships) & $5 \%$ & Short \\
\hline Improved design (new ships) & $5-20 \%$ & Short \\
\hline Lightweight & $5-15 \%$ & $>10$ years \\
\hline Air lubrication & $10-17 \%$ & Unknown \\
\hline \multicolumn{3}{|l|}{ Propeller } \\
\hline Improved propeller & $20-30 \%$ & Short \\
\hline Whale tail/experimental propulsion systems & $25-50 \%$ & Unknown \\
\hline \multicolumn{3}{|l|}{ Engine } \\
\hline More efficient engines & $15-20 \%$ & $>10$ years \\
\hline Diesel electric propulsion & $10 \%$ & $>10$ years \\
\hline
\end{tabular}

(Sources: Skinner 2009; Hazeldine et al. 2009)

\subsubsection{Great Lakes Shipping Fuel Reduction Measures}

Often called "America's Fourth Seacoast," the Great Lakes-St. Lawrence Seaway System is vital for connecting America's heartland with foreign markets (especially Canada) and for connecting the states that surround it. With dry and liquid bulk freighters (or "Lakers"), tug-barges, and OGVs ("salties") that travel the Great Lakes, these shipping lanes account for approximately $11 \%$ of U.S. domestic waterborne trade (Barrami and Dyer 2009). There are 15 large international ports and 50 smaller, regional ports on 
the Great Lakes-St. Lawrence Seaway System (GLIN, undated). Many of the international, coastal, and inland maritime fuel savings measures presented and analyzed in the previous sections are equally applicable to this system's vessels. Current research funded by the Great Lakes Maritime Research Institute explores refinements of the ballast-free ship concept, optimal hydrodynamic propeller designs to facilitate these ballast-free ships (Parsons and Kotinis 2011), and air lubrication drag reduction on Great Lakes ships (Ceccio 2011). These are all measures that were set forth as available or potential areas of technological maritime fuel savings in prior sections.

\subsubsection{Marine Summary and Energy Use Projections}

\subsubsection{Shipping Energy Efficiency Potential}

Separate studies of OGVs used for transporting international marine freight to and from U.S. ports are not available. We use international studies to gauge the potential impact of international trade growth on GHG emissions. The international marine component accounts for nearly $80 \%$ of U.S. marine freight energy demand. It has a potential for a $25-80 \%$ improvement in its energy intensity by 2050 . For the domestic component, we estimate a $15 \%$ reduction in energy intensity by 2030 and a $30 \%$ reduction by 2050. Unfortunately, we did not find comprehensive cost data associated with the improvements cited by various studies.

\subsubsection{International Shipping Growth}

The EIA Annual Energy Outlook (AEO) (EIA 2011b) projects U.S. international maritime trade to grow $263 \%$ between 2010 and 2035 . We extended EIA's projections to 2050 by incrementally reducing the rate of average annual growth from $4.7 \%$ to $2.8 \%$ per year. This results in an estimated $490 \%$ growth in constant dollars of trade between 2010 and 2050. This growth does not account for an increase in the value per ton of shipment, and most likely would result in lower ton-miles than the $490 \%$ growth in dollar value indicates. In comparison, global international shipping ton-mile projections for 2050 are in the range of 150-380\% growth over 2008 (IMO 2009, IEA 2009).

Because of the expected nearly six-fold increase in U.S. international shipping trade by 2050 , even at the $80 \%$ high-end $\mathrm{CO}_{2}$ reduction potential estimate, total GHG emissions from international shipping are not expected to decrease from their 2010 level.

\subsubsection{Domestic Shipping Growth}

The EIA Annual Energy Outlook (AEO) (EIA 2011b) estimates a 20\% growth in domestic shipping tonmiles from 2010 to 2035 . We extend that to 2050 by using the average growth rate from the last five years: 2030 to 2035 . This leads to a 32\% growth in domestic ton-miles by 2050 compared with 2010 .

Domestic shipping is already a very efficient freight transportation mode, but implementing energy efficiency measures can further reduce energy intensity and GHG emission by $30 \%$ in 2050 , effectively canceling out the increase in activity and leaving GHG emissions at 2010 levels.

\subsubsection{Shipping Energy Projections to 2050}

In Figure 3.9, we have extended EIA's projections of marine activity to 2050. It turns out that EIA is estimating substantial reductions in marine energy intensity and projecting nearly constant energy consumption by the marine mode. 


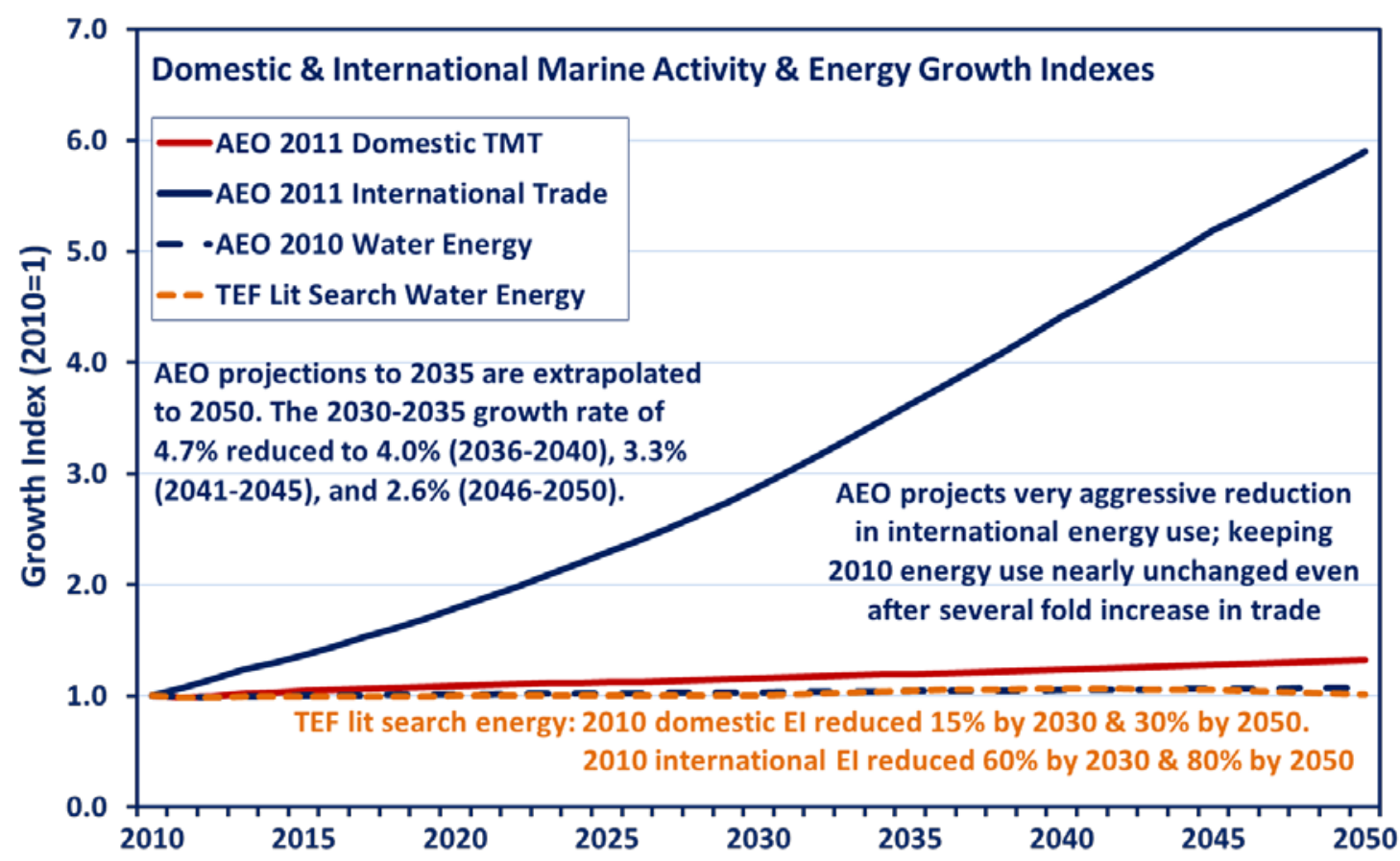

Figure 3.9. Marine energy growth projections

\subsection{Pipeline}

Pipelines are used to transport crude oil, natural gas, and refined products. Of these, only natural gas pipeline energy consumption is assigned to the transportation sector and reported separately (Davis et al. 2011; EIA 2011a). All other pipeline energy consumption is assigned to the industrial sector and is not reported separately. Natural gas pipelines consumed 0.86 quadrillion Btu of energy in 2009. Of this energy use, $72 \%$ was in the form of natural gas and $28 \%$ was electricity (Davis et al. 2011). The pipeline energy consumption represented $6.4 \%$ of combined non-LDV modes and off-road equipment energy consumption and $7.7 \%$ of non-LDV modes energy consumption. The mode carried 318 billion ton-miles of natural gas in 2009, a 9.1\% share of total ton-miles (BTS 2012).

According to EIA, more than 210 pipeline systems, consisting of more than 300,000 miles of pipeline, are used to transport natural gas (EIA 2007a). Nearly 2,400 compressor stations are situated at 50- to 100mile intervals pump natural gas along these pipelines. While most of the compressors operate on natural gas, some 17\% operate on electricity (Folga 2011). The electrically operated compressors are usually located in major urban areas where air quality requirements necessitate electricity use.

Petroleum pipelines transport crude petroleum and petroleum products. These pipelines use centrifugal pumps placed 20 to 100 miles apart (Allegro 2001). These pumps are electrically driven and, because they do not have to compress the product, they use less energy, roughly one-sixth the amount of energy per ton-mile compared with natural gas pipelines (CBO 1982). The energy consumed by petroleum pipelines is reported as industrial energy use, rather than pipeline energy use.

Natural gas pipeline energy intensity can be improved through more efficient compressors and improved operation. A pipeline compressor has a very long life of 40 or more years. A majority of main pipeline compressors are approaching their retirement age. The newer compressors will be more energy efficient and quieter (EIA 2007b). A natural gas compression station consists of scrubbers and filters, several compressors and their power units, interstage coolers, after coolers, emergency shutdown system, and computerized flow control and dispatch system. The number of compressor units per station can be as 
high as 23. A large trunk line compressor station may have banks of compressors arranged to boost pressure to 1,500 to 1,750 psig. Minor improvements, such as retrofitting compressor units and/or replacement of scrubbers, filters, and coolers as well as addition of a compressor unit in a compressor station can occur under a "blanket certificate" granted by the Federal Energy Regulatory Commission (FERC), as long as the estimated cost does not exceed \$10 million (EIA 2007b). Compressor stations are occasionally upgraded by adding more or larger compressors or a new compressor station may be added to upgrade a pipeline. Upgrades that cost \$10-28 million and changes in compressor unit arrangement are subject to prior approval and review by the FERC. If the total cost of an upgrade exceeds $\$ 28$ million, the pipeline company must file a formal certificate application with FERC and undergo a full review process (EIA 2007b).

Natural gas pipelines underwent substantial expansion from 1998-2007. During this period, 20,830 miles of pipeline were added and capacity was increased by 35,840 billion cubic feet per year (EIA 2007b). Pipeline energy intensity in terms of Btu per cubic feet declined at an annual rate of $0.57 \%$ during this 10 year period (Davis et al. 2011; EIA 2011a). With the recent increase in natural gas exploration, pipelines are likely to be used more intensively and maintain at least a 5\% decline in energy intensity per decade. We estimate a $10 \%$ improvement in pipeline energy intensity by 2030 and a $20 \%$ improvement by 2050 . Additional GHG reductions can also be achieved by switching to renewable or less carbon intensive fuels, however unless required by regulation, natural gas will continue to be used.

\subsection{Rail}

The rail mode used 0.54 quadrillion Btu of energy in 2009. This amounted to $4.1 \%$ of the combined nonLDV modes and off-road energy use and 4.9\% of non-LDV modes energy use without off-road. Most of this energy $(82.6 \%)$ is used for freight movement and the remainder for passenger transportation. A large portion $(85 \%)$ of passenger transport energy is used by transit and commuter rail systems in the urban areas. Diesel fuel supplied $87 \%$ of total rail energy and $13 \%$ was powered with electricity. All electricity use and about $5 \%$ of rail diesel use is for passenger transport. In 2009, freight railroads accounted for 1,582 billion ton-miles, a $42.4 \%$ share of total ton-miles. The freight rail energy intensity works out to 282 Btu per ton-mile (BTS 2012). The literature search presented here focuses on U.S. Class I freight railroads, which carry $90 \%$ of the rail freight tonnage and an even greater percentage of ton-miles.

\subsubsection{Rail Car Types, Commodities, and Demand}

Rail revenue ton-miles have grown by $66 \%$ since 1980 (AAR 2010). This includes the drop off in revenue due to the current recession, where 2009 experienced a 14\% decline in revenue ton-miles compared with the previous year.

Different commodities are transported by different types of trains and rail cars, which can have widely varying energy intensities. The more dense goods, like coal and grains, tend to have higher efficiencies.

Coal is the primary commodity transported by rail, consisting of $47 \%$ of the total weight of goods shipped by rail in 2009 (AAR 2010). Other products include chemicals, farm products, minerals, metals, paper, wood, and motor vehicles. Through 2006, coal had the highest growth rate of any commodity transported by rail, primarily because of the increased demand for low-sulfur coal from Montana and Wyoming.

Since then, coal shipments have experienced a 10\% decline by tonnage due to the current recession and the recent decrease in natural gas prices (AAR 2010).

Through 2006, intermodal rail traffic also had a strong growth rate. This trend is attributed to the increase in containerized goods coming through West Coast ports. Specially designed intermodal freight containers can be easily swapped between several transportation modes without unloading and reloading contents. The growth in container traffic led to the development of the double-stack well car, which has largely replaced the trailer on flat car (TOFC) intermodal trains. In 2009, TOFC accounted for only $17 \%$ of intermodal units, as opposed to $36 \%$ a decade earlier (AAR 2010). 
Most coal and intermodal freight travel on unit trains (ICF International 2009a). Unit trains typically have 100 or more identical cars, carrying one commodity and traveling from origin to destination without stopping at switching yards. Because of the lack of switching service, unit trains are very energy efficient.

Mixed trains move many different shipments at once. They stop at switching yards to be disassembled and reassembled with different cars. This work is done by switching engines, and it is energy intensive. The different car types on mixed trains can include tank cars used to carry liquids; hopper cars with a bottom-emptying hatch used for loose bulk cargo, such as coal, ore, and grains; gondola cars, which are similar to the hopper but without the hatch; auto-rack cars; and box cars.

The different rail car types have a large range of energy efficiencies, as shown in Figure 3.10. Here energy efficiency is measured in ton-miles per gallon of diesel fuel.

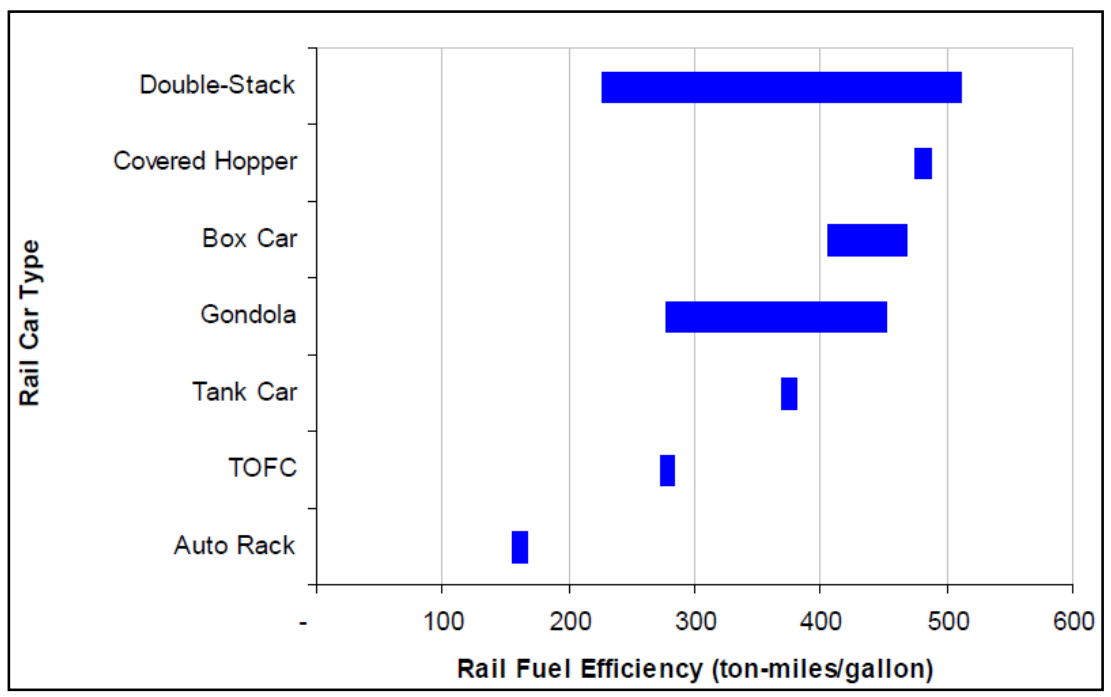

Figure 3.10. Range of rail car fuel efficiencies

(Source: ICF International 2009a)

Freight rail has achieved a 50\% improvement in energy intensity, measured in Btu per ton-mile, since 1980 (AAR 2010) (Figure 3.11). Primary factors contributing to this improvement include changes in the traffic mix, improved locomotive technology, and increased payload weight. Other energy efficiency improvements include distributed power, rail lubrication, low-friction bearings, and reduced idling time. 


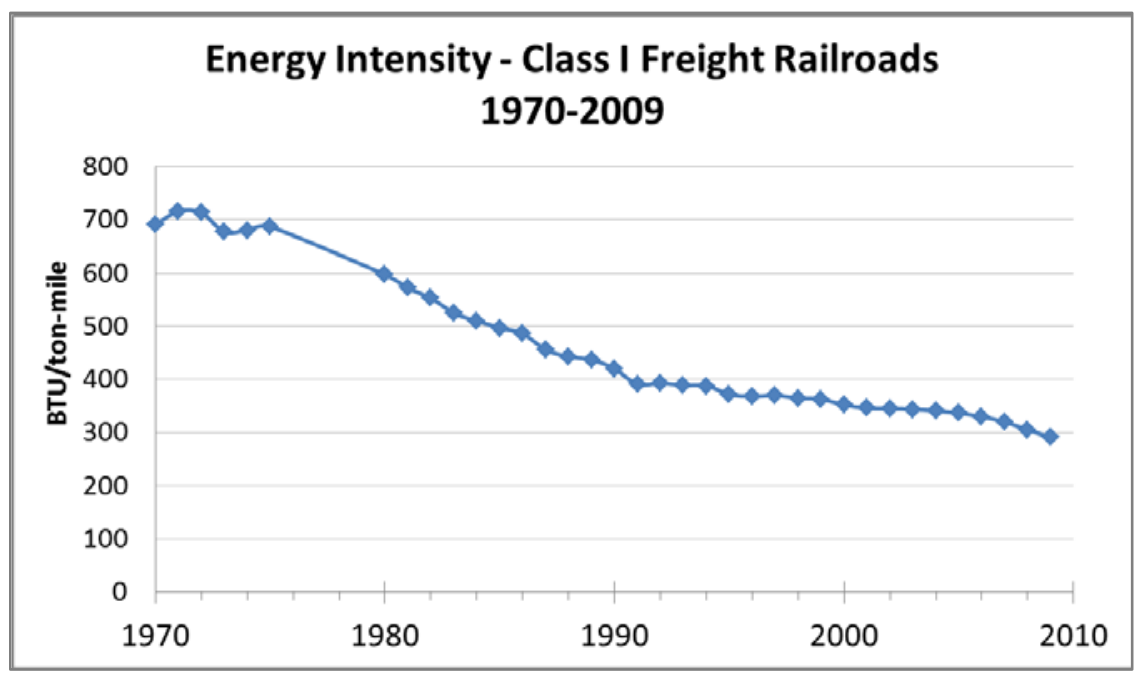

Figure 3.11. Rail energy intensity, 1970-2009

(Source: Davis et al. 2011, Table 9.8)

\subsubsection{Historical Energy Efficiency Improvements}

\subsubsection{Changes in Traffic Mix}

The increased use of unit trains for coal and other bulk commodities and long intermodal trains have improved rail energy efficiency. Before the 1990s, most rail shipments were made on mixed trains. However, unit trains, which are more energy efficient, now carry more than half of the ton-miles. Coal trains have the highest energy efficiency of all rail commodities because, in addition to traveling on unit trains, the trains tend to be longer and heavier, and they travel at low speed. In intermodal traffic, the shift from TOFC to double-stack containers increases energy efficiency with improved aerodynamics. This is especially important, since intermodal trains travel at high speeds of up to $80 \mathrm{mph}$.

\section{Locomotive Technology}

In diesel locomotives, the diesel engine is used to generate electricity, which then drives the traction motors to move the wheels. There is no mechanical connection between the locomotive engine and wheels. Therefore, the engine can be run for desired power levels and corresponding engine speed.

The main improvements in locomotives have been to the supervisory and power controls, including electronic fuel injection control, traction motor control, and engine cooling and auxiliary system controls. Improvements in engine technology have followed the broader diesel engine industry. This includes improvements in injector design and controls, combustion chamber, turbochargers, inlet air cooling, and engine system cooling. These improvements in electric power controls and engines have brought about higher energy efficiency, higher power, and lower emissions. The newer engines also have reduced the amount of fuel consumed when idling. An engine from the 1990s uses half the amount of fuel at idle as a 1970s engine (FRA 2011).

The AC traction motors are becoming more prevalent than DC motors. This is mostly due to their simpler design and improved reliability. AC motors have a 25\% improvement in adhesion and low-speed tractive effort (pulling force) over DC motors (ICF 2009a). This makes it possible to use fewer locomotives when the limiting factor is tractive effort instead of horsepower. Fewer locomotives save fuel, not only because of reduced weight, rolling resistance, and air drag, but also because of idling fuel use savings.

Since the 1970s, locomotive technology improvement has decreased the number of locomotives needed by up to half. This trend has improved the overall energy efficiency by about $20 \%$. 
Increased Payload Capacity

In the mid-1990s, the maximum gross weight of a rail car was increased from 263,000 lb. to 286,000 lb. (a 9\% increase). With the exception of pressurized tank cars, most new cars are manufactured to carry the maximum gross weight of 286,000 lb. The greatest benefit is for high-density products such as coal, grains, and chemicals. For these types of commodities, lightweight car construction permits more freight to travel in each carload before the weight limit is reached. Examples of lightweighting include aluminum coal cars and composites used on hopper cars. The increase in specialized cars, such as center-spine cars for lumber and steel coil cars, also has increased car capacity.

\subsubsection{Future Energy Efficiency Improvements}

\subsubsection{Locomotive Improvements}

Replacing older locomotives with newer, more efficient ones will be the most important rail energy efficiency improvement over the next 20 years. Because locomotives have a lifespan of nearly 40 -years, time required to replace the locomotive fleet is very long. Even with no new improvement in locomotive technology, the replacement of old locomotives is expected to increase fleet energy efficiency of the longhaul Class I fleet by $8-10 \%$. However, if manufacturers continue to improve the energy efficiency of new line-haul locomotives at the same rate as in the past, the fleet average energy efficiency will increase by $15-20 \%$ by 2030 (this is an energy intensity decrease of 13-17\%) (ICF 2009a).

Traditionally, when Class I locomotives were retired, they would be bought by the smaller, non-Class I lines. These older locomotives would then stay in service with minor rebuilds and upgrades, which did little to improve fuel economy. However, the combination of increasing fuel prices and EPA emissions standards for rebuilt locomotives has led to the purchase of more new, rather than used, locomotives in regional and shortline service, and for manufacturers to offer locomotive repowering programs. The resulting energy efficiency gains affect trains in mixed service, as opposed to unit or intermodal trains, because these dominate the regional and shortline markets. This leads to energy efficiency improvements for those services in competition with trucks. This will result in an overall $5 \%$ decrease in fuel consumption for carload shipments (ICF 2009a).

Truck engine technology leads the way for locomotive engine development. This is because trucks have shorter life spans, higher demand, and more stringent emissions requirements. However, the technology developed for truck engines cannot be applied directly and must be adapted to locomotive engines, which are larger, run at a lower speed, and must be durable enough to last 40 years.

Current locomotive engines achieve $40 \%$ thermal efficiency, but $50-55 \%$ efficiency is attainable with a focused research effort, which would lower fuel consumption by $20 \%$ (Stodolsky 2002; ICF 2009a). Future engine technologies that can lead to a $20 \%$ reduction in fuel consumption include HCCI, improvements in fuel injection technology, turbochargers, and intercooling systems (ICF 2009a). Advances in onboard control systems and sensors will allow for feedback and optimum operation.

While engine improvements up until now have improved energy efficiency and emissions simultaneously, future EPA emissions standards, Tiers 3 and 4, may offset some of the potential energy efficiency improvements. It is expected that in order to achieve Tier $4 \mathrm{NO}_{\mathrm{x}}$ and $\mathrm{PM}$ standards, aftertreatment technologies will be utilized and will negatively impact fuel economy, however more efficient technologies can reduce the magnitude of that effect (ICF 2009a; Stodolsky 2002).

Genset and hybrid locomotives have been available in the last decade for switching and local freight service. They meet EPA's Tier 2 standards and can decrease fuel consumption by as much as $50 \%$ (ICF 2009a). These hybrid locomotives have batteries for energy storage, but no regenerative braking. Genset locomotives use two or three diesel alternator sets, powering them up as needed. Although this technology has been available for some time, the growth of hybrid and genset locomotives depends heavily on government grants, since the industry view is that this technology does not meet the railroads' 
expected ROI (ICF 2009a). GE has a prototype hybrid line-haul locomotive with regenerative braking, which has an expected fuel savings of about $10 \%$.

\subsubsection{Aerodynamics}

Intermodal freight is time sensitive, so these trains tend be the fastest, with speeds up to $80 \mathrm{mph}$. Because of their high speeds, improvements in aerodynamics can have a significant impact on energy efficiency. Matching container size to car size to reduce gaps, filling open slots with empty containers, and placing smaller gaps as close to the front of the train as possible are all strategies to reduce air drag (Lai et al. 2005, 2007). Reconfiguring trains in this way can improve fuel savings by one gallon per mile per train (Lai et al. 2005). Applying these changes on a major route can reduce fuel consumption by 15 million gallons or nearly 2.1 trillion Btu per year (Lai et al. 2007).

Aerodynamics can also be improved by manufacturing new rail cars to minimize the gaps between cars and rounding the corners of the car body. Covering open top hoppers and gondolas also decreases air resistance.

\subsubsection{Electronically Controlled Pneumatic (ECP) Brakes}

Conventional brakes on freight trains have a slow response time and limited precision. In ECP brakeequipped trains, brake application and release is simultaneous on all cars, and the braking force on each car can be varied, depending on car weight, to achieve uniform deceleration. This gives the train operator greater control and results in shorter stopping distances.

All cars on a train must be equipped with ECP brakes to realize these advantages. Unit trains were the first to be outfitted with ECP brakes, and the technology is expected to become universal on these trains in 10 to 15 years (ICF 2009a). Benefits include reduced delays, improved safety, less brake wear, and increased rail line capacity. Energy efficiency would benefit from less stop-and-go operation and less stopping for maintenance inspections. One of the barriers to ECP brake use in mixed freight trains is that all cars must be equipped, which can cause considerable confusion at switching yards.

\subsubsection{Rail Lubrication and Steerable Trucks}

Trains already have a much lower rolling resistance than on-road vehicles. This is because steel wheels experience much less elastic deformation than tires. Rail and wheel lubrication can further reduce rolling resistance. Wayside rail lubrication on sections with sharp curves is already an ongoing practice. Onboard lubricators, which apply lubricant after the trailing axle of the locomotive passes, are a future possibility for reducing wear and rolling resistance.

Steerable or radial trucks allow the wheels to pivot around the curves, keeping them parallel to the direction of the track. This reduces rolling resistance on the curved track by as much as $70 \%$ (for a $12-$ degree curvature) (ICF 2009a). Steerable trucks also reduce rail and tie wear. The greatest improvements in fuel economy will be seen on rail cars that carry bulk commodities. Currently, less than $5 \%$ of rail cars are equipped with steerable trucks. The benefits of steerable trucks and rail lubrication overlap with each other, and implementation of one will reduce the potential benefits of the other.

\section{Operational Improvements}

Positive train control (PTC) is an integrated system that monitors and controls train movements to prevent collisions, derailments, and worker casualties. This includes a Global Positioning System (GPS) to track train movements, digital radio communications between the control center and trains, and the onboard computer, which can slow the train if the operator fails to do so. With PTC, trains can operate in closer proximity, thereby allowing increased rail capacity. Energy efficiency benefits can result from overall improved train movement efficiency, less stop-and-go, and higher average speeds.

Technology aimed at predicting equipment problems before they cause delays can improve energy efficiency by eliminating backups and unforeseen stops. One example of this type of technology is the hot-box detector, which measures temperatures as trains go past in order to find overheated wheel 
bearings. Another example is the trackside acoustic detector (TAD), which uses microphones to evaluate the sounds of axle bearings. Information from detectors is analyzed in order to determine if train maintenance is needed.

\section{Congestion and Rail Infrastructure Improvements}

Increasing congestion is a major concern for rail traffic. Congestion has been made worse with the increase in intermodal traffic which travels at higher speeds than bulk commodities. Idling and stop-andgo traffic, in addition to consuming more fuel, results in delayed and unpredictable shipping times, which is costly for the industry. In $200512 \%$ of primary rail corridors were at or near capacity and less than $1 \%$ were over capacity. Using the U.S. Freight Analysis Framework (FAF) freight demand forecast, the American Association of Railroads estimates that by 2035, if there are no capacity improvements, $25 \%$ of primary rail corridors will be at or near capacity, and $30 \%$ will be running above capacity (Cambridge Systematics 2007).

Currently, bottlenecks occur in southern California, the Southwest, and Baltimore, with the largest choke point in Chicago where it can take 30 hours or more to get through the city (Schwartz 2012, Tarm 2008). It is estimated that $46 \%$ of intermodal traffic and $25 \%$ of all freight rail traffic in the U.S. goes through Chicago (CREATE 2011). The Chicago Regional Environmental and Transportation Efficiency (CREATE) program, a public-private partnership started in 2003, was created to addresses this issue and improve rail infrastructure in the Chicago area. Projects include constructing overpasses at intersections with other traffic and separating commuter and freight rail tracks at certain junctions (CREATE 2011).

\subsubsection{Rail Alternative Fuel}

\subsubsection{Electrification}

Electrification of the freight railroad system has the potential to reduce onsite emissions and the dependence on petroleum. Reduction of GHG also is possible, but it depends on the primary energy sources. Efficiency benefits include the potential to capture energy through regenerative braking and the elimination of idling when trains are stopped. Electrification is a well-established technology. Europe, Japan, Russia, and China have some or most of their freight running on electric rail (Smith et al. 2008).The United States has no electric freight rail. While the high capital cost for infrastructure development is a serious barrier, high petroleum prices and higher traffic density on main lines make the economics of electrification more attractive than in the past.

\subsubsection{Biodiesel}

Recently, there has been an increased interest in using biodiesel blends to replace petroleum diesel in passenger and freight trains. The National Biodiesel Board (NBB), in collaboration with the Society of Automotive Engineers (SAE) and the Locomotive Maintenance Officers Association, is investigating the impacts of using biodiesel in U.S. railroads. Blends of up to 5\% diesel (B5) and lower, which meet ASTM standards, are already supported by major U.S. railroad engine manufacturers (Biodiesel 2011). More assessment is needed to determine the effects of using B20. Amtrak and Burlington Northern Santa $\mathrm{Fe}$ (BNSF) Railways participated in one-year trials of B20, starting in mid-2010. One issue with use of this alternative fuel is that railroads have less leeway than the trucking industry in terms of equipment. Locomotives are in service for a very long time, and if one is in disrepair due to biofuel issues, a "spare" is not necessarily available in the fleet (Voegele 2011).

\subsubsection{Natural Gas}

As with trucks, moving from diesel to natural-gas-powered locomotives has the possibility to reduce GHG emissions. Over the years, natural-gas-powered demonstration projects have been conducted for freight trains (Fritz 2000) and switcher locomotives (TIAX 2010). The low energy density of CNG compared with LNG makes it less suitable for freight rail use. A natural gas engine can be spark ignition or compression ignition by using diesel as an ignition source. The higher power requirements of freight locomotives make compression ignition more suitable. In 2011, it was announced that a demonstration 
natural gas locomotive is expected to be built as part of the Sustainable Development Technology Canada project (Millikin 2011b). The locomotive will have high-pressure direct-injection technology. Natural gas is $28 \%$ less carbon intensive than diesel. However, the energy required to cool LNG will add to the overall carbon emissions. In the 2008 TIAX study, it was found that $12 \%$ of natural gas was lost in the fueling process. Since methane is 20 times stronger than $\mathrm{CO}_{2}$ as a $\mathrm{GHG}$, this issue must be addressed in order for natural gas to be a viable alternative to diesel.

\subsubsection{Rail Summary and Energy Growth Forecast}

Locomotive energy efficiency improvement rates are expected to keep pace with historical trends. This means that Class I locomotive fleet energy intensity will decrease by 13\%-17\% by 2030 (ICF 2009a). Improved engine design can reduce fuel consumption in new locomotives by $20 \%$ (ICF 2009a; Stodolsky 2002). Other railroad improvements could further decrease energy intensity. These include reducing intermodal train aerodynamic resistance through improved loading patterns, application of ECP brakes, wheel and rail lubrication, steerable trucks, and improved operation through PTC. When extended to 2050 , these ongoing improvements can decrease the freight rail energy intensity by $35 \%$ from that in 2010. We did not find any cost analysis data in the literature for rail efficiency improvements.

Most energy savings benefits from improved energy efficiency will be overwhelmed by expected increases in rail activity, leaving the overall energy usage unchanged from 2010 levels. The AEO freight projections, extended out to 2050 by using the average 2030-2035 growth rate, are shown in Figure 3.12. Freight railroad activity, measured in ton-miles of travel (TMT), is expected to grow by $48 \%$ in 2050 compared with 2010 . If rail fleet energy intensity improves by $35 \%$ in 2050 , we can expect energy consumption to be just under 2010 levels by 2050 .

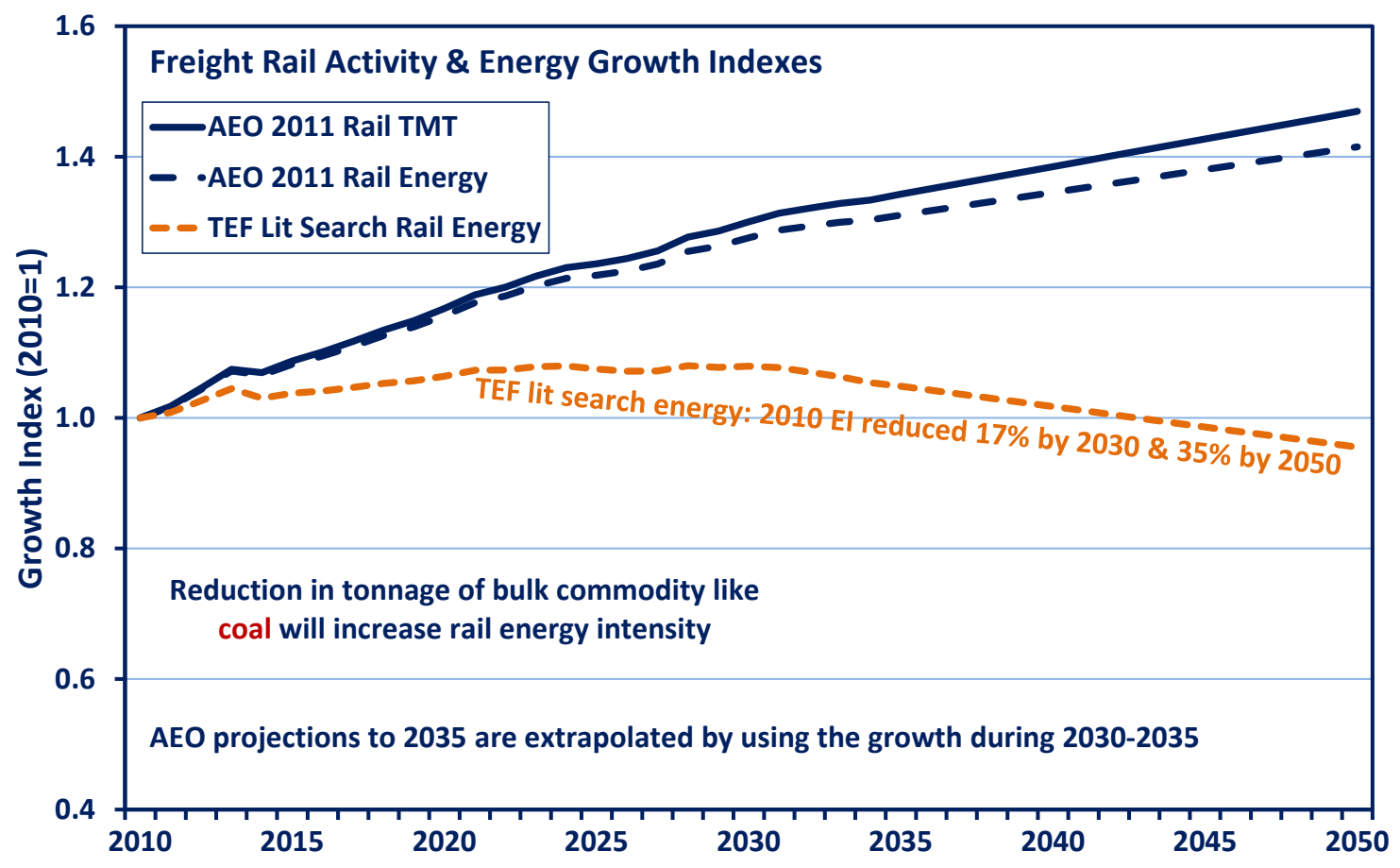

Figure 3.12. Railroad activity and energy consumption forecast 


\section{Off-Road Equipment}

Off-road equipment includes the nine subsectors listed in Table 4.1. They are estimated to use 2.36 quadrillion Btu of energy and account for $17.4 \%$ of the combined non-LDV modes and off-road equipment energy consumption (Davis et al. 2011). Among the fuels consumed are gasoline (22.1\%), diesel (68.6\%), LPG (8.5\%), and CNG (0.8\%). The off-road equipment also uses some electricity to charge battery-operated equipment (e.g., forklift trucks and some airport ground service equipment). However, no separate estimate of off-road electricity use is available. An off-road energy estimation model was sponsored by the Vehicle Technologies Program within the DOE Office of Energy Efficiency and Renewable Energy. The model is a spreadsheet tool developed using Microsoft Excel software. The model has been updated with historical equipment inventory, equipment use, and fuel-type use information from EPA's NONROAD2008 model. The current version of the model classifies equipment stock by four fuel types: (1) gasoline, (2) diesel, (3) CNG, and (4) LPG.

The model is capable of estimating changes in equipment stock, new equipment addition, and old equipment retirement. It can incorporate user-specified equipment use patterns and fuel-type use. The model also allows specification of biofuel blend levels for ethanol blended in gasoline and biodiesel blended in diesel. Table 4.1 lists the off-road subsectors and the equipment covered by this model.

Table 4.1. Off-Road Subsectors and Equipment Type

\begin{tabular}{|c|c|}
\hline Subsector & Equipment Types \\
\hline Air & Airport ground service equipment \\
\hline Rail & Rail maintenance equipment \\
\hline \multirow[t]{2}{*}{ Recreational watercraft } & Recreational boats \\
\hline & Personal watercraft \\
\hline \multirow[t]{2}{*}{ Lawn and garden } & Commercial lawn and garden equipment \\
\hline & Residential lawn and garden equipment \\
\hline \multirow[t]{5}{*}{ Personal and recreational } & Snowmobiles \\
\hline & Golf carts \\
\hline & All-terrain vehicles \\
\hline & Off-road motorcycles \\
\hline & Specialty vehicle carts \\
\hline \multirow[t]{2}{*}{ Agricultural } & Agricultural tractors \\
\hline & Other agricultural equipment \\
\hline \multirow[t]{2}{*}{ Construction } & Off-road trucks and tractors \\
\hline & Other construction equipment \\
\hline \multirow[t]{2}{*}{ Industrial } & Forklifts \\
\hline & Other industrial equipment \\
\hline \multirow[t]{3}{*}{ Mining, forestry, and oil field } & Underground and surface mining equipment \\
\hline & Forestry equipment \\
\hline & Oil field equipment \\
\hline
\end{tabular}

The model uses the future year non-road equipment stock and usage data developed by the EPA (EPA 2010a, 2010b). Because the EPA excludes equipment that does not produce direct criteria pollutant emissions, the EPA data are supplemented by information on off-road electrical equipment from other sources. 
Not much information is available about the future energy efficiency improvement potential for these types of equipment. Large agricultural equipment and most construction and surface mining equipment have diesel engines. These types of equipment will benefit from research and development in diesel engines. Because the off-road equipment is not always constrained by regulation of noise, vibration, and harshness, some energy efficient technologies that cannot be introduced in highway vehicles can be used in off-road equipment. Aside from this, because many types of off-road equipment use diesel engines, they will likely benefit from energy efficient technologies being introduced in trucks.

We estimate the potential for a $15 \%-18 \%$ energy intensity improvement by 2050 . Energy intensity here is defined as fuel use per hours of operation. The hours of off-road equipment use depends on population and economic growth. If their hours of operation, resulting from demand growth, increase at half the population growth rate, then by 2050 there will be a $20 \%$ increase in off-road activity. Combining the upper end of the potential energy intensity improvement with the activity increase expected in 2050, total fuel use is projected to stay close to the 2010 value. 


\section{Military}

Aside from the above-listed non-LDV modes and off-road equipment, military energy use is sometimes included as an additional non-LDV sector. Although we summarize some energy consumption data for military here, we do not provide any energy efficiency improvement estimates. This is because an analysis of the military energy use is not the primary purpose of this research. Also, because most of military's non-LDV equipment, including aircraft, naval vessels, tanks, and heavy vehicles, are tactical equipment, their future energy efficiency potential is not readily available.

The EIA reports the total 2009 energy consumption by the U.S. Department of Defense (DOD) as 880 trillion Btu (EIA 2011a) for all operations of which transportation is a major component. The total also includes energy consumed at foreign installations and in foreign operations. Petroleum products account for 680 trillion Btu of this consumption. The remaining 200 trillion Btu of energy is consumed as electricity (101 trillion Btu), natural gas (74 trillion Btu), coal (16 trillion Btu), and others (9 trillion Btu). Among the petroleum products consumed, jet fuel accounts for 501 trillion Btu, distillate fuel oil accounts for 149 trillion Btu, motor gasoline accounts for 19 trillion Btu, and LPG accounts for 11 trillion Btu. Because DOD operates almost 200,000 cars and light trucks (Davis et al. 2011), all of the motor gasoline and some of the LPG are likely to be used by LDVs. The remaining 650 trillion Btu of energy ( $74 \%$ of DOD's energy use) is likely to be consumed by non-LDV modes.

Historically, military energy consumption declined from 1.24 quadrillion Btu in 1990 to 0.79 quadrillion Btu in 2001. There was an upward trend to 2004, reaching a temporary high of 0.96 quadrillion Btu. Since then, the energy consumption has declined, as shown in Figure 5.1.

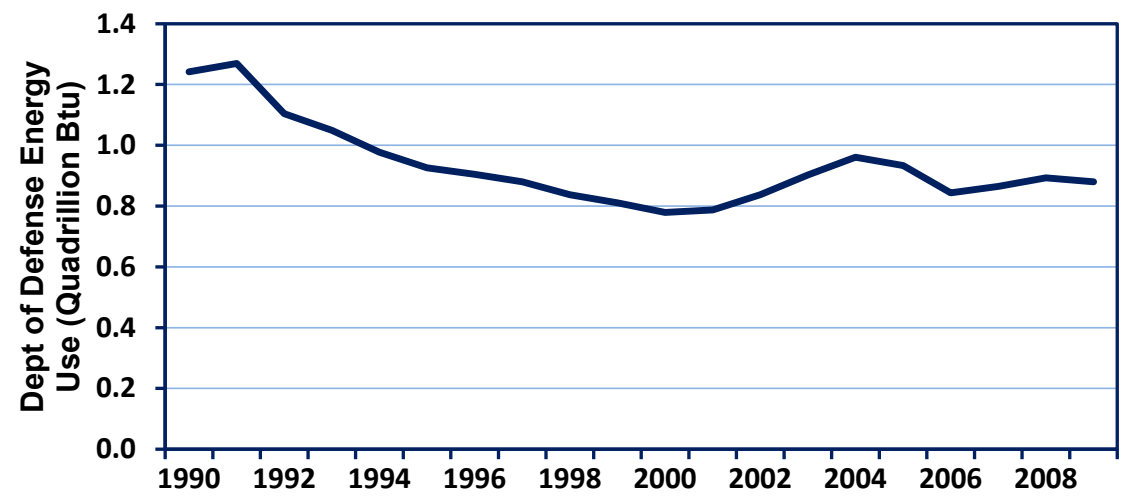

Figure 5.1. Trend in Department of Defense energy consumption

(Source: EIA 2011a)

A DOD Strategic Sustainability Performance Plan states that the department will reduce the use of petroleum products by non-tactical vehicle fleets by $2 \%$ annually, relative to FY 2005 , for a total $30 \%$ reduction by FY 2020 (DOD 2010). This goal is further specified as a 12\% reduction by 2011, increasing by $2 \%$ each subsequent year to meet the target $30 \%$ reduction by 2020 . Most non-LDV military transportation energy consumption is by tactical vehicles, which are exempt from this goal. Consequently, only some modest reduction in military non-LDV energy consumption is likely, mostly from the retirement of inefficient old vehicles. The extent of such a reduction is very difficult to assess with the absence of detailed data. As stated in the beginning of this section, 19 trillion Btu of gasoline and some LPG were consumed by the LDV fleet. A $30 \%$ reduction in this consumption would equal nearly 7 trillion Btu. 


\section{Conclusions}

The non-light-duty component of the U.S. transportation sector is diverse and uses many fuels. This research report covers six sub-sectors or modes: (1) trucks and buses, (2) aviation, (3) marine modes, (4) pipeline, (5) railroads, and (6) off-road equipment. These modes use seven different fuels: (1) diesel, (2) electricity, (3) gasoline, (4) jet fuel, (5) LPG, (6) natural gas, and (7) residual fuel oil. Of these fuels, diesel, gasoline, and jet fuel can be blended with biofuels to reduce full fuel cycle GHG emissions. Although several low GHG emitting renewable sources of electricity generation have been identified by other researchers, the amount of electricity used by the non-light duty component is very small and the substitution effect would be minimal.

Various technological and operational improvements that would lead to better energy intensity of each non-light duty transportation sub-sector were reviewed and summarized.

\section{Non-LDV Sector Can Improve Energy Efficiency Substantially}

We reviewed many publications relating to technological and operational improvements that could provide substantial reduction in energy intensities of non-LDV modes by 2050 . A range of potential energy intensity and GHG emission reductions were found. Depending on the mode, the high end of this range varied from $18 \%$ to $75 \%$. In other words, some non-LDV modes would use $82 \%$ of the current energy use rate per unit activity, while for others the energy use rate would be as low as $25 \%$ of the current.

Trucks, which currently account for $45 \%$ of non-LDV energy consumption, can improve their energy intensity through use of better components and powertrain improvements. These include low rollingresistance tires; better aerodynamics; turbo compounding and other waste heat recovery technologies; engine improvements; high-efficiency transmissions and drivelines; hybrid powertrains; increased use of lightweight materials; and plug-in electric powertrains for short range delivery operations. The maximum improvement potential for trucks is estimated as $50 \%$ by 2050 .

Aviation currently accounts for $16 \%$ of non-LDV energy consumption. Options for future energy efficiency improvements in this mode include better engine and propulsion designs, more aerodynamic body designs, and weight reduction. These include near-term improvements to turbofan engines and advanced open rotor engines, and improved airframe designs such as winglets and riblets, as well as longer-term options, such as the blended wing body and increased wingspan. The maximum improvement potential for aviation is estimated as $65 \%$ by 2050 .

Marine modes currently account for nearly $10 \%$ of non-LDV energy consumption. The marine freight mode has two major components: domestic and international. The international component accounts for nearly $80 \%$ of the marine modes energy consumption and is expanding its share with increased global trade.

Potential energy efficiency improvements to the international marine mode include improved engines, improved driveline, better vessel designs, use of accessories that tap wind and solar energy, and operational improvements. Engine and driveline options include higher efficiency engines, diesel-electric powertrains, better thermal management, and improved propellers. Vessel design options include larger vessels; better hull and super structure designs; improved bows and bow thrusters; and weight reduction measures. The operational improvements include reduced speed, voyage planning, fleet management, increased load factor, reduced port time, and cold ironing. The maximum improvement potential for international marine is estimated as $75 \%$ by 2050 . Options for decreasing inland marine energy intensity include improved engines; better barge, tug, and vessel designs; and operational improvements. Better engine designs and operational improvements would contribute the most. The maximum improvement potential for inland marine is estimated to be $30 \%$ by 2050 . 
Pipelines currently account for nearly $6 \%$ of non-LDV energy consumption. Although pipelines carry many liquids and gases, only natural gas pipeline energy consumption is assigned to the transportation sector. Energy consumption by other pipelines is assigned to the industrial sector. Natural gas pipelines can improve their energy intensity through more efficient compressors and operational improvements. These include improved powerplant, high-efficiency compressors, better compressor bank designs, and optimization of the batch sizes. The maximum improvement potential is estimated to be $20 \%$ by 2050 .

Rail mode currently accounts for $4 \%$ of non-LDV energy consumption. Although the mode has halved its energy intensity since 1980, more improvements are possible. The mode can improve its energy intensity through more efficient locomotives, rail cars, and operational procedures. These include more efficient diesel engines; better configuration of locomotive powertrains; improved rail car aerodynamics; more efficient truck (wheel assembly) design; ECP brakes; rail and wheel lubrication; reduced idling times; and positive train controls. Two locomotive options, Genset and hybrid, would also improve energy intensity. Genset locomotives improve energy intensity in selected operations. The hybrid option most likely would be limited to yard operations. The maximum improvement potential is estimated to be $35 \%$ by 2050 .

Off-road equipment currently accounts for $17 \%$ of non-light duty energy consumption. This equipment is used in agriculture, airport ground service, construction, forestry, industry, yard maintenance, mining, oilfield, rail maintenance, and off-road recreation. Most equipment is powered by internal combustion engines fueled by diesel and gasoline. The equipment sub-sector would benefit from ongoing research in internal combustion engines. The maximum improvement potential is estimated as $18 \%$ by 2050 .

\section{Non-LDV Activity Will Grow by 2050}

The EIA projected activity growth out to 2035 for each non-LDV mode in its Annual Energy Outlook (AEO) 2011. We extended activity growth projections for trucks, marine, pipeline, and rail by assuming that the average annual growth during the 2030-2035 period would continue through 2050. For aviation we used the projections by Federal Aviation Administration (FAA) and extended them through 2050. The off-road equipment activity growth depends on equipment stock and hours of operation. We assumed this activity to grow at half the population growth. The resulting activity growth over the 2010 value was: $87 \%$ for trucks, $217 \%$ for aviation, $32 \%$ for domestic marine, $450 \%$ for international marine, $16 \%$ for pipeline, $47 \%$ for rail, and $20 \%$ for off-road equipment.

\section{Non-LDV Activity Growth Could Diminish the Effect of Energy Efficiency Gains}

Both EIA and FAA project much lower energy efficiency improvements than the maximum improvements we estimate here. We extended EIA projected energy efficiency gains to 2050, assuming the average annual change during the 2030-2035 period to continue through 2050 for truck, marine, pipeline, and rail modes. Similarly we extended the FAA's energy efficiency projections through 2050. The resulting improvement in energy intensity was $12 \%$ for trucks, $36 \%$ for aviation, $7 \%$ for inland marine, $75 \%$ for international marine, $8 \%$ for pipeline, and $4 \%$ for rail. We estimated a $5 \%$ improvement in off-road equipment. The $75 \%$ improvement in international marine is in terms of energy use per dollar of trade. The gain includes the effects of reduction in tonnage due to increased value per ton and improved packaging.

Using the EIA and FAA estimates for energy efficiency improvements, combined with the projected activity growth, results in a 54\% increase in energy consumption by 2050 relative to 2010 .

When the maximum energy intensity improvement potential from our research is applied to the projected activity growth, a $1 \%$ reduction in non-light-duty energy consumption in 2050 , relative to 2010 , is projected. 
Examination of options for energy efficiency improvements outlined in existing literature reveals that the most promising non-LDV-sector energy efficiency improvements can only maintain, but not decrease, non- GHG emissions. Failure to implement these measures, however, could increase GHG emissions by as much as $50 \%$. 


\section{AppendiX. MARIne Technical Background}

The marine mode is less known compared to trucks and railroad. Aside from this, due to recent expansion of international trade, the mode is undergoing many changes. The domestic marine share of ton-miles shrank following petroleum price collapse after mid-1980s. The mode is undergoing some revival. This prompted us to include more description of this mode, which we include in this appendix.

\section{A.1 Maritime Highway Program and Coastal Shipping}

The U.S. DOT/MARAD Marine Highway Program is the result of the National Strategy for the Marine Highway Transportation System, which was developed by 18 federal agencies under the leadership of the Secretary of Transportation. The program establishes a strategy to make coastal shipping and inland and intracoastal waterways an extension of the U.S. landside transportation system to reduce landside congestion (Perry 2008). The National Strategy was the basis for the "Energy Independence and Security Act of 2007" (or 2007 Energy Act), which required MARAD to designate "short sea transportation routes" and focus "public and private efforts to use the waterways to relieve landside congestion along coastal corridors." The Act therefore encompasses container vessels (ships and container-on-barges) and roll-on/roll-off (RO/RO) vessels, but not vessels that transport commodities or other cargoes in bulk, such as grain, coal, or petroleum products. It also mandated that DOE/MARAD recommend legislative and administrative action, which could include funding recommendations (Black and Papavizas 2008). In addition, while not directly benefiting from the 2007 Act, the harbor and coastal tug and towboat vessels that assist the movements of these coastal vessels also indirectly benefit from the program's initiatives.

On August 11, 2010, DOE identified 18 marine corridors, 8 projects, and 6 initiatives for further development under “America's Marine Highway Program." Particularly important among the Marine Highway Corridors were East Coast M-95, West Coast M-5, and Gulf Coast M-10, which include ports along highway interstates I-95, I-5, and I-10, respectively (Comeaux 2010). In April 2011, DOE/MARAD submitted a Report to Congress that described the Marine Highway Program's activities to date, cited ship and barge energy intensities as lower than the truck and rail modes, and identified reduced reliance on foreign oil and decreased GHG emissions as major benefits of the fuel savings that will occur with the reduced landside congestion accomplished by the Program (MARAD 2011).

Many fuel reduction measures from the international maritime studies (IMO 2009; McCollum 2009; IEA 2009) also are applicable to coastal vessels because of the existing containership, RO/RO, and containeron-barge (COB) routes that are operated by American Feeder Lines (AFL) on the East Coast and planned for the Gulf Coast, plus those from U.S. coastlines to Hawaii, Anchorage, Kodiak, and Puerto Rico. In addition, another important reason for the applicability of these measures to achieve reductions in fuel use and $\mathrm{CO}_{2}$ emissions through 2050 is the large number of potential coastal shipping ports on United States coastlines at which the U.S. DOT/MARAD program and other policies could facilitate coastal ship, harbor vessel, and COB operations by 2050.

For example, the Tufts University study compiled the list of current and potential future U.S. coastal ports is based upon its researchers' interviews with MARAD, port officials, and industry experts. In addition, the Tufts study (Perry 2008) cites The 2005 Urban Mobility Report by the Texas Transportation Institute (Schrank and Lomax 2007), which found six Atlantic Coast cities with existing truck traffic congestion, as indicated by mean peak-hour travel times more than 30\% greater than off-peak times - namely: Boston, New York, Philadelphia, Baltimore, Washington, and Orlando.

This congestion provides potential markets for small containership operators such as AFL, which provides East Coast feeder services to Hapag Lloyd. Another key factor likely to substantially increase large containership traffic, smaller feeder line traffic, and truck traffic congestion on all three U.S. coasts is the completion of the deepening of the Panama Canal's maximum draft depth from 39.5 feet to 50 feet in 2014. This deeper draft will allow a tripling of the size of the containerships traversing the canal in 
terms of containers aboard (from 4,400 to 12,600). Currently, only the Port of Norfolk, Virginia, can handle these larger ships. Therefore, coastal feeder lines are likely to have near-term cargo increases servicing Norfolk from other East Coast ports, which must complete multi-year deep-draft port dredging or bridge clearance height raising projects so they can service the huge, deep-draft containerships (Thorton 2011; Vock 2012). See Section 3.2.4.2 for more details.

East Coast truck traffic congestion also indicates a potential for $\mathrm{RO} / \mathrm{RO}$ coastal shipping routes. Cargo types that are compatible with RO/RO ships were identified by Tufts with an analysis of FHWA's 2006 Freight Analysis Framework data for coastwise movements between states located only on the Atlantic Coast (FHWA 2006). Pointing out that newer RO/RO ships take trailers directly onboard the ships, without tractors in most cases Tufts notes that trailers may be parked at dock at the origin city and picked up at the destination city for landside transport.

\section{A.2 International Marine Fuel and GHG Reduction Strategies}

We identified three major reports that provided estimates of ranges of possible emissions reductions possible by 2050 (Pew 2009, IMO 2009, and IEA 2009), as discussed in the body of this report. There is consistency among these reports as to the measures that could have an effect. IEA 2009 adds many more measures, compared to the first two and estimates maximum energy efficiency gains for all of them and payback periods for most of them. Tables 8.2-8.6 of the 2009 IEA study (IEA 2009) provide a uniquely compact set of lists of the individual measures going into each component $\mathrm{CO}_{2}$ savings grouping of the Pew Center and 2009 IMO study. In addition, the tables add many more applicable measures; describe all measures; indicate their applicability by ship type; and indicate whether they are for newly built ships, can be retrofitted onto existing ships, or both, thus buttressing the defensibility of those aggregate savings estimates.

In addition to these three major studies, a 2000 IMO study (IMO 2000) provides more detailed supporting information than is available in the 2009 IMO study, which often chose to simply reference information in the 2000 study. Similarly, the 2009 study did not take the same systems analysis approach to looking at potential savings available from ship speed reduction, which is the single greatest fuel and $\mathrm{CO}_{2}$ emissions savings measure examined in the 2000 IMO study, Pew Center study, IEA study, and Det Norske Veritas study (Det Norske Veritas 2010). These latter studies combine ship speed reduction with the time-in-port savings available through cargo handling efficiency improvements, better anchoring and mooring, new maintenance techniques, and optimized ship routing (weather routing) to enable slower ship speeds at sea and the subsequent fuel savings. These latter studies also highlight the major potential fuel and $\mathrm{CO}_{2}$ savings available with cargo pooling and ship (especially super-tanker) pooling. Nevertheless, the 2009 IMO study's thorough analysis of the ship design and alternative fuel technologies developed from 2000 2009 , plus those potentially developed and useable from 2009-2050, provide an invaluable contribution to the making of defensible $\mathrm{CO}_{2}$ and other GHG emissions growth projections through 2050.

Below we present, in detail, the various operational and technological improvement potentials for maritime fuel use and GHG reduction. Ship speed reduction, steady power, cargo handling, anchoring and mooring, maintenance, ship routing, cargo pooling, trim, ballast, propeller pitch, optimal rudder, and energy management are all operational improvements. The last four subsections - ship concept, hull and superstructure, power and propulsion, and retrofits - are technological ship design improvements.

\section{A.2.1 Ship Speed Reduction}

The 2009 Pew Center on Global Climate Change report (McCollum et al. 2009), authored by University of California, Davis and ORNL researchers, identifies certain accepted individual fuel and $\mathrm{CO}_{2}$ emission savings measures. The report also describes how effectively combining at-sea speed reduction, ship efficiency, and optimized routing with time-saving portside efficiency improvement measures can overcome time lost at sea due to "slow steaming," as well as the need for additional trips to move the same amount of annual cargo (cited as a drawback by the 2009 IMO study). This systems integration 
thinking (i.e., treating each voyage as a set of interacting components to be optimized as a system) is comparable to that of the 2000 IMO study (IMO 2000), the 2009 IEA study (IEA 2009), and the Det Norske Veritas study (Det Norske Veritas 2010). Table 4 in the Pew study identifies in more detail the currently available but not fully implemented measures for combining optimized routing and reduced port time with speed reduction. Since some of these two groups of measures are discussed both in the Pew report and the 2000 and 2009 IMO reports, the latter two reports and their fuel and GHG emissions estimates are described in the text below. The components of the groups of measures are discussed in more detail to buttress their defensibility.

Although both IMO studies thoroughly discuss speed reduction, the 2000 IMO study, while dated, includes more complete descriptions of the fuel, $\mathrm{CO}_{2}$, and other $\mathrm{GHG}$ emissions reductions available through the reduction of ship speed. Certain efficient cargo handling, mooring, berthing, anchoring, and maintenance activities in port minimize off-hire time that can generate "time saved in port [and]... may be used to lower the speed at sea accordingly and thus [result in] saving of fuel [and emissions]" (IMO 2000). The 2000 IMO study has a more complete description of the benefits of weather routing and cargo pooling, which, through voyage time-savings and improved cargo load factor, also support speed reduction.

The 2000 IMO study also identified reduction of ship speed "as the single measure that results in the highest reduction of $\mathrm{CO}_{2}$ emissions" (IMO 2000), although admitting that finding ways of making up for lost time at sea is necessary for the full reduced fuel and emissions benefits to be achieved. (These additional measures are discussed immediately below). This study estimated a $23 \%$ savings with a fleetwide $10 \%$ speed reduction (IMO 2000), whereas the 2009 IMO study adjusted this savings amount to $19 \%$ for a $10 \%$ speed reduction. The 2009 IMO study also pointed out that slower speeds often lower fleet cargo capacity and result in more ships being needed (IMO 2009) because of lost time. The 2009 IEA study kept the $19 \%$ fuel reduction for a $10 \%$ speed reduction (IEA 2009). It also points out that permanently slower ship speeds should be accompanied with derating the engine to maintain and improve fuel economy performance. The 2009 IMO study agreed with this and noted that the greatest benefits available from speed reduction in ships occur on the fastest ships (e.g., containerships). The 2000 IMO study also points out that in low-demand shipping markets, with excess available capacity of tonnage compared with cargoes available, reduced speed (also called "slow steaming" and "just-in-time arrivals") can be favorable, as long as cargo owner demands are met. It concludes that it works best when the number of ships and transport capacity are high in relation to a given market. When cargo shipping demands are high relative to the number of ships available, a "minimum time" trip strategy tends to be used, with law-imposed speed limitations and high penalty taxes for violations (IMO 2000). The 2009 Pew Center, 2009 IEA, 2010 Det Norske Veritas, and 2000 IMO studies' more optimistic view of the economic viability of speed reduction is supported by lower speed policies adopted in 2008 by several major shipping lines, including Nippon, Yusen, Kaisha, Maersk, American President Lines (APL), and others (Corbett et al. 2009, slide 4). Furthermore, Morton Engelstoft, Chief Operating Officer of Maersk Line has said, "Slow steaming is here to stay" (Engelstoft 2010).

Researchers on and above in a NOAA research aircraft followed an arriving Maersk containership approaching the Port of Los Angeles on May 21, 2011. They "sniffed" and measured the emission results of the 96,500 DW Margarethe Maerske, while it both reduced its speed from 22 knots (maximum speed is 25 knots) down to 12 knots and gradually converted from $3.15 \%$ sulfur HFO (heavy fuel oil) to $0.07 \%$ sulfur MGO (marine gas oil). The speed reduction reduced the ship's $\mathrm{CO}_{2}$ emission and fuel consumption by $55 \%$, and the higher heat content of the reduced sulfur fuel added another $6 \% \mathrm{CO}_{2}$ savings, for a total of $58 \% \mathrm{CO}_{2}$ emissions saved. (See Appendix A.5 for additional details on the importance of $\mathrm{CO}_{2}$ and other emissions reductions in U.S. port areas.)

The above-mentioned $\mathrm{CO}_{2}$ savings were a valuable byproduct finding. The primary purpose of the research was to determine whether the operational changes produced an even greater reduction in sulfur oxides $\left(\mathrm{SO}_{\mathrm{x}}\right)(96 \%), \mathrm{SO}_{4}$ (sulfate $99 \%$ ), and particulate organic matter $(88 \%)$ emissions. All were 
reduced mostly by the fuel change, but all had a more than $54 \%$ savings contribution from the speed reduction. The authors of the article do warn that "these results are a snapshot for a single vessel" (Lack et al. 2011). However, this research provides a strong measure of validation to the findings of researchers from the University of Delaware and the Rochester Institute of Technology (Corbett et al. 2009), who determined that speed reductions of up to $10-50 \%$ can produce $\mathrm{CO}_{2}$ reductions of $20-70 \%$, as cited in the Pew Center study (McCollum et al. 2009). Of course, the Pew Center study has the caveat of the probable need for more annual ship voyages for such a major speed reduction on an entire voyage. More information about efforts in U.S. ports to promote ship speed reduction is available in Appendix A.5.

\section{A.2.2 Steady Power}

Minimizing variations in speed and power is another potential source of fuel and emissions savings, but in far smaller amounts than the reduced speed (with supporting in-port and weather-routing time reduction strategy). Steady power (minimum revolutions per minute variations) fuel savings are estimated at 0-2\% when compared with the normal practice of higher speed in the early part of voyages. And here also, effective use of weather routing by talented, motivated navigators is needed (IMO 2000, 2009).

\section{A.2.3 Cargo Handling}

Efficient cargo handling may be used (among other options) to reduce the time in port and enable ship speed reduction at sea and "thus save fuel and GHG emissions in the range of $1-5 \%$ of total fuel consumption compared with normal practice. For cargoes with high handling complexity, special planning tools may be implemented. In most cases however, systematic follow-up of handling actions in relation to handling time, may be used for determination of more efficient procedures and development of new technology" (IMO 2000). The 2009 IEA study recommends design features, such as ramps and alongside hold access, together with port-side improvements, such as gantry cranes (IEA 2009). Also, the IMO study cites a specific 1996-1998 project funded by the European Commission entitled, "Improved Port Ship Interface - IPSI," during which new technologies were developed for RO/RO ships. The project showed a potential for a $75 \%$ reduction of time in port compared with conventional technologies. As a result, both the IPSI project and the IMO study concluded that these in-port time savings can greatly influence the capacity utilization of the vessel "and may as such also influence total emissions." Similarly, the 2000 IMO study using a Freight Transit Model calculates that containerships have an ability to reduce transit speed by 1 knot on a 2,000 mile trip with a 6-hour (25\%) reduction in port turnaround time and achieve a $17 \%$ savings in fuel and $\mathrm{CO}_{2}$ emissions (IMO 2000).

\section{A.2.4 Anchoring and Mooring}

The 2000 IMO study also describes how efficient mooring, berthing, and anchoring not only can reduce port time and facilitate reduced ship speeds at sea, but such logistical efficiencies also can include requiring "use of low emission tugboats rather than having large ship engines running in port." Altogether, the portside logistical efficiencies are estimated to save $1-2 \%$ in GHG local emissions (IMO 2000).

\section{A.2.5 Maintenance}

Efficient maintenance is another key shoreside activity. It is important primarily to reduce off-hire time; to maximize at-sea performance of the ship hull, propeller, and machinery without the need for corrective maintenance delays later; and to enable reduced ship speeds at sea. No separate fuel or emissions savings are estimated.

\section{A.2.6 Optimized Ship Routing}

Weather routing was used in the mid-1970s during the U.S. Maritime Administration's Maritime Satellite Program. It continues to be used today and is discussed in both the 2000 and 2009 IMO studies, as well as the Pew Center study. The fullest description of weather routing is in the 2000 IMO study. Noting that "varying weather current and depth conditions during a voyage affect the ship speed," the study points out 
that weather routing techniques that use reliable weather and ocean current forecasts can optimize time, fuel, and emissions savings. It states that the "main parameters for choice of route are safety, avoidance of cargo damage, comfort of crew and passengers, limitations on time of arrival, maintenance work and economy" (IMO 2000). Further, it cites another study indicating that its benefits increase "in areas with unstable weather, such as northern and southern parts of the Atlantic and the Pacific oceans, southern part of Indian Ocean ...particularly in the winter," and in the spot [for hire vessels] market where ships "operate in various waters not well known or frequently visited by the crew" (Lepsoe 1997). In addition, the shipping market for use of weather routing is particularly strong on these oceans, since a Det Norske 2008 briefing estimates that $75 \%$ of world maritime traffic is on these three oceans (Endresen et al. 2008, slide 12). The costs of such systems are noted as $\$ 5,000-\$ 10,000$, and time and fuel savings are estimated at $2-4 \%$ (IMO 2000).

The 2009 IEA study also cites weather routing as a potential fuel and $\mathrm{CO}_{2}$ saver, and it estimates savings of up to $10 \%$. However, the Det Norske Veritas 2010 assessment of measures estimates a 0-5\% savings, noting that many ship owners already use weather routing and have lower potential savings, which could still be increased with an upgrade in service (Det Norske Veritas 2010).

\section{A.2.7 Cargo and Ship Pooling}

Another item in the 2000 IMO study is cargo pooling and ship pooling. Cargo pooling for ships is similar to the land-side shipment consolidation efficiency improvement identified in a 2009 International Conference on Industrial Engineering and Systems Management (IESM paper by Pan et al. (2009), which proposed merging supply chains of large retailers to overcome fragmentary freight consolidation efforts for truck and rail shipments. The Pew Center study also cites improving ship load factors as a way of achieving better ship utilization (McCollum et al. 2009). This is another way to eliminate the need to increase the number of voyages required annually when "slow steaming." In addition, it will become increasingly important as containerships keep increasing in size. Examples of portside companies engaged in dry cargo pooling include Bellingham Cold Storage Company, Fak Distribution, Quintiq, and the Mindanao Federation of Shippers Association, Inc. (Mindanao 2009). This also is similar to the ship pools of existing tankers, which reduce fuel use, emissions, and costs by reducing the length of the ballast (empty) legs of tanker triangulated (three-port) round trips by committing their very large crude carrier (VLCC) tankers to honest broker pooling organizations. The largest and oldest tanker pool is Tankers International Pool, which was created in 2000 (www.tankersinternational.com). Since the purpose of these tanker pools is to minimize the distance of the ballast (no oil cargo; only water for ship stability) leg of the three-port voyage, they will be discussed in more detail below.

The 2000 IMO study points out that pooling of cargo for increased vessel capacity utilization, with shippers actively cooperating to build a common coordinated logistics system, also can increase international maritime logistics efficiency and reduce GHG emissions. It then cites a documented Norwegian pooling of the products of land-based industries (i.e., fertilizer, ferro products, aluminum, and forest products) to build a coordinated export logistics system for maritime exports to Continental European and other foreign markets. By increasing the amount of cargo per ship, such cargo pooling can help support ship speed reductions without increasing the number of ship trips required for a given volume of cargo. Combined with the reduced time in port that also helps make up for slower ship speeds, this efficiency increase complements those measures in helping to reduce fuel use and GHG emissions (IMO 2000).

Load factors and ship utilization are particularly important for container ships because, while in 2007 they comprised only $4 \%$ of the world maritime fleet, they emitted $20 \%$ of the $\mathrm{CO}_{2}$ (Wang 2009; IMO 2009). By 2009, the container ship share of maritime fleet had increased to $9 \%$. A German modeling study addresses this problem. The study cites the minimization of trim and ballast water usage and effective hatch usage as the key goals that the model is designed to help containership operators achieve (Giemsch and Jellinghaus, undated). 
In addition, reducing the length of the ballast (empty) leg of a voyage with a triangulated (three-port) route through membership in a pool of ship (e.g., oil tanker) owners can reduce major amounts of fuel use and emissions. For example, one major oil tanker company (OSG) has its tankers travel a typical cargo route from Venezuela to Northwest Europe, and from there ballasting (empty) to the North Sea, where it loads cargo for delivery to the East Coast of the United States (OSG 2012). The company can do so because it is the member of the Tankers International Pool, which is an independent consortium of tanker fleet owners that began in 2000 (Tankers International 2011). In addition, all OSG Suezmax tankers are in the International pool and trade in the spot market in the Atlantic. It also is in the other two crude oil tanker pools, Panamax International and Aframax International (OSG 2012). These pooling activities accomplish three interrelated fuel savings goals: (1) maximizing ship load factors, (2) minimizing ballast water onboard (and the resultant underwater resistance to the ship's hull and the extra fuel used to transport this water), and (3) minimizing the ballast (water only, no oil) legs of the tanker trips through careful management of ships in the fleet.

\section{A.2.8 Optimal Trim}

Trim, the angle of the motor with respect to the hull, can be adjusted to allow more of the hull to ride on top of the water, instead of plowing through it. Optimal trim would provide another small $(0-1 \%)$ potential fuel savings measure (according to the 2000 IMO study when compared with normal practice) by optimizing adjustments of the autopilot and reducing use of the rudder, in order to give maximum speed at a given draft and engine power. However, the Det Norske Veritas 2010 study estimates that "ships that often trade in partial load conditions (e.g., containerships and RO/RO vessels) can improve trim with careful, computer-assisted loading and save up to $5 \%$ in fuel and $\mathrm{CO}_{2}$ emissions" (Det Norske Veritas 2010), which is an estimate matched by the 2009 IEA study (IEA 2009).

\section{A.2.9 Minimum Ballast}

Minimizing ballast and the extra bunker fuel required to transport it on a voyage also has a $0-1 \%$ fuel savings potential compared with normally high ballast. Implementation requires ensuring improved propulsion efficiency and ship safety procedures for handling inclement weather and other stresses upon the ship, according to the 2000 IMO study (IMO 2000). However, as described in the Ship Concept, Design, and Capability subsection, designed-in minimization of ballast requirements on giant containerships can save far greater amounts of fuel and reduce $\mathrm{CO}_{2}$ emissions. The IEA estimates up to a $7 \%$ fuel savings by designing-in reduced ballast, which reduces the area of the hull under water and decreases resistance.

\section{A.2.10 Propeller Pitch}

Propeller pitch is determined by the angle of the propeller blades about their long axis. On ships with controllable-pitch propellers, optimal propeller pitch may provide a savings potential of $0-2 \%$ compared with normal practice, according to the 2000 IMO study. However, it can save up to $5 \%$ with better matching of propeller rotational speeds with ship speeds, according to the 2009 IEA study (IEA 2009). To implement these savings, optimal pitch conditions dependent on ship draft and speed, as well as weather, must be determined. Pitch adjustments are made manually or by an automatic system.

\section{A.2.11 Optimal Rudder}

Steady and minimum rudder angle variations (requiring autopilot adjustments) to minimize fuel consumption and emissions may provide a savings potential of $0-3 \%$ fuel use compared with normal practice (IMO 2000; IEA 2009). Implementation requires optimal autopilot adjustments based on draft speed and weather conditions, as well as readjustments when these variables change. Computer-based autopilots with multivariable controller principles usually perform best and, where possible, should be installed to replace old autopilots. 


\section{A.2.12 Energy Management and Maintenance}

The 2009 IMO study also has a $1-10 \%$ estimate for all ships' fuel and $\mathrm{CO}_{2}$ emissions savings for management of propulsion energy and the several auxiliary energy types used by ships (IMO 2009). Noting that cooling water pumps, ventilation fans, navigation systems, onboard cargo handling gear, living facilities, and cargo heating and cooling all require non-propulsion energy, the study lists several measures that can conserve shipboard energy (IMO 2009):

- Avoidance of unnecessary consumption of energy (e.g., turning off lights when not needed);

- Avoidance of parallel operation of electrical generators;

- Optimization of steam plant (tankers);

- Optimization of the fuel clarifier/separator;

- Optimization of heating, ventilation, and air conditioning (HVAC) operation onboard;

- Cleaning of the economizer and other heat exchangers; and

- Detection and repair of leaking steam and compressed-air systems, etc.

In addition, it cites optimal maintenance of the main engines, as well as engine tuning to achieve the most effective (highest) operating pressures, as potentially contributing $1-2 \%$ fuel savings to the $1-10 \%$ savings range. Similarly, it recommends maintaining both a clean hull and propeller, as well as an appropriately chosen hull coating, which can contribute up to 5\% fuel savings (IMO 2009).

\section{A.2.13 Ship Concept, Speed, and Capability Design}

The industry trend of constructing and adding new, larger ships to existing fleets is projected to continue, thus increasing the efficiency of scale of these fleets. Besides size (economies of scale), speed flexibility (maximum and minimum efficient speeds), optimized beam (width at the widest point), draught (draft, depth), and length, alternative fuel use capabilities, cargo handling capabilities (designed-in cranes or $\mathrm{RO} / \mathrm{RO}$ facility for particular trades) all can help improve efficiency and fuel emissions savings. Further, ship design concepts and decisions are especially important given that the newest ships are expected to have lifetimes greater than 30 years. Also, because most existing ships last up to 32 years (IEA 2009), this component of the ship design contribution to reduced fuel use and emissions is expected to be gradual, with "only a limited portion of the fleet. ...changed by 2020." The energy efficiency improvement contribution of new ships and their technology is not likely to achieve its full savings, up to $50 \%$, until 2050 (IEA 2009).

A Det Norske Veritas article highlights the potential savings of new ship design, and it describes a fleet of seven Chinese containerships recently ordered and considered the world's most efficient. These ships have a 10,000 TEU capacity, an increase of $10 \%$ over the prior design, which reduces fuel consumption and emissions by 20\% (Barnard 2011). A key feature of the new design is that it allows ships to carry a minimum amount of ballast water while in operation, as described in the prior Minimum Ballast subsection. Such ships are also a part of a "move towards holistic, multi-objective and multi-constrained ship design [that] will require greater utilization of computational modeling tools and formal optimization methods...in the shipping industry...in order to facilitate this process, and the participation of some firstmover ship owners is critical" (Det Norske Veritas 2010). Similarly, the Maersk Line has announced a $\$ 1.9$ billion order for 10 container ships (and options for 20 more ships) with 18,000-TEU capacity, thereby setting an even larger scale standard for the industry. Maersk says the 1,312-foot- long triple-E (nicknamed for the three design principles of this ship class: economy of scale, energy efficient, and environmentally improved) vessel is only 9.8 feet longer and 13 feet wider than Maersk's next largest, a 15,500 TEU E-class ship. However, it can handle 2,500 more containers. In addition, the triple-E ships will be $50 \%$ more fuel efficient than the containership industry average and will consume $20 \%$ less fuel than E-class ships. Designed for a maximum speed of 25 knots, Maersk plans to operate the vessels at a "slow steaming" speed of 19 knots (Barnard 2011). The Chinese and Maersk ship orders should help start the needed trend. 


\section{A.2.14 Hull and Superstructure Design}

Certain hull improvements are critical to reducing the fuel use and emissions of the new generation of ships. Lightweight construction that uses materials that are lighter than steel, such as aluminum, glass fiber, or carbon-fiber, is identified in both the 2009 IMO study (IMO 2009) and the 2009 IEA study, and the IEA study estimates up to a 7\% fuel and emissions savings. In addition, the IEA study identifies optimum hull dimensions to reduce frictional resistance, with maximum $9 \%$ savings, and an underwater bulbous (balloon-like) bow to improve water flow around the bow, with maximum $20 \%$ savings (IEA 2009).

\section{A.2.15 Power and Propulsion Systems}

Engine derating, especially for permanent speed reduction strategies, can be either retrofitted onto existing vessels or designed into new ones. The IEA estimates a potential savings of 3\% (IEA 2009).

Both the 2009 IMO and IEA studies identify engine waste heat recovery by describing how capturing and using exhaust gas heat to replace direct-engine fuel requirements could result in potential savings of up to 10\% (IMO 2009; IEA 2009). Upgrading to diesel-electric drives to facilitate frequent changes in drive shaft load in maneuvering can reduce fuel use by up to $23 \%$ in $\mathrm{RO} / \mathrm{RO}$ ships and passenger ships (IEA 2009).

Similar propulsion system improvements are identified in both the 2009 IMO and IEA studies, but the IMO simply groups contra-rotating propellers, high-efficiency and asymmetric rudders, fins, vanes, vane wheels, and ducts. It estimates the potential energy and $\mathrm{CO}_{2}$ savings of this grouping at 5-10\% (IMO 2009). The IEA, on the other hand, estimates up to a $12 \%$ savings for coupled, counter-rotating propellers, with the rear-most propeller recovering energy from the forward propeller. In addition, the IEA cites several specific new propeller technologies and their potential savings, including twin-wing thruster propellers (up to 10\%), optimized propeller blade sections to reduce friction and cavitation (up to $2 \%$ ), propeller tip winglets to reduce trailing turbulence (up to $4 \%$ ), and propeller nozzles that circle the propeller to reduce trailing turbulence (up to 5\%). The IEA also cites an optimized propeller-hull interface to reduce hull-propulsion system interference (up to $4 \%$ savings), an optimized propeller-rudder with coordinated shapes (e.g., rudder bulb) to reduce drag (up to $4 \%$ savings), propeller efficiency monitoring (up to $4 \%$ savings), and efficient propeller speed modulation to reduce its rotational speeds to match ship speed instead of modulating propeller pitch (up to 5\% savings) (IEA 2009). The 2009 IMO study points out that not all propulsion devices are suitable for all ships. The above-mentioned lengthy IEA lists are termed "options" in their study, thus indicating that due-diligence in assessing risks should be exercised before investing in them (IMO 2009). As a result, the IMO study uses a 5-15\% estimate of total power and propulsion systems fuel savings to indicate a parametric savings range. The 2009 IEA study, while providing a far more complete list of options, caveats its estimates by providing the potential savings of each with an upper-bound percentage only, and it provides no lower-bound percentages.

\section{A.2.16 Retrofits}

Several ship design improvements can be retrofitted onto existing ships to increase fuel savings. These include modifications to operate with less ballast and the resultant resistance from a higher percent of ship underwater (up to $7 \%$ savings), low-profile hull openings (with scalloped rears) to reduce turbulence $(5 \%$ savings maximum), interceptor trim plates behind propellers to create lift ( $4 \%$ savings maximum), and aft (rear of vessel) waterline extension to reduce wake turbulence (7\% maximum savings) (IEA 2009).

\section{A.2.17 Alternative Fuels}

\section{Biofuels}

The 2009 IMO study notes that the $\mathrm{CO}_{2}$ reduction potential of each biofuel heavily depends upon how it is produced. It expresses strong concerns about potential biofueling causing engine deposits, filter plugging, wax formations, and biological growth in fuel tanks with present-day food crop biofuels (sugar, 
starch, vegetable oils, and animal fats). However, the study is more optimistic about the long-range potential of "second-generation" residual non-food biological substances, stating that biofuel use is "technically possible" with technological advancements. Non-food biological substances include nonfood (leaves and stems) parts of food crops; industry waste, including wood chips; and skins and pulp from food pressing, which call for technologically advanced conversion processes to facilitate use in biocrude oil fuel for maritime use. The study, however, does not estimate any significant $\mathrm{CO}_{2}$ savings from biofuel use in 2050, citing only some possible use if the petroleum based fuels become more costly than significantly expensive biofuels (IMO 2009).

On the other hand, the IEA study does state that "typical large, low-speed two-stroke engines on most ships can handle a wide range of fuels, including HFO, raw vegetable oils, waste oil and cotton, as long as they conform to specific acidity, viscosity, and performance characteristics." Stating that biodiesel derived from oil seed may also be used, it notes that biocrude has low quality, much like the HFO currently used on ships, and it calls for an assessment of its viability, costs, and potential contribution to fuel and GHG savings. Similar to the IMO study, the IEA study indicates that biofuel use probably will require some modifications to HFO-based fuel systems to "avoid precipitate formation and clogging of components" (IEA 2009).

Nevertheless, the IEA study, in the BLUE map scenario, which assumes that policy support enables lowGHG biofuels to achieve a 30\% maritime market share in 2050, increased use of second-generation biofuels would reduce the $\mathrm{CO}_{2}$ emissions attributable to the petroleum fuels they displaced by $80 \%$ to $90 \%$. This would result in an additional $25 \% \mathrm{CO}_{2}$ emissions savings (IEA 2009).

\section{Liquefied Natural Gas (LNG)}

The 2009 IMO study is very positive on the potential use of LNG primarily in future newly built ships for reducing not only $\mathrm{CO}_{2}$, but also $\mathrm{NO}_{\mathrm{x}}$ and $\mathrm{SO}_{\mathrm{x}}$. The study projects $5-15 \% \mathrm{CO}_{2}$ /ton-mile savings by 2050 with LNG used as a major low-carbon fuel, along with the marine diesel oil (MDO) discussed in the next subsection. It notes that LNG's limiting factors are storage aboard ship, since it has a volume 1.8 times larger than diesel oil; lack of widespread availability in bunkering (fuel supplying) ports, which will have to be developed from virtually no current availability; and current applicability for only four-stroke engines, which requires a new gas-engine concept, based on direct injection, to be developed for twostroke engine use. However, its lower cost than petroleum, and high applicability for short-sea operations on coastlines, especially in ports and the other Emission Control Areas (ECAs), which are expected to increase with increased maritime ton-miles, will provide strong incentives for the necessary technology development. Ports, which tend to be high pollution areas, will strongly benefit from the $\mathrm{CO}_{2}$ reductions, as well as from LNG's sulfur-free power, which eliminates $\mathrm{SO}_{\mathrm{x}}$; its $90 \%$ reduction in $\mathrm{NO}_{\mathrm{x}}$; and its virtual elimination of PM (IMO 2009). According to Det Norske Veritas, use of LNG could be significantly facilitated by the development of marine fuel cells with LNG storage aboard ship for use as a hybrid ship fuel system, if substantial development obstacles can be overcome.

\section{Marine Diesel Oil}

The revised Montreal Protocol (MARPOL) Annex VI maritime industry agreement (in force for new ships on July 1, 2010, and existing ships on January 1,2011) requires new, additional, or replacement ship engines on new or existing ships to be compliant with the maritime industry agreement's Tier II emission limits for $\mathrm{NO}_{\mathrm{x}}, \mathrm{SO}_{\mathrm{x}}, \mathrm{PM}$, and hydrocarbon vapors from tankers [volatile organic compounds (VOCs)]. The 2009 IMO study points out that the agreement significantly reduces $\mathrm{CO}_{2}$ emissions as well as $\mathrm{SO}_{\mathrm{x}}$, because it requires the use of lower sulfur (and lower $\mathrm{CO}_{2}$ ) MDO instead of the far dirtier HFO. Replacing HFO with MDO reduces $\mathrm{CO}_{2}$ emissions by 4-5\% (McCollum et al. 2009).

Wind Power (Onboard Use)

The 2009 IMO study identifies several ways to exploit wind power to help propel ships, including:

- Traditional sails

- Solid wing sails 
- Kites

- Flettner-type rotors

The 2009 IEA study explains that traditional sail configurations with advanced fabric or composite materials and/or kites attached to the bow can harness wind power irrespectively of its direction and reduce fossil fuel use considerably. The IEA also notes that sails require available deck space. It estimates up to a $20 \%$ energy efficiency gain. This option is available for new and retrofitted existing ships (IEA 2009).

In addition, the 2009 IMO (IMO 2009) described a Technical University of Berlin study (Clauss et al. 2007), which modeled three types of sails on three different routes, using historical weather data to assess potential fuel savings. The Berlin study found that sail energy savings are better at low speeds (5\% at 15 knots; $20 \%$ at 10 knots) due to lower propulsion demand. It also determined that sail energy has the most potential use in the North Atlantic and North Pacific (where most international trade routes are), rather than in the South Pacific. For example, a Det Norske Veritas 2008 briefing by Oyvind Endresen and Magnus Eide indicates that about $80 \%$ of world maritime traffic is in the Northern Hemisphere, distributed as 32\% in the Atlantic, $29 \%$ in the Pacific, $14 \%$ in the Indian, and 5\% in the Mediterranean Oceans (Endresen and Eide 2008, slide 12). As a result, the IMO, while admitting that experience as of 2009 with these sail technologies was limited, still concluded that "wind-assisted power appears to have long-term potential," confirming at least the possibility of the IEA's substantial (up to $20 \%$ ) fuel and $\mathrm{CO}_{2}$ savings estimate.

In addition, the 2009 IEA study also identifies the Flettner rotor as a viable wind power technology, describing it as a "spinning vertical rotor that converts prevailing wind into propulsive energy." It harnesses wind power regardless of direction and "can considerably reduce fossil fuel use," with an estimated savings of up to $30 \%$ (IEA 2009).

Solar Power (Onboard Use)

The 2009 IMO and 2009 IEA studies agree that solar power has some on-deck applications for reducing fuel consumption to generate heat and electricity. The IMO specifically cites the decks of large oil tankers as good venues for solar panels, but notes that such applications can provide only a fraction of the ship's auxiliary power needs, and they are not available at night, thus rendering them as only a complementary source of energy that requires backup power. The IMO regards solar power as costly, but the IEA rates it as having a medium length payback period. Both studies indicate a potential for up to $3-4 \%$ fuel savings.

\section{A.3 Economic Constraints Facing Coastal Shipping Technology Investments}

Despite the factors that favor potential growth in coastal shipping, it is important that investments made in fuel and $\mathrm{CO}_{2}$ reduction technologies be made wisely. Although the ship technology measures in shown in Table 3.3 (Skinner 2009; Hazeldine et al. 2009) are generically similar to those identified in the 2009 IMO study, coastal vessels have a different operating environment that involves shorter voyages, less time on the high seas, higher levels of financial risks, greater likelihood of bankruptcies, and smaller vessels. The authors of one of the studies constructed for a European Commission briefing relied heavily on the 2009 IMO study, which was first on its reference list and cited in its assessment of each technology area. However, this European study, which was also funded by the European Commission's Directorate General Environment, also uses economic data from a European shipbuilder (Wartsila 2008) to estimate payback periods for fuel and GHG savings technology measures wherever possible. Furthermore, the authors do note that:

"For the majority of measures there is still uncertainty as to the costs and reduction potentials. Costs of the measures vary with the ship types and whether they are retrofitted or applied to a new ship. Cost data is often not available at all or only available for a certain ship type. The abatement potential varies with the ship types but also with the 
routes these take, as well as with the respective weather conditions. Thus long-term field tests on a large scale are needed to take account of these 'real world' conditions."

(Hazeldine et al. 2009).

These are key reasons why neither this study (MARAD 2011) nor the European Commission briefing (Skinner 2009), which relies heavily upon it, make any aggregate coastal ship, COB, or harbor craft fuel savings estimates for 2030 or 2050 . In addition, the caveat regarding routes (above) is particularly important, because of the demand problems that have caused many U.S. coastal shipping operations to go out of business. The other route factor that affects coastline-traversing ships is competition, which is not a factor for international ships. There are no trucks, with their faster delivery times, competing with international ships the way they do along the U.S. East, West, and Gulf Coasts. This is a major reason why purely East, West, and Gulf Coast shipping (when inland barges and routes involving Alaska or Hawaii are excluded) is only $2 \%$ of domestic freight traffic (Perry 2008). Therefore, until the FHWA projections of increasingly severe congestion materialize for I-95, I-5, and I-10 highway truck traffic, it is likely that (without U.S. DOT Marine Highway Programs, state, or seaport funding) coastal vessels are likely to focus on only the very short, short, and short/medium payback technology investment items that are the most economically viable and help, rather than hinder, their profitability and survivability. This could dramatically change, however, if successful completion of the Panama Canal expansion (Thornton 2011 ) is combined with a significant increase in I-95, I-10, and I-5 highway truck traffic congestion by 2015-2020.

\section{A.4 Coastal Harbor Tugboats and Towboats Fuel Reduction Strategies}

Operational measures for reducing tugboat and towboat fuel use include:

Shutting down [not idling] main engines as often as possible between jobs: The PANYNJ has committed, as part of the New York City Phase II Maritime Support Study (2009-2011), to identifying harbor area locations where tugs can tie up and shut down engines between work assignments in the same general vicinity (Port Authority NY-NJ 2009). An EPA study ranks this strategy as being easily implemented and having the highest emission [and fuel] reduction potential, although it gives no percentage estimate (ICF International 2009b). The PANYNJ has committed, as part of the New York City Economic Development Corporation's Phase II Maritime Support Study, to identify places where tugs can tie up and shut down engines between assignments in the same area (NJ-DEP 2011).

Using shore power whenever possible between jobs: All California ports are providing shoresidegenerated electricity to tugboats and towboats. For example, the Ports of Los Angeles and Long Beach require all tugs to use shore power while at their home fleeting location (Port of Long Beach and Port of Los Angeles 2011), and of the 130 tugs, tow boats, articulated tug-barges and integrated tug-barges servicing California ports in 2008, all but 11 shut down at dock and plug in to shore electricity at dock; only "live aboard" tugs do not shut down and plug in (CARB 2008, slide 48). The Port of Portland, Oregon, also provides shoreside power to some tugs (IISS 2010), but other Gulf and East Coast ports, such as PHA and PANYNJ, only list this measure among possible future actions (Port of Houston 2011; Port Authority NY-NJ 2009). However, one tugboat operator, Moran Towing Corporation, has built shore power plug-in ports at its facility in the Port of Baltimore (Port of Baltimore 2011).

Running at reduced speed in harbor situations: The Wilmington Tug Company in Delaware, which replaced all of its tug engines but one to save fuel, noted that with the new engine, reducing vessel speed from full ahead reduced fuel consumption by more than $50 \%$, but it did not give the speed reduction amount (Walsh 2007). The above-mentioned EPA study identified a voluntary tug and towboat vessel speed reduction (VSR) program at the Ports of Los Angeles and Long Beach (ICF international 2009b), and the PANYNJ has updated its clean port plan's commitment to institute voluntary speed reduction for tugs and tow boats by identifying an Automatic Identification System (AIS) to monitor incoming vessel 
speeds (NJ-DEP 2011). In addition, the EPA study ranked tug and towboat speed reduction as tied at third among operational strategies for reducing harbor vessel emissions (and fuel use) (ICF International 2009b).

Using fuel flow monitoring equipment for wheelhouse and shoreside management: Management control of tug and towboat speeds for energy efficiency reasons is a particular area of investigation for professionalmariner.com. It describes how tug companies are using elaborate fuel management systems available from industry suppliers, among others. It notes that the systems provide real-time fuel consumption for each ship assist or towing job via satellite, not only to vessel captains who control the throttle, but also to management thousands of miles away at data centers (Walsh 2007). In addition, PANYNJ is committed to using Automatic Identification System (AIS) to monitor incoming vessel and tug speeds and facilitate just-in-time arrivals, as mentioned above (Port Authority NY-NJ 2009).

Educating captains and crews on savings through throttle optimization: Throttle control (fuel management) systems analyze the forces working against a tug and help captains find the point of throttle optimization "to achieve the best speed mode or best economy" (Walsh 2007). For example, the Sause Brothers Ocean Towing Company in Coos Bay, Oregon, states that they are "working to evaluate various fuel management systems, but we know that the key will be educating our captains and mates to get involved with these systems as they are introduced." The firm has a goal of achieving maximum energy efficiency while towing loaded oil barges at a speed of 9 knots and burning roughly 3,400 gallons per day in open ocean conditions, but it did not give a percentage savings estimate (Walsh 2007).

Technical tugboat and towboat improvements include:

Adopting streamlined hull design and towing gear, and outfitting a tug with more energy efficiency nozzles, propellers, and rudders: The professional mariner journal also gives examples of operators such as Penn Maritime, which added propeller nozzles (housings) and a triple-rudder system to two of its large tugs. This enhancement resulted in a 2-knot increase in towing speed and a substantial fuel consumption decrease. No percentage fuel savings is given, although nozzle and high-performance propeller manufacturers claim a 10 to $20 \%$ fuel savings (Walsh 2007).

Reducing underwater friction with hull coatings: This improvement is cited in the EPA study as having moderate levels of implementation, is readily available, and has manufacturer claims of single-digit fuel and $\mathrm{CO}_{2}$ savings potential. The study ranks these coatings sixth in its technology strategies list (ICF International 2009b). The PANYNJ, for example, has using anti-fouling hull coating on marine vessels on its list of future actions (Port Authority NY-NJ 2009). In addition, a major European builder of ships and offshore support vessels (OSVs) indicates that "modern hull coatings have smoother and harder surface finish that results in reduced friction. As typically $50-80 \%$ of resistance is friction, better coatings can result in lower total resistance." It also notes that modern coatings also result in less fouling, which combines with the hard surface to increase fuel savings. Though it estimates about $9 \%$ fuel savings for containerships and tankers, its savings range from OSVs is $0-6 \%$ (Wartsila 2008).

Replacing older engines with new, more efficient engines: Sause Brothers towing service company, operating at the Ports of Los Angeles and Long Beach, and OXY/THUMS, a primary client operating four oil field islands in the Long Beach Harbor, partnered and replaced 17 engines on five Sause Brothers tugboats to achieve maximum energy efficiency and meet emission requirements (Sanfield and Wong 2011; Walsh 2007). In addition, the Crowley Maritime Corporation, with $\$ 4$ million of Port of Los Angeles funding support, has upgraded the main engine and generators to both meet the emission standards of the port, the EPA, and the IMO, and become more fuel efficient (AAPN 2010). Similarly, the Port of Houston Authority (PHA) has provided advocacy, support, and documentation for due credit to both companies that use Texas Low Emission Diesel fuel and the towboat operator that retrofitted its vessels with new fuel efficient engines that meet the pending IMO and EPA emission requirements (Port of Houston 2011). In addition, PANYNJ has already completed 15 engine replacements on PANYNJ 
harbor tugboats. It is committed to expanding its marine engine replacement or retrofit program (MERP) for tugs and towboats (Port Authority NY-NJ 2009).

Adopting hybrid propulsion technology for tug fleets: This technology now exists, both for newly built tugboats and as a retrofit option for them. The Ports of Los Angeles and Long Beach financed Foss Maritime Company's building of the first hybrid tugboat, Carolyn Dorothy (with \$1.35 million), and it now moves tankers and containerships to the port, to the pier, and from the port. When not using lowsulfur MGO/MDO fuel to power its main diesel engine, it uses energy from its 126 batteries and smaller diesel engines for the $50 \%$ of the time it is either idling or moving around the harbor. The vessel can work with diesel, diesel-electricity, diesel plus electricity, or just electric power. Also noteworthy about hybrid tugs is that their batteries can be charged with cheaper and lower emissions shoreside electricity. It also can use new energy forms like biodiesel and ethanol (VEM Motors 2009). In partnership with the Ports of Los Angeles and Long Beach, and with the aid of a \$1 million grant from the California Air Resources Board (CARB), the same shipyard also is currently refitting an existing tugboat with hybrid technology that includes generators, batteries, and control systems (Greenpacks.org 2010). The tugboat builderoperator estimates a $27 \%$ diesel fuel and $\mathrm{CO}_{2}$ reduction for hybrid tugs (Port of Long Beach and Port of Los Angles 2011). In addition, PHA lists demonstrating the viability of a harbor hybrid tugboat in its Future Actions list (Port of Houston 2011), and PANYNJ lists implementing a hybrid tugboat pilot program among its future actions (Port Authority NY-NJ 2009). However, the EPA study lists hybrid tugs as having moderate potential emission and fuel savings for shifting and fleeting services in harbors, but it states that they are not applicable for line-haul tugs. It ranks hybrid tugs as eleventh among its favored technological strategies (ICF International 2009b).

Using alternative fuels, such as biofuel: The EPA study cites several instances of test uses of alternative fuels, including the emulsified fuel being used at Ports of Philadelphia (ICF International 2009b; EC/R 2005) and Boston (ICF International 2009b; NESCAUM 2006), and natural-gas-powered tugs also being tested at the Port of Philadelphia (ICF International 2009b; EC/R 2005). Similarly, ethanol also has been tested at the Port of Boston (ICF International 2009b; NESCAUM 2006). However, the EPA report also cites the same professional mariner article that has been cited repeatedly here, and it quotes a company official from Pacific Tugboat Services in San Diego, California, which has experimented with biofuels and would like to be a distributor for them. The executive notes, as quoted in both the marine journal article and the EPA study: "It has to be close in price or actually less for it to make sense for us" (Walsh 2007; ICF International 2009b). Therefore, despite having several alternative fuels ranked highly in the EPA tug/towboat study emission and fuel/reduction study, this strategy has not been gaining traction. Among its ranked operational strategies, using ethanol is ranked first, biodiesel is ranked third, natural gas and propane are ranked ninth, and emulsified diesel is ranked twelfth (ICF International 2009b). However, PHA and PANYNJ do not even have the use of these fuels listed as Future Actions (Port of Houston 2011; Port Authority NY-NJ 2009). And even the Ports of Los Angeles and Long Beach had the only alternative fuel project partnerships project using LNG-fueled tugboat engines, designed by the shipyard partner, put on hold by the corporation due to "the decrease in work load for tugs at the ports." (Port of Los Angeles and Port of Long Beach 2009). So it appears that although technically feasible, in the near-to- intermediate term, implementation of tug and towboat use of alternative fuel is likely to be a longer term strategy for reducing petroleum fuel use and GHG (and other) emissions by 2050.

\section{A.5 Marine Port Area Emission Reduction Policies and Programs}

Since an estimated $70 \%$ to $80 \%$ of international maritime pollutants are released within 248 miles of shore, it is important that every effort be made to reduce such coastal area pollutants from international ships (ICCT, undated). For this reason, in response to an EPA request, on March 26, 2010, the International Maritime Organization (IMO) officially designated waters off North American Coasts as an Emission Control Area (ECA) under the International Convention for the Prevention of Pollution from Ships (MARPOL), with stringent emissions standards for fuel sulfur and nitrogen oxides $\left(\mathrm{NO}_{\mathrm{x}}\right)$. This is 
similar to the $90 \%$ reduction in sulfur emissions that the European Union (EU) has required in EU ports, effective January 2010 (deKat 2011). However, even before those standards were set, California dealt with poor air quality and negative health effects in "asthma-ridden neighborhoods" around its seaports by adopting in 2008 and implementing on July 1, 2009, regulations that limit the amount of sulfur in auxiliary and main diesel engines (Barringer 2011). The California and IMO MARPOL regulations will do much to reduce $\mathrm{NO}_{\mathrm{X}}$, sulfur oxides $(\mathrm{SO})$, and carbon dioxide $\left(\mathrm{CO}_{2}\right)$ emissions by forbidding the use of heavy fuel oil (HFO, with its often more than 3\% or $4 \%$ sulfur content) and reducing marine diesel oil (MDO) and marine gas oil (MGO) sulfur content. The EPA has estimated the amount of HFO, MDO, and MGO bunker fuel expected to be demanded by international trade and domestic fleet vessels in 2020. About $66 \%$ of the bunker consumption demand burned in the U.S. Emission Control Area (ECA) will be for international trade, while $34 \%$ will be used for the domestic fleet. Further, it estimates that only $22 \%$ (3.6 million metric tonnes) of the bunkers consumed will be the low-sulfur MDO/MGO used in coastal ECAs, whereas $78 \%$ (12.5 million metric tonnes) of the bunkers demanded will be HFO consumed in the U.S. ECA (RTI 2009).

In addition to the above estimates of fuel demand consumed within the U.S. ECA to support its involvement in international trade, the EPA (through its contractor, Global Insights, Inc.) has made estimates of the "fuel use by the international cargo fleet engaged in delivering trade goods to and exporting trade goods from the United States" for the period 2001-2020. The estimates comprise part of total worldwide bunker fuel use and do not include fuel used for U.S. domestic shipping. The estimates show this fuel use doubling, from 47 million metric tonnes of U.S. foreign trade tankers in 2001 to 94 million metric tonnes in 2020. The EPA study also notes that "while this fuel is used to carry trade goods to and from the United States, it is not necessarily all purchased in the United States" (RTI 2009). The data provided in the study do indicate, however, that of the 94 million total metric tonnes of HFO and MDO/MGO bunker fuel that support U.S. foreign trade, 10.66 million metric tonnes of this bunker fuel, $11.3 \%$, is consumed within U.S. ECA waters.

$\mathrm{CO}_{2}$ is the primary greenhouse gas (GHG) emitted by ocean-going vessels (OGVs), with $\mathrm{NO}_{\mathrm{x}}$ and ozoneproducing reactive organic gases (ROGs) also being produced, when OGVs approach, are berthed at, and depart U.S. seaports. However, the recent IMO and California air emission regulations have focused primarily on the sulfur content of marine bunker fuel, to reduce $\mathrm{SO}_{\mathrm{x}}$ emissions and several other air pollutants, with $\mathrm{CO}_{2}$ reduction being a valuable byproduct of these regulations. In addition, the nation's largest ports - namely, the Ports of Los Angeles and Long Beach on the West Coast in particular-have instituted various clean air policies and, in recent years, voluntary programs that especially involve speed reduction in U.S. coastal waters, which reduces petroleum fuel use, the GHG pollutants, and other health damaging pollutants, including $\mathrm{SO}_{\mathrm{x}}, \mathrm{NO}_{\mathrm{x}}$, particulate matter $(\mathrm{PM})$, black carbon, and sulfate $\left(\mathrm{SO}_{4}\right)$. Similarly, the Port of Richmond, while a relatively small California port, has estimated which port area activities of OGVs cause the most GHG emissions, as shown in Table A.1 (City of Richmond, California 2010). It indicates how the most annual tons of emissions consist of $\mathrm{CO}_{2}(6,448)$ and some $\mathrm{NO}_{\mathrm{x}}(119)$ and ROGs (4.7), with normal cruising emitting the most $\mathrm{CO}_{2}$, and slow cruising (voluntarily at 12 knots instead of the California-required 15 knots, from the Golden Gate Bridge to Richmond) currently emitting about $16 \%$ less $\mathrm{CO}_{2}$. (The financial incentives of speed reduction in port coastal waters are addressed in the following sections).

Substantial fuel and emissions savings are achievable and already are being accomplished at dockside through reducing the hotelling shipboard power use of berthed vessels, not only at Richmond, but also at Los Angeles and Long Beach. As shown in Table A.1 (City of Richmond, California 2010), though hotelling (using a ship's onboard auxiliary diesel engine and its MDO/MGO fuel to power onboard lights, heating, food preparation, and so forth) contributes about one-fourth of the $\mathrm{NO}_{\mathrm{x}}, \mathrm{SO}_{\mathrm{x}}$, and $\mathrm{PM}$ that the nation's ports are trying to eliminate to protect local area air quality, it also contributes about one-fourth of the $\mathrm{CO}_{2}$ of visiting and embarking OGVs. Therefore, this appendix also focuses on port hotelling 
designed to reduce emissions of primarily $\mathrm{NO}_{\mathrm{x}}, \mathrm{SO}_{\mathrm{x}}$, and $\mathrm{PM}$, since they also reduce significant amounts of $\mathrm{CO}_{2}$, the longest lasting global warming pollutant.

Table A.1. Estimated Annual OGV Port of Richmond Emissions by Operational Mode (tons/year)

\begin{tabular}{lcccccc}
\hline \multicolumn{1}{r}{ Source } & $\mathrm{ROG}$ & $\mathrm{CO}$ & $\mathrm{NO}{ }_{\mathrm{x}}$ & $\mathrm{PM}$ & $\mathrm{SO}_{\mathrm{x}}$ & $\mathrm{CO}_{2}$ \\
\hline Cruise & 1.8 & 3.9 & 49.4 & 5.0 & 37.6 & 2,410 \\
\hline Slow cruise & 1.8 & 3.2 & 34.5 & 3.0 & 18.2 & 2,000 \\
\hline Maneuvering & 0.4 & 0.6 & 6.1 & 0.6 & 4.3 & 389 \\
\hline Hotelling & 0.7 & 2.3 & 28.6 & 2.7 & 23.0 & 1,649 \\
\hline Total & $\mathbf{4 . 7}$ & $\mathbf{1 0 . 0}$ & $\mathbf{1 1 9}$ & $\mathbf{1 1 . 3}$ & $\mathbf{8 3 . 1}$ & $\mathbf{6 , 4 4 8}$ \\
\hline
\end{tabular}

Sources: Port of Richmond Clean Air Action Plan, June 28, 2010, Draft Final, and SF Bay Area Seaports Air Emission Inventory; Port of Richmond 2005 Emissions Inventory, Bay Planning Coalition, October 2009; and Honda Port of Entry at the Point Potrero Marine Terminal, Final Environmental Impact Report, September 2008 (City of Richmond, California, 2010).

The Ports of Los Angeles and Long Beach will be discussed first because, as shown in Table A.2 (City of Richmond, California), their 2008 combined emissions of $\mathrm{CO}_{2}$ annually comprise more than 2.175 million short tons, a substantial portion of the world's international maritime emissions, which were 1,157 million short tons (1,050 metric tons) in 2007. Their importance to domestic GHG emissions is heightened because $45 \%$ of maritime cargo entering the United States goes through these two ports. By comparison, Port Elizabeth, New Jersey, the next largest port, handles 11\% (Quinter 2011).

Table A.2. Estimated Annual Emissions (tons/year) for Selected California Ports

\begin{tabular}{lrrrrrr}
\hline \multicolumn{1}{c}{ Port } & $\mathrm{ROG}$ & $\mathrm{CO}$ & $\mathrm{NO}$ & $\mathrm{PM}$ & $\mathrm{SO}_{\mathrm{x}}$ & $\mathrm{CO}_{2}$ \\
\hline Port of Richmond & 8.6 & 28.1 & 164 & 13.4 & 84.7 & 11,573 \\
\hline Port of Oakland & 248 & 886 & 4,005 & 273 & 1,427 & $\mathrm{NA}$ \\
\hline Port of Long Beach & 705 & 2,938 & 13,687 & 882 & 5,534 & $1,024,087$ \\
\hline Port of Los Angeles & 837 & 4,052 & 15,223 & 857 & 3,804 & $1,151,983$ \\
\hline
\end{tabular}

Sources: SF Bay Area Seaports Air Emission Inventory, Port of Richmond 2005 Emissions Inventory, Bay Planning Coalition, October 2009; Honda Port of Entry at the Point Potrero Marine Terminal, Final Environmental Impact Report, September 2008; Revised Port of Oakland 2005 Seaport Air Emissions Inventory, Environ International Corporation, March 14, 2008; Port of Long Beach Air Emissions Inventory - 2008, Starcrest Consulting Group, December 2009; and Port of Los Angeles Air Emissions Inventory - 2008, Starcrest Consulting Group, December 2009 (as cited in City of Richmond, California, 2010).

\section{A.5.1 West Coast}

In 2005, the Ports of Los Angeles and Long Beach jointly adopted a Green Port Plan to reduce emissions generated by incoming, outgoing, and berthed ships; cargo handling equipment; harbor crafts (towboats and tugboats); and trucks and rail carriers that deliver and receive cargo at dockside. This was closely followed by the California Global Warming Solutions Act of 2006, which applied to these ports plus the Ports of Oakland, San Francisco, and Hueneme. This regulation requires ships at-berth to turn off auxiliary engines and use either shore-based power or other measures to reduce $\mathrm{SO}_{\mathrm{x}}, \mathrm{NO}_{\mathrm{x}}$, and $\mathrm{PM}$ to improve local air quality. Of course, far larger amounts of $\mathrm{CO}_{2}$ are reduced at the same time. 


\section{Ship Speed Reduction}

The combination of voluntary programs for OGVs under the Green Port Program at the Los Angeles and Long Beach facilities, plus other California regulations, has done much in recent years to reduce emissions at California ports, which immediately impact both local landside air quality and global climate change. The voluntary measures at these ports implemented for ocean-going ships that have achieved additional reductions of $\mathrm{CO}_{2}$ include $100 \%$ compliance of Hamburg Sud ships, which have employed the 12-knots or less speed-reduction policy to reduce $\mathrm{CO}_{2}$ emissions once they were 20 nautical miles from the Port of Long Beach; also, 99\% of their ships did so within 40 miles of the port (Port of Long Beach, undated; Sanfield and Wong 2011). For the two San Pedro Bay ports, the acceptance of the voluntary speed reduction part of both ports' strategy is apparent by the fact that overall compliance began at $67 \%$ in 2005, increased to $84 \%$ in 2007, and in 2008, rose to $92 \%$ at Long Beach and $89 \%$ at Los Angeles (City of Richmond, California 2010). The success of the ship (OGV) portion of the San Pedro Bay Ports Clean Air Action Plan in reducing $\mathrm{CO}_{2}$ emissions and a comparable amount of low-sulfur marine diesel fuel, the only petroleum fuel allowed in these harbors, is evident in Table A.3, which shows a $24 \%$ reduction between 2005 and 2009 (the Port of Los Angeles). In addition, the Port of Los Angeles 2010 Inventory of Air Emissions indicates an additional 45,000 metric tons reduction of total port $\mathrm{CO}_{2}$ equivalent emissions (Starcrest 2010), which is a 60\% increase over the 75,000 annual ton reduction achieved between 2005 and 2009. Notably, the total twenty-foot container equivalent units (TEUs) handled increased from 7.48 million in 2005 to 7.83 million in 2010 (Starcrest 2010).

\section{Cold Ironing}

Another key aspect of the emissions reductions at the Ports of Los Angeles and Long Beach has been their development of "cold ironing"-namely, shore-power or ship electrification - the practice of supplying electrical power from shore-side sources while a ship is at berth. Most ships at berth worldwide still operate their auxiliary engines by using MDO onboard to accomplish the "hotelling" functions described above. The Port of Los Angeles, which has trademarked the term "Alternative Maritime Power" (AMP) for its cold ironing systems, is installing AMP systems at 15 of its berths, and the Port of Long Beach is installing cold ironing systems at 16 of its berths. The $\mathrm{CO}_{2}$ GHG emissions savings described above and shown in Table A.3 (Port of Los Angeles Air Quality Report Card, 2005-2009) at the Port of Los Angeles also occurred in part due to the use of the ships' auxiliary engines at berthside, since six of their planned AMP berths have not yet been built (Tetra Tech 2007), while the rest used power supplied by area power plants. Although the populations in the vicinity of power plants in the area have experienced some increase in these and other emissions, California and Los Angeles city and port officials have chosen this tradeoff option to provide significant relief from the very high levels of pollution to which citizens in the port-area, asthma-ridden neighborhoods were being exposed.

Table A.3. Port of Los Angeles $\mathrm{CO}_{2}$-equivalent Reductions by Source Type, 2005-2009

\begin{tabular}{lcc}
\hline & \multicolumn{2}{c}{ Calendar Year 2005-2009 } \\
\cline { 2 - 3 } Source Type & $\begin{array}{c}\% \mathrm{CO}_{2} \\
\text { Reduction }\end{array}$ & Metric Tons \\
\hline Ocean-going vessels & $-24 \%$ & 74,724 \\
Harbor craft & $-2 \%$ & 1,164 \\
Cargo handling equipment & $-5 \%$ & 6,125 \\
Rail & $-32 \%$ & 26,744 \\
Heavy-duty vehicles & $-13 \%$ & 67,170 \\
Total & & $\mathbf{1 7 5 , 9 2 7}$ \\
\hline
\end{tabular}

Source: Port of Los Angeles Air Quality Report Card, 2005-2009.

Other U.S. West Coast ports that use cold ironing include those in Oakland, California (the first U.S. port to introduce cold ironing technology at a container terminal); Tacoma (Cannon 2008; Corbetta; Port of 
Seattle 2010) and the Port of Portland in Oregon, which is using shore power for resident harbor vessels, such as tugs and small ships, that berth for extended periods (IISS 2010); and the Port of Houston's new Bayport Terminal (Cannon 2008). Similarly, the Port of Vancouver, Canada, and six European ports are using shore power, as well as the Ports of Shanghai and Osaka in Japan. This is complemented by more than 200 shore-power connecting units that are installed or being installed on ships that use or plan to use these facilities (Corbetta, undated).

Several factors are leading to the worldwide growth of cold ironing, which is still in the evaluation stage at most U.S. East and West Coast ports. These factors include the steadily increasing cost of onboard fuel versus shore-side electricity. For example, in 2008, a British port technology journal estimated that for a vessel calling in California and paying $11 \notin$ per $\mathrm{kW}-\mathrm{hr}$, the 24 -hour bill for drawing 1,600 kW of shoreside electricity would be $\$ 4,200$ - less than half the price of burning medium diesel oil onboard (Sisson and McBride). Further, the U.S. cost comparison is improving with time for cold ironing because the IMO has officially designated the waters off North American Coasts as an ECA under the MARPOL agreements, with stringent emission standards for fuel sulfur and $\mathrm{NO}_{\mathrm{x}}$. In addition, as previously described in this appendix, while set in 2010 at 10,000 ppm, this standard will tighten in 2015 to $1,000 \mathrm{ppm}$ and thereby require a substantially more expensive fuel.

\section{A.5.2 Gulf Coast}

\section{Ship Speed Reduction}

Vessel speed reduction (VSR) for OGVs in the Houston Ship Channel (HSC) has been evaluated by the Port of Houston Authority (PHA). However, it has been found to be ineffective for fuel and emission reduction, since OGVs are already required to slow down to navigate the channel. In its 2011 Clean Air Strategy Plan, the port does list as a potential future action "having ships slow their speed approximately 20 miles from the entrance to the HSC" (Port of Houston 2011 The strategy document does not state whether this would be attempted through regulation or by implementing the financial incentives used by other ports. A review of several other research studies and industry trade publications (cited in the previous West Coast subsection) found no other references to potential VSR programs at Gulf Coast ports, such as New Orleans.

\section{Cold Ironing}

The PHA also has been investigating usage of shoreside power (cold ironing) to reduce MDO/MGO use by OGVs while at berth. In its 2011 Clean Air Strategy Plan, the PHA found that this measure had only limited potential. This is despite the 2008 study information (cited in the previous West Coast subsection) that the PHA had invested \$1.4 million at the new Baymont Terminal to provide infrastructure for cold ironing cables (Cannon 2008). However, listed as potential actions are (1) to determine whether the type and frequency of OGV visits at the Barbour Cut, Bayport, and Jacintoport Terminals are sufficient in number to make shore power feasible and (2) to conduct a cost-benefit analysis (Port of Houston 2011). Similarly, a study of best environmental practices at worldwide seaports found that "the infrequency of repeat same-ship visits makes shore power much less cost effective for smaller seaports" (Port of Seattle 2010), as compared with major containership ports. This issue also has contributed to the fact that cold ironing has not even been considered at any other Gulf Coast port.

\section{A.5.3 East Coast}

\section{Ship Speed Reduction}

The Port Authority of New York and New Jersey (PANYNJ) has committed to and implemented an OGV speed reduction policy that differs somewhat from those on the West Coast. As noted in its clean air strategy report (Port Authority NY-NJ 2009), it is designed as a four-year program from 2009 through 2012. After that, the program will incorporate, as a mandatory component, an OGV low-sulfur fuel-use program that includes financial incentives. The financial incentives will be awarded only if a vessel uses $0.2 \%$ low-sulfur MDO or MGO instead of high-sulfur HFO while operating within 20 nautical miles of the Port of New York or New Jersey, as well as while hotelling at berth. Additionally, a vessel must 
operate at no more than an average-weighted speed of 10 knots within the 20 nautical mile zone (Port Authority NY-NJ, undated). The financial incentives, which began in 2010 , provide $50 \%$ reimbursement of the additional cost of using the $0.2 \%$ low-sulfur MDO/MGO instead of the high-sulfur HFO.

Furthermore, the program takes advantage of shipping company preparations to comply with the IMO requirement that 1\% sulfur fuel must be used in U.S. ECAs beginning in 2015.

Unfortunately, this research could find no other voluntary or combination voluntary/mandatory OGV speed reduction policies on the East Coast.

\section{Cold Ironing}

The New York and New Jersey Clean Air Plan does not commit to the installation of cold-ironing shoreside power at any OGV cargo terminals. Instead, it relies on the portion of the low-sulfur fuel/speed reduction program that specifies the use of low-sulfur MDO/MGO fuel while berthing. Similarly, while the PANYNJ and other East Coast ports are investigating the use of cold ironing and other measures to reduce tug and towboat GHG emissions, none have any definitive commitments (Port Authority NY-NJ 2009).

Currently, the West Coast (especially California) and the PANYNJ are the only U.S. major seaports that operate voluntary VSR policies, and only West Coast ports extensively use cold ironing with shoreside power at berth. However, considerable potential remains for more success in implementing these OGV policies in U.S. waters by 2050. 


\section{REFERENCES}

Åkerman, Jonas. 2005. "Sustainable air transport—on track in 2050." Transportation Research Part D: Transport and Environment no. 10 (2):111-126.

Allegro. 2001. How Pipelines Make the Oil Market Work -- Their Networks, Operation and Regulation. New York, NY: Allegro Energy Group. http://www.iatp.org/files/451_2 31375.pdf

American Apparel Producers Network. 2010. "Crowley Completes Harbor Class Tugs Re-Powering Project in LA/Long Beach.” In American Apparel Producers Network.

American Feeder Lines. American Feeder Lines: Vision and Mission: The Realization of America's Marine Highway undated. http://www.american-feeder-lines.com/en/home/index.html .

American Trucking Associations. 2008. New Generation Wide Base Single Tires.

. 2010. Is Natural Gas a Viable Alternative to Diesel for the Trucking

Industry? http://www.truckline.com/AdvIssues/Energy/Natural\%20Gas/Natural\%20Gas\%20Alternative \% 20-\%20White\%20Paper\%200610.pdf

Andersen, Stephen, Durwood Zaelke. 2003. Industry Genius: Innovations and People Protecting the Climate and Fragile Ozone Layer. Sheffield UK: Greenleaf Publishing.

Association of American Railroads. 2010. Railroad Facts 2010 Edition.

2011. Freight Railroads Help Reduce GHG Emissions Factsheet. Association of American Railroads. http://www.aar.org/ /media/aar/background-papers/freight-rr-help-reduce-emissions.ashx

Bachman, L.Joseph, Anthony Erb, Cheryl L. Bynum. 2005. "Effect of Single Wide Tires and Trailer Aerodynamics on Fuel Economy and NOx Emissions of Class 8 Line-Haul Tractor-Trailers." SAE International no. 05CV-45.

Ball, Jeffrey. 2011. "Natural Gas Trucks Face Long Haul.” The Wall Street Jounal, May 17, 2011.

Barami, B., M. Dyer. 2009. Appendix G-Assessment of Short-Sea Shipping Options for Domestic Applications, Final Report. Prepared by The Volpe Center, Research and Innovative Technology Administration (RITA), U.S. Department of Transportation, Cambridge (ONR), prepared for Office of Naval Research, Arlington, VA. http://ntl.bts.gov/lib/32000/32700/32734/ONR_SSS_Final_Report Revised_Dec 23.pdf

Barnard, Bruce. 2011. "Maersk Buys 10 Super-Sized Containerships.” Journal of Commerce (Feburary 21):1-3. http://joc.com/maritime/maersk-buys-10-super-sized-container-ships

Barringer, Felicity. 2011. “Court Affirms California's Marine Emissions Rules.” In New York Times (green blogs).

Biodiesel Magazine. 2011. "NBB technical team collaborates with railway industry."

Black, H.A., C. Papavizas. 2008. U.S. Kick Starts New Marine Highway Program. Winston \& Strawn LLP. http://www.martindale.com/members/Article_Atachment.aspx?od=101644\&id=534046\&filename= asr-534050.pdf

Braslow, Albert L. 1999. A History of Suction-Type Laminar-Flow Control with Emphasis on Flight

Research. Washington DC: NASA History

Division. http://www.nasa.gov/centers/dryden/pdf/88792main_Laminar.pdf

Breitling, U. 2010. "Sustainable Shipping and Port Development." In 5th Regional EST Forum in Asia. Bankok, Thailand. 
Bureau of Transportation Statistics. 2010. 2007 Commodity Flow Survey. Washington DC: Bureau of Transportation Statistics and U.S. Census

Bureau. http://www.bts.gov/publications/commodity flow survey/

2011. T-100 Market and Segment. Washington DC: Bureau of Transportation

Statistics. http://www.bts.gov/xml/air traffic/src/index.xml\#CustomizeTable

2012. National Transportation Statistics 2012. Washington, DC.: Bureau of Transportation Statistics, Research and Innovative Technology Administration, U.S. Department of Transportation.

California Air Resources Board. 2008. Reducing Ship Hotelling (Phase II) - Workgroup Meeting.

California Environmental Protection

Agency. http://www.arb.ca.gov/ports/shorepower/march08presentation.pdf

Cambridge Systematics. 2007. National Rail Freight Infrastructure Capacity and Investment Study. prepared for Association of American Railroads.

Cannon, J.S. 2008. U.S. Container Ports and Air Pollution: A Perfect Storm. Energy Futures, Inc. http://s3.amazonaws.com/energy-futures.com/port study ef.pdf

Capps, Gary, Oscar Franzese, Bill Knee, Mary Beth Lascurain, Pedro Otaduy. 2008. Class-8 Heavy Truck Duty Cycle Project Final Report. ORNL/TM-2008/122. Oak Ridge, Tennessee: Oak Ridge National Laboratory.

Ceccio, Stephen. 2011. Air Lubrication Drag Reduction on Great Lakes Ships. University of Michigan study for Great Lakes Maritime

Institute. http://www.glmri.org/downloads/2011Reports/Ceccio_Simo2011.pdf

City of Richmond California. 2010. Clean Air Action Plan for the Port of Richmond, Draft Final Report. http://www.ci.richmond.ca.us/DocumentView.aspx?DID=5917

Clauss, G.F. , H. Sickmann, B.G. Tampier. 2007. Simulation of the Operation of Wind-Assisted Cargo Ships. In 102 Hauptversammlung der Shiffbautechnischen Gesellschaft. Berlin, Germany, November 2123.

Comeaux, N.P. 2010. Department of Transportation Announces Selection of Marine Highway Corridors, Projects, Initiatives, and Grants as Part of Marine Highway Program. Office of Marine Highways and Passenger Services, Maritime Administration, U.S. Department of Transportation. http://www.marad.dot.gov/ships_shipping_landing_page/mhi_home/mhi home.htm

Congressional Budget Office. 1982. Energy Use in Freight Transportation. Washington DC:

Congressional Budget

Office. http://www.cbo.gov/sites/default/files/cbofiles/ftpdocs/53xx/doc5330/doc02b-entire.pdf

Corbett, J. J., H. Wang, J. J. Winebrake. 2009. Impacts of Speed Reductions on Vessel-Based Emissions for International Shipping. In 88th Annual Meeting of Transportation Research Board. Washington DC.

Corbett, James J., James J. Winebrake, Haifeng Wang. 2010. "International Shipping and GHG Emissions: From Assessment to Mitigation.” TR News no. 268 (May-June):40-

44. http://onlinepubs.trb.org/onlinepubs/trnews/trnews268.pdf

Corbetta, Luciano. undated. Making Cold Ironing Make Sound Business Sense. Port Technology International, 23-26 pp. http://www.porttechnology.org/images/uploads/technical papers/23-261.pdf

CREATE. 2011. CREATE Presentation, October 2011.

Crist, Philippe. 2009. GHG Emissions Reduction Potential from International Shipping. Discussion Paper No. 2009-11. Joint Transport Research Centre of the OECD and the International Transport Forum. http://www.internationaltransportforum.org/jtrc/discussionpapers/DP200911.pdf 
Croft, John. 2012. Open rotor noise not a barrier to entry: GE. In Flight Global. Washington DC.

Davis, Stacy C., Susan W. Diegel, Robert G. Boundy. 2011. Transportation Energy Data Book: Edition 30. Oak Ridge, TN: Oak Ridge National Laboratory. http://cta.ornl.gov/data/download30.shtml

deKat, J.O. 2011. Sustainable Shipping: Innovative Solutions. EP Visit Briefing, Innovation Department, Maersk Maritime Technology, January 13.

Det Norske Veritas. 2010. Assessment of measures to reduce future $\mathrm{CO}_{2}$ emissions from shipping,

Research and Innovation, Position Paper. Hovik,

Norway. http://www.dnv.com/binaries/assessments $\% 20$ of $\% 20$ measures $\% 20$ to $\% 20$ reduce $\% 20$ future $\% 20 \mathrm{c}$ o2\%20emissions $\% 20$ from $\% 20$ shipping tcm $4-438729$.pdf

Dryer, Jay. 2010. ARMD Fundamental Aeronautics Program. In NASA Green Aviation Summit. Mountain View, CA.

EC/R Incorporated. 2005. The Philadelphia Port-Diesel Particulate Emissions Sources and Potential Control Measures. prepared for U.S. Environmental Protection

Agency. http://www.dieseldifference.org/resources/reports/EPA\%20Port\%20PM\%20Emissions\%20Repo rt.pdf

U.S. Department of Energy Office of Energy Efficiency and Renewable Energy. 2011. "Natural Gas Vehicle Emissions." In Alternative and Advanced Vehicles Data Center.

Energy Information Administration. 2007a. About US Natural Gas Pipelines - Transporting Natural Gas. Washington DC: Energy Information Administration, U.S. Department of Energy. http://www.eia.gov/pub/oil_gas/natural_gas/analysis_publications/ngpipeline/index.html .

- 2007b. Natural Gas Compressor Stations on the Interstate Pipeline Network: Developments Since 1996. Washington DC: Energy Information Administration, U.S. Dept. of Energy. http://www.eia.gov/pub/oil_gas/natural gas/analysis_publications/ngcompressor/ngcompressor.p $\underline{\mathrm{df}}$

2011a. Annual Energy Outlook 2011 with Projections to 2035. Washington DC: Energy Information Adminstration, U.S. Dept. of Energy. http://www.eia.gov/analysis/projectiondata.cfm\#annualproj

. 2011 b. Annual Energy Review 2010. Washington, DC: Energy Information Administration, U.S. Department of Energy. http:/www.eia.gov/totalenergy/data/annual/pdf/aer.pdf

Endresen, O., M.S. Eide. 2008. "The Environmental Impacts of Increased International Maritime Shipping - Past Trends and Future Perspectives." In Det Norske Veritas briefing.

Engelstoft, M. 2010. "Slow Steaming Is Here to Stay.” Lloyd's List:July 7.

U.S. Environmental Protection Agency. 2010a. Median Life, Annual Activity, and Load Factor Values for Nonroad Emissions Modeling. Washington, DC.: Office of Transportation and Air Quality

Report. http://www.epa.gov/oms/models/nonrdmdl/nonrdmdl2010/420r10016.pdf

- 2010b. Nonroad Engine Population Estimates. Washington, D.C.: Office of Transportation and Air Quality Report. http://www.epa.gov/oms/models/nonrdmdl/nonrdmd12010/420r10017.pdf

Environmental Protection Agency, National Highway Traffic Safety Administration. 2011. "Greenhouse Gas Emissions Standards and Fuel Efficiency Standards for Medium- and Heavy-Duty Engines and Vehicles: Final Rules." Federal Register Vol. 76 No. 179. http://www.gpo.gov/fdsys/pkg/FR-2011-0915/pdf/2011-20740.pdf 
Federal Aviation Administration. 2005. Aviation and Emissions: A Primer. Federal Aviation Administration Office of Environment and

Energy. http://www.faa.gov/regulations_policies/policy_guidance/envir_policy/media/aeprimer.pdf

. 2011. Aerospace Forecast: Fiscal Years 2011-2031. Washington DC: Federal Aviation

Administration, U.S. Department of

Transportation. http://www.faa.gov/about/office org/headquarters offices/apl/aviation forecasts/aerospac e forecasts/2011-2031/media/2011\%20Forecast $\% 20$ Doc.pdf

Federal Highway Administration. 1999. Highway Statistics 1998. Washington DC: Federal Highway Administration, U.S. Department of Transportation. http://www.fhwa.dot.gov/ohim/hs98/hs98page.htm

- 2006. Freight Analysis Framework. Federal Highway Administration, U.S. Department of Transportation. http://ops.fhwa.dot.gov/freight/freight analysis/faf/index.htm

- 2009. Highway Statistics 2008. Washington DC: Federal Highway Administration, U.S. Department of Transportation. http://www.fhwa.dot.gov/policyinformation/statistics/2008/

Federal Railroad Administration. 2011. Rail Fuel Efficiency Study (Draft). Washington DC: U.S. Dept. of Transportation, Federal Railroad Administration.

Folga, S. 2011. personal communication.

Franzese, Oscar, Helmut Knee, Lee Slezak. 2010. "Effect of Wide-Based Single Tires on Fuel Efficiency of Class-8 Combination Trucks." Transportation Research Record: Journal of the Transportation Research Board (2191). http://info.ornl.gov/sites/publications/files/Pub20686.pdf

Fritz, S. G. 2000. "The Potential for LNG as a Railroad Fuel in the US." Transactions of the ASME no. 122 (January):130.

Gaines, Linda, Anant Vyas, John L. Anderson. 2006. "Estimation of Fuel Use by Idling Commercial Trucks." In 85th Annual Meeting of the Transportation Research Board, Washington DC.

Giemsch, P. , A. Jellinghaus. undated. Optimizing Models for the Containership Stowage Problem. Karlsruhe, Germany: Universitat Karlsruhe.

Gravel, Ronald. 2011. Overview of the DOE High Efficiency Engine Technologies R\&D.

Great Lakes Information Network. undated. Great Lakes Ports \& Shipping - Travel Between Ports. In Great Lakes Information Network.

Greener by Design. 2005. Air Travel - Greener by Design: Mitigating the Environmental Impact of Aviation: Opportunities and Priorities. Royal Aeronautical

Society. http://www.greenerbydesign.org.uk/ FILES/publications/GbD\%20\%202005\%20Science \%20and\%20Technology\%20Report.pdf

Greenpacks.org. 2010. Green Tugboats for Greener Seas.

Grenzeback, L.R.; Brown, A.; Fischer, M.J.; Hutson, N.; Lamm, C.R.; Pei, Y.L.; Vimmerstedt, L.; Vyas, A.D.; Winebrake, J.J. 2013. Freight Transportation Demand: Energy-Efficient Scenarios for a LowCarbon Future. Transportation Energy Futures Series. Prepared by Cambridge Systematics, Inc., and the National Renewable Energy Laboratory (Golden, CO) for the U.S. Department of Energy, Washington, DC. DOE/GO-102013-3711.

Greszler, Anthony. 2010. "Technologies and Policies for Improving Truck Fuel Efficiency and Reducing $\mathrm{CO}_{2}$. . In Climate and Transportation Solutions, edited by Daniel Sperling and James S. Cannon.

Hapag-Lloyd. 2011. New American Feeder Line Service Connecting Halifax with Portland, Maine and Boston, Massachusetts. 
Hazeldine, T., A. Pridmore, D. Nelisen, J. Hulskotte. 2009. EU Transport GHG: Routes to 2050? Technical Options to Reduce GHG for Non-Road Transport Modes (Paper 3). AEA Plc, CE Delft, and TNO paper prepared for Directorate-General Environment, European Commission. http://www.eutransportghg2050.eu/cms/assets/UPDATED-EU-Transport-GHG-2050-Paper-3-Technicaloptions-for-non-road-modes-30-10-09.pdf

Hoifodt, Tore. 2011. "World's Most Efficient Container Vessels Contracted in China.” Det Norske Veritas-Managing Risk (June 20):1-

2. http://www.dnv.com/press area/press_releases/2011/seaspancontainership.asp

Holter, Andreas, Heikki Liimatainen, Alan McKinnon, Julie Edwards. 2010. "Double-deck Trailers: A Cost-benefit Model Estimating Environmental and Financial Savings." In 15th Annual Logistics Research Network Conference. Harrogate, UK.

Hughes, Chris. 2010. “Geared Turbofan Technology.” In NASA Green Aviation Summit. Mountain View CA.

ICAO. 2010. "Report of the independent experts on fuel burn reduction technology goals." Paper read at Committee on Aviation Environmental Protection (CAEP) Steering Group Meeting, Novemeber 2010, at Toulouse, France.

ICF International. 2009a. Comparative Evaluation of Rail and Truck Fuel Efficiency on Competetive Corridors. Prepared for the Federal Railroad

Administration. http://www.fra.dot.gov/Downloads/Comparative Evaluation Rail Truck Fuel Efficienc y.pdf

- 2009b. Tug/Towboat Emission Reduction Feasibility Study - Draft Final Report. Prepared for U.S. Environmental Protection Agency.

IEA. 2009. Directorate of Sustainable Energy Policy. Paris, France. http://www.iea.org/textbase/nppdf/free/2009/transport2009.pdf

IISS. 2010. The International Institute for Sustainable Seaports, Environmental Initiatives at Seaports Worldwide: A Snapshot of Best Practices - Final. Prepared for Port of

Portland. http://ecbiz103.inmotionhosting.com/ getfor5/wp-content/uploads/2011/06/FINALEnvironmental-Initiatives-at-Seaports-Worldwide-April-2010.pdf

IMERS. 2011. International Maritime Emission Reduction Scheme - Case for Affordable Action.

International Council of Clean Transportation. undated. Marine. Washington, D.C.: International Council of Clean Transportation, 1-3 pp.

International Maritime Organization. 2000. Study of Greenhouse Gas Emissions from Ships. Trondheim, Norway: International Maritime Organization, in partnership with MARINTEK, Carnegie Mellow University, Det Norske Veritas, and ECON, Center for Economic

Analysis. http://unfecc.int/files/methods and science/emissions from intl transport/application/pdf/imoghg main.pdf

2009. Second IMO GHG Study 2009. London UK: International Maritime Organization.

Intergovernmental Panel on Climate Change. 2007. "Transport and its infrastructure." In Climate Change 2007: Mitigation. Contriution of Working Group III to the Fourth Assessment Report of the Intergovernmental Panel on Climate Change, edited by B. Metz, O.R. Davidson, P.R. Bosch, R. Dave and L.A. Meyer. Cambridge and NY: Cambridge University Press.

Jamin, Solomon, Andreas Schäfer, Moshe E. Ben-Akiva, Ian A. Waitz. 2004. "Aviation emissions and abatement policies in the United States: a city-pair analysis." Transportation Research Part D: Transport and Environment no. 9 (4):295-317. 
Lack, Daniel A., Christopher D. Cappa, Justin Langridge, Roya Bahreini, Gina Bualoe, Charles Brock, Kate Cerully, Derek Co!man, Katherine Hayden, John Holloway, Brian Lerner, Paola Massoli, Shao-Meng Li, Robert McLaren, Ann M. Middlebrook, Richard Moore, Athanasios Nenes, Ibraheem Nuaanan, Timothy B. Onasch, Jeff Peischl, Anne Perring, Patricia K. Quinn, Tom Ryerson, Joshua P. Schwartz, Ryan Spackman, Steven C. Wofsy, Doug Worsnop, Bin Xiang, Eric Williams. 2011. "Impact of Fuel Quality Regulation and Speed Reductions on Shipping Emissions: Implications for Climate and Air Quality.” Environmental Science \& Technology no. 45 (20):9052-9060.

Lai, Yung-Cheng (Rex), Christopher P.L. Barkan. 2005. "Options for Improving the Energy Efficiency of Intermodal Freight Trains." Transportation Research Record: Journal of the Transportation Research Board no. 1916:47-55. http://ict.illinois.edu/railroad/CEE/pdf/Lai\%20\%26\%20Barkan\%202005.pdf

Lai, Yung-Cheng, Christopher P.L. Barkan, Hayri Onal. 2007. "Optimizing the aerodynamic efficiency of intermodal freight trains." Transportation Research Part

E:doi:10.1016/j.tre.2007.05.011. http://ict.illinois.edu/railroad/CEE/pdf/Lai\%20et\%20al\%202007\%20TR E.pdf

LaMonica, Martin. 2010. Navistar eStar electric delivery trucks get rolling. In CNET News.

Lee, David S., David W. Fahey, Piers M. Forster, Peter J. Newton, Ron C. N. Wit, Ling L. Lim, Bethan Owen, Robert Sausen. 2009. "Aviation and global climate change in the 21st century." Atmospheric Environment no. 43 (22-23):3520-3537.

Lee, Joosung J., Stephen P. Lukachko, Ian A. Waitz, Andreas Schafer. 2001. "Historical and Future Trends in Aircraft Performance, Cost, and Emissions." Annu. Rev. Energy Environ. no. 26:167200. http://dx.doi.org/10.1146/annurev.energy.26.1.167

Lepsoe, Arve. 1997. Use of computer aided weather routing systems on ships, (in Norwegian only). Trondheim Norway: Norwegian University of Technology and Science, Faculty of Marine Technology.

Lloyd's Register. 2009. "Fairplay.”

Macintosh, Andrew, Lailey Wallace. 2009. "International aviation emissions to 2025: Can emissions be stabilised without restricting demand?" Energy Policy no. 37 (1):264-273.

Mack, R., A Haines. 2011. “American Feeder Line to Launch First Service.” March 1.

Maritime Administration. 2011. Maritime Administration, in consultation with U.S. Environmental Protection Agency, America's Marine Highway: Report to Congress. Washington, D.C: U.S. Department of Transportation. http://www.marad.dot.gov/documents/MARAD AMH Report to Congress.pdf

McCollum, David, Gregory Gould, David Greene. 2009. GHG Emissions from Aviation and Marine Transportation: Mitigation Potential and Policies. Pew Center on Global Climate Change. http://www.pewclimate.org/docUploads/aviation-and-marine-report-2009.pdf

Melaina, M.W.; Heath, G.; Sandor, D.; Vimmerstedt, L.; Warner, E.; Webster, K.W. 2013 (forthcoming). Alternative Fuel Infrastructure Expansion: Costs, Resources, Production Capacity, and Retail Availability for Low-Carbon Scenarios. Transportation Energy Futures Series. Prepared for the U.S. Department of Energy by National Renewable Energy Laboratory, Golden, CO. DOE/GO-102013-3710.

Merchant, B. 2010. “Obama Admin. to Speed Up Offshore Wind Power Development” In Treehugger. Millikin, Mike. 2011a. "ASTM committee votes to approve biojet fuel in blends up to 50\%." In Green Car Congress.

- 2011b. "Westport enters consortiaum agreement with EMD to develope natural gas fuel system for rail locomotives." In Green Car Congress. 
Mindanao Federation of Shippers Association Inc. 2009. "North to South Mindanao Logistics Corridor Key to Fast Track, It's Economic Development." Paper read at 1st Mindanao Logistics Conference, Nov. 25-26, at Cagayan de Oro, Philippines. http://www.minfesa.org/

Nakicenovic, N. , J. Alcamo, G. Davis, B.D. Vries. 2000. Special Report on Emissions Scenarios. Cambridge, U.K.: Cambridge University Press.

Nakicenovic, N., R. Swart. 2001. Special Report on Emissions Scenarios: A Special Report of Working Group III of the International Panel on Climate Change. Cambridge, U.K.: Cambridge University Press.

National Academy of Sciences. 2010. Technologies and Approaches to Reducing the Fuel Consumption of Medium- and Heavy-Duty Vehicles. Washington DC: Board on Energy and Environmental Systems Division on Engineering and Physical Sciences, Transportation Research Board http://www.nap.edu/catalog.php?record id=12845

NESCAF, ICCT, SwRI, TIAX LLC. 2009. Reducing Heavy-Duty Long Haul Combination Truck Fuel Consumption and $\mathrm{CO}_{2}$ Emissions.

http://www.nescaum.org/documents/heavy-duty-truck-ghg report final-200910.pdf/view

NESCAUM. 2006. "Scoping Study to Evaluate the Emissions of Harbor Craft Operating in Boston Harbor and Potential Control Options." http://www.northeastdiesel.org/pdf/2006-0425--BostonHarborScopingFinalReport.pdf

National Highway Traffic Safety Administration (NHTSA). 2000. Vehicle Indentification Number Requirements. 49CFR565.6. Washington, DC.: National Highway Traffic Safety Administration, U.S. Department of Transportation. http://longhorntrailers.com/pdf/Vehicle-Identification-NumberRequirements.pdf

National Renewable Energy Laboratory. 2009. Biodiesel Handling and Use Guide.

New Jersey Department of Environmental Protection. 2011. Estimated Air Quality Impacts on Surrounding Communities of PM 2.5 and SO2 Emissions Resulting from Maritime Operations at the Elizabeth Port Authority. Marine Terminal and Port Newark: Phase 2 Future Impacts (2015). Division of Air Quality Environmental Regulation, Department of Environmental

Protection. http://www.stopthesoot.org/port\%20modeling\%20phase \%202\%20FINAL\%206-24-11.pdf

Nyhus, Eirik. 2009. "Climate change policies and shipping - decoding the issues." Det Norske Veritas:1-3. http://www.dnv.com/industry/maritime/publicationsanddownloads/publications/dnvcontainer shipupdate/2009/3-2009/climatechangepoliticsandshippingdecodingtheissues.asp

Ocean Policy Research Foundation. 2008. Ocean Policy Research Foundation, Research Study: The World's Changing Maritime Industry and a Vision for Japan.

Tokyo. http://www.sof.or.jp/en/report/pdf/200805 ISBN978 4 88404 212 7.pdf

OSG. Crude Oil.

Owen, Bethan, David S. Lee, Ling Lim. 2010. "Flying into the Future: Aviation Emissions Scenarios to 2050." Environ. Sci. Technol. no. 44:2255-2260. http://dx.doi.org/10.1021/es902530z

Pan, Ballot, Fontaine. 2009. "The reduction of greenhouse gas emissions from freight transport by merging supply chains." In International Conference on Industrial Engineering and Systems Management (IESM), May 13-15.

Parsons, M.G., M Kotinis. 2011. Refinement of the Ballast-Free Ship Concept - Final Report. Department of Naval Engineering, University of Michigan, prepared for Great Lakes Maritime Institute. http://www.glmri.org/downloads/2010Reports/ParsonsKotinis0910.pdf

Paur, Jason. 2011. "High Cost Makes Aviation Biofuel Slow to Take Off.” In Wired Autopia Blog. 
Peeters, P. M., J. Middel, Hoolhorst A. 2005. Fuel efficiency of commercial aircraft, An overview of historical and future trends. NLR-CR-2005-669. The Netherlands: National Aerospace Laboratory NLR.

Pepsico. 2011. Frito-Lay Electric Delivery Trucks Hit the "Green” Streets of Orlando.

Perry, J.C. 2008. America's Deep Blue Highway - How Coastal Shipping Could Reduce Traffic

Congestion, Lower Pollution, and Bolster National Security. Institute for Global Maritime Studies, in cooperation with The Fletcher School of Law and Diplomacy, Tufts

University. http://www.igms.org/sites/default/files/publishedworks/americas_deep_blue highway_IGMS report_sept_2008.pdf

Plotkin, S.; Stephens, T.; McManus, W. 2013. Vehicle Technology Deployment Pathways: An Examination of Timing and Investment Constraints. Transportation Energy Futures Series. Prepared for the U.S. Department of Energy by Argonne National Laboratory, Argonne, IL. DOE/GO-102013-3708.

Port Authority of New York and New Jersey. undated."Ocean-Going Vesel Low-Sulfur Fuel Program.” 2009. A Clean Air Strategy Plan for the Port of New York and New Jersey -

Final. http://www.panynj.gov/about/pdf/CAS-FINAL.pdf

Port of Baltimore. 2011. "Moran Pulls Its Weight - Company Gets Plugged in to Environmental Efforts." Port of Baltimore Magazine.

Port of Houston. 2011. Clean Air Strategy Plan. Port of Houston Authority. http://www.portofhouston.com/static/gen/inside-the-port/Environment/CASP-2011.pdf

Port of Long Beach. undated. "Green Flag Incentive Program."

- 2011. The Port of Los Angeles, San Pedro Bay Ports Clean Air Action Plan - Strategies to Reduce Emissions from Harbor Craft.

Port of Los Angeles, Port of Long Beach. 2010. San Pedro Bay Ports Clean Air Action Plan Technology Advancement Program, 2009 Annual Report, Moving Towards Zero

Emissions. http://www.cleanairactionplan.org/civica/filebank/blobdload.asp?BlobID $=2470$

Port of Seattle. 2010. Port of Seattle, Port of Tacoma, Port Metro Vancouver, Northwest Ports Clean Air Strategy 2010 Implementation Report. http://www.portoftacoma.com/nwpcas

Porter, C.D.; Brown, A.; DeFlorio, J.; McKenzie, E.; Tao, W.; Vimmerstedt, L. 2013. Effects of Travel Reduction and Efficient Driving on Transportation: Energy Use and Greenhouse Gas Emissions.

Transportation Energy Futures Series. Prepared by the National Renewable Energy Laboratory, (Golden, CO) and Cambridge Systematics, Inc., for the U.S. Department of Energy, Washington, DC. DOE/GO102013-3704.

Porter, C.D.; Brown, A.; Dunphy, R.T.; Vimmerstedt, L. 2013. Effects of the Built Environment on Transportation: Energy Use, Greenhouse Gas Emissions, and Other Factors. Transportation Energy Futures Series. Prepared by the National Renewable Energy Laboratory (Golden, CO) and Cambridge Systematics, Inc., for the U.S. Department of Energy, Washington, DC. DOE/GO-102013-3703.

Quinter, Peter. 2011. “Todd Owen - U.S. Customs Commission Bersin's Hand-Picked Leader in Los Angeles." In Customs \& International Trade Law Blog: Becker \& Poliakoff.

Rodrique, J P. 2011. "Chapter 5, The Geography of Transport Systems.” In Globalization and International Trade. Hofstra University Department of Global Studies and Geography.

Rotz, Derek, Kevin Sisken. 2011. Daimler SuperTruck Program: Vehicle Project Review.

RTI International, EnSys Energy \& Systems Inc. 2009. Global Trader and Fuels Assessment - Additional ECA Modeling Scenarios. Washington, D.C: prepared for Assessment and Standards Division, Office of Transportation and Air Quality, U.S. Environmental Protection Agency. 
Ruth, M.; Mai, T.; Newes, E.; Aden, A.; Warner, E.; Uriarte, C; Inman, D.; Simpkins, T.; Argo, A. 2013. Projected Biomass Utilization for Fuels and Power in a Mature Market. Transportation Energy Futures Series. Prepared for the U.S. Department of Energy by National Renewable Energy Laboratory, Golden, CO. DOE/GO-102013-3707.

Rutherford, Daniel, Mazyar Zeinali. 2009. Efficiency Trends for New Commercial Jet Aircraft 1960-2008. The International Council on Clean

Transportation. http://www.theicct.org/sites/default/files/publications/ICCT Aircraft Efficiency final.pdf

Sabnis, Jayant. 2010. "Propulsion System Challenges and Solutions." In NASA Green Aviation Summit. Mountain View CA.

Safe Seas. 2010. Maritime - U.S. Approves New Jones Act Feeder Line.

Sanfield, P., A. Wong. 2011. "Ports of Los Angeles and Long Beach Announce Clean Air Award Winners," News Release of the Port of Los Angeles and Port of Long Beach, July 26.

Schrank, D, W Lomax. 2007. The 2005 Urban Mobility Report. Texas Transportation Institute. http://mobility.tamu.edu/ums/

Sisson, P.E., K McBride. 2010. “The Economics of Cold Ironing." Port Technology International (October):1-

4. http://www.broward.org/Port/MasterPlan/Documents/PTI\%20Cold\%20Ironing\%20Economics.pdf

2009. EU Transport GHG: Routes to 2050? - Technical Options for Maritime and Inland Shipping. briefing at European Commission Stakeholder Meetings July 2.

Smith, Richard F., Xudong Jia, Jawaharial Mariappan. 2008. Electrification of the Freight Train Network from the Ports of Los Angeles and Long Beach to the Inland Empire. Pomona CA: California State Polytechnic University.

Stanton, Donald. 2011. Cummins SuperTruck Program: Technology and System Level Demonstration of Highly Efficient and Clean, Diesel Powered Class 8 Trucks.

Starcrest Consulting Group. 2011. The Port of Los Angeles Inventory of Air Emissions for Calendar Year 2010. Prepared for the Port of Los

Angeles. http://www.portoflosangeles.org/pdf/2010_Air_Emissions_Inventory.pdf

Stephens, T. 2013. Non-Cost Barriers to Consumer Adoption of New Light-Duty Vehicle Technologies. Transportation Energy Futures Series. Prepared for the U.S. Department of Energy by Argonne National Laboratory, Argonne, IL. DOE/GO-102013-3709.

Stodolsky, Frank. 2002. Railroad and Locomotive Technology Roadmap. Argonne National Laboratory.

Stollery, Phil. 2008. ATM Global Environment Efficiency Goals for 2050, Reducing the Impact of Air Traffic Management on Climate Change. CANSO Environment Work Group.

Straight, Brian. 2011. Paper Transport Testing a Dual-Fuel Engine. FleetOwner.

Tankers International. "What is a Pool."

Tetra Tech, Inc. 2007. Use of Shore-Side Power for Ocean-Going Vessels. prepared for American Association of Port Authorities.

http://www.westcoastcollaborative.org/files/sector-marine/AAPA-ShorePower-050107.pdf

The Economist. 2011. "The future of flight: Changes in the air." Sept. 3, 2011.

Thornton, M. 2011. "Panama Canal Expansion Could Bring Shift in Distribution Patterns." In REJournals.com. 
TIAX LLC. 2010. Demonstration of a Liquid Natural Gas Fueled Switcher Locomotive at Pacific Harbor Line, Inc. Irvine, CA: prepared for the Port of Long

Beach. http://www.cleanairactionplan.org/civica/filebank/blobdload.asp?BlobID=2462

U.S. Census Bureau. 2004. Vehicle Inventory and Use Survey 2002, Microdata File and User Documentation. VIUS02. Washington DC: U.S. Census Bureau, U.S. Dept. of Commerce. http://www.census.gov/svsd/www/vius/2002.html

U.S. Department of Defense. 2010. Strategic Sustainability Performance Plan FY 2010.

VEM Motors. 2009. "Worlds First Hybrid Tugboat in Long Beach.” In VEM Motors Finland Oy.

Vock, Daniel C. 2012. "Eastern ports scramble to get ready for new Panama Canal era." In Stateline.

Voegele, Erin. 2011. "Steaming Ahead to a Better Fuel.” In Biodiesel Magazine.

Vyas, A. D.; Patel, D. M.; Bertram, K. M. 2013. Potential for Energy Efficiency Improvement Beyond the Light-Duty-Vehicle Sector. Transportation Energy Futures Series. Prepared for the U.S. Department of Energy by Argonne National Laboratory, Argonne, IL. DOE/GO-102013-3706.

Wahls, Rich. 2010. "N+3 Technologies and Concepts." In NASA Green Aviation Summit. Mountain View CA.

Wald, Matthew L. 2011. "UPS Finds a Substitute for Diesel: Natural Gas, at 260 Degrees Below Zero." In New York Times Green Blog.

Walsh, G.M. 2007. "Fuel Management for Tugs Becoming an Increasing Challenging." Professional Mariner (106). http://www.professionalmariner.com

Wang, Haifeng. 2009. GHG Marginal Abatement Cost and Its Impacts on Emissions Peer Import Value from Containerships in United States. Marine Policy Program, University of Delaware. http://www.epa.gov/ttnchie1/conference/ei18/session7/wang.pdf

Wartsila. 2008. "Boosting Energy Efficiency.” Energy Efficiency Catalogue/Ship Power R\&D. 


\section{REFERENCES BY MODE}

Trucks: (ATA 2008, 2010; Bachman, Erb, and Bynum 2005; Ball 2011; Capps et al. 2008; CFS07 2010; Davis, Diegel, and Boundy 2011; Rotz 2011; EERE 2011; EPA and NHTSA 2011; Brown, Dunphy, et al. 2012; FHWA 1999, 2009; Franzese, Knee, and Slezak 2010; Gaines, Vyas, and Anderson 2006; Gravel 2011; Greszler 2010; ICF International 2009a; LaMonica 2010; NAS 2010; NESCAF et al. 2009; NHTSA 2000; National Renewable Energy Laboratory 2009; Pepsico 2011; Stanton 2011; Straight 2011; VIUS02 2004; Wald 2011; Holter et al. 2010; EIA 2011a; BTS 2012)

Aviation: (Stephens 2012; Åkerman 2005; Grenzeback et al. 2012; Braslow 1999; BTS 2011; Dryer 2010; FAA 2005, 2011; GbD 2005; Hughes 2010; ICAO 2010; IPCC 2007; Plotkin, Stephens, and McManus 2012; Jamin et al. 2004; Ruth et al. 2012; Lee et al. 2009; Lee et al. 2001; Macintosh and Wallace 2009; McCollum, Gould, and Greene 2009; Millikin 2011a; Melaina et al. 2012; Vyas, Patel, and Bertram 2012; Owen, Lee, and Lim 2010; Paur 2011; Peeters, Middel, and A. 2005; Rutherford and Zeinali 2009; Sabnis 2010; Stollery 2008; The Economist 2011; Brown, DeFlorio, et al. 2012; Wahls 2010; Croft 2012; EIA 2011a; BTS 2012; Andersen and Zaelke 2003)

Marine: (AAPN 2010; AFL undated; Barami and Dyer 2009; Barnard 2011; Barringer 2011; Black and Papavizas 2008; Breitling 2010; Cannon 2008; CARB 2008; Ceccio 2011; City of Richmond California 2010; Clauss, Sickmann, and Tampier 2007; Comeaux 2010; Corbett, Wang, and Winebrake 2009; Corbett, Winebrake, and Wang 2010; Corbetta undated; Crist 2009; deKat 2011; Det Norske Veritas 2010; EC/R Incorporated 2005; Endresen and Eide 2008; Engelstoft 2010; FHWA 2006; Giemsch and Jellinghaus undated; GLIN undated; Greenpacks.org 2010; Hapag-Lloyd 2011; Hazeldine et al. 2009; Hoifodt 2011; ICCT undated; ICF International 2009b; IEA 2009; IISS 2010; IMERS 2011; IMO 2000, 2009; Lack et al. 2011; Lepsoe 1997; Lloyd's Register 2009; Mack and Haines 2011; MarAd 2011; McCollum, Gould, and Greene 2009; Merchant 2010; Mindanao Federation of Shippers Association Inc. 2009; Nakicenovic et al. 2000; Nakicenovic and Swart 2001; NESCAUM 2006; NJ-DEP 2011; Nyhus 2009; OPRF 2008; OSG; Pan, Ballot, and Fontaine 2009; Parsons and Kotinis 2011; Perry 2008; Port of Authority of NY and NJ undated; Port of Baltimore 2011; Port of Houston 2011; Port of Long Beach undated; Port of Seattle 2010; Quinter 2011; Rodrique 2011; RTI International and EnSys Energy \& Systems Inc 2009; Safe Seas 2010; Sanfield and Wong 2011; Schrank and Lomax 2007; Sisson and McBride 2010; Skinner 2009; Starcrest Consulting Group 2011; Tankers International; Tetra Tech 2007; The Port Authority of NY and NJ 2009; The Port of Long Beach 2011; Thornton 2011; VEM Motors 2009; Vock 2012; Walsh 2007; Wang 2009; Wartsila 2008; Port of Los Angeles and Port of Long Beach 2010; EIA 2011a)

Pipeline: (Allegro 2001; EIA 2007a, 2007b; Folga 2011; CBO 1982; EIA 2011b; BTS 2012)

Rail: (AAR 2010, 2011; Biodiesel Magazine 2011; FRA 2011; Fritz 2000; ICF International 2009a; Lai, Barkan, and Onal 2007; Lai and Barkan 2005; TIAX LLC 2010; Millikin 2011b; Smith, Jia, and Mariappan 2008; Stodolsky 2002; Voegele 2011; Cambridge Systematics 2007; CREATE 2011; EIA 2011a; BTS 2012)

Off Road: (EPA 2010a, 2010b; Davis, Diegel, and Boundy 2011)

Military: (DOD 2010) 



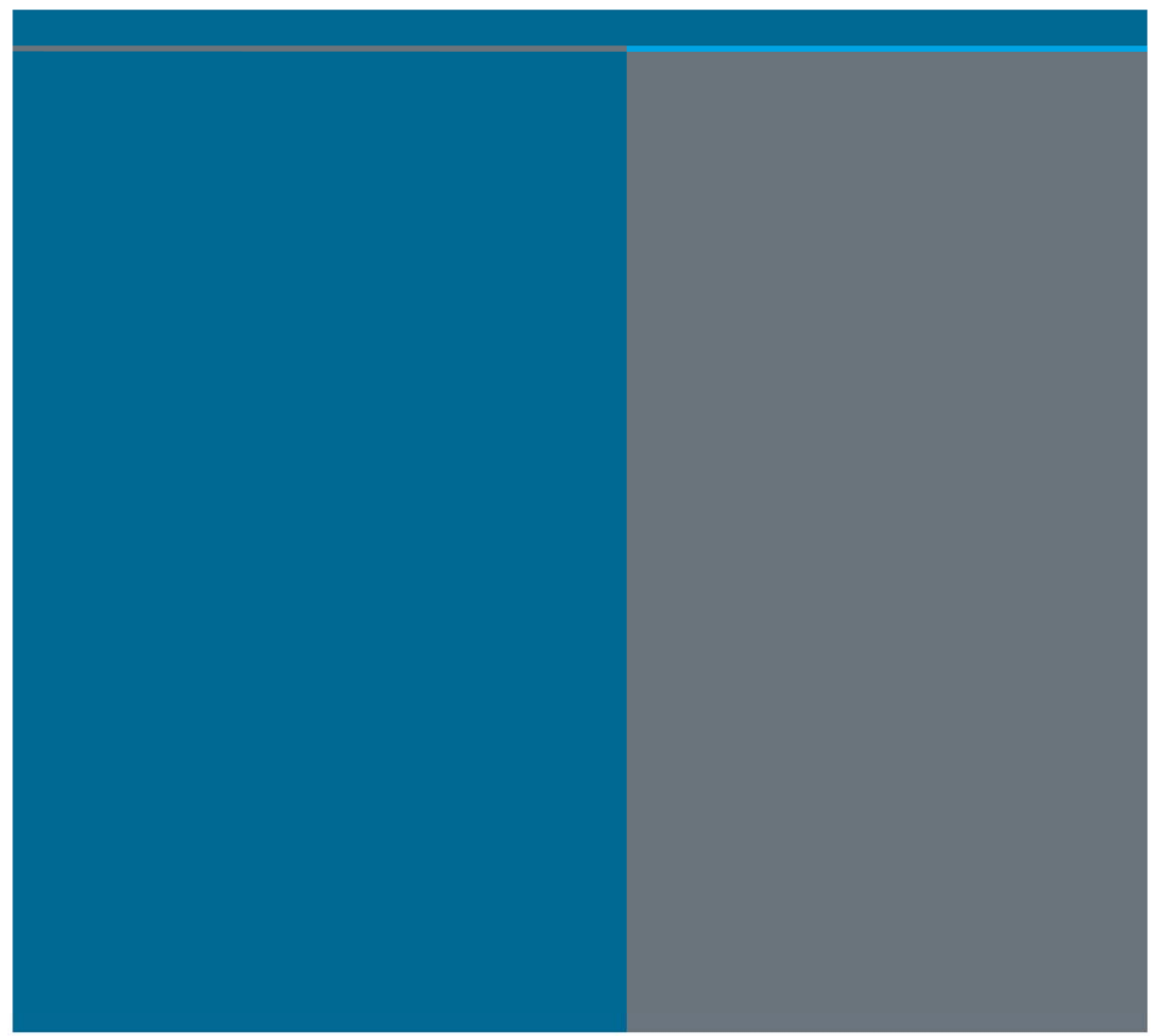

\section{u.s. Department of | Energy Efficiency \& Renewable Energy}

\section{MNREL}

Argonne

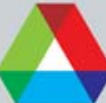

national laboratory

Prepared by ANL for the U.S. Department of Energy

The Transportation Energy Futures Series is a joint project of the National Renewable Energy Laboratory (NREL) and Argonne National Laboratory (ANL), national laboratories of the U.S. Department of Energy, Office of Energy Efficiency and Renewable Energy.

eere.energy.gov/analysis/transportationenergyfutures

DOE/GO-102013-3706 • March 2013

Printed with a renewable-source ink on paper containing at least $50 \%$ wastepaper, including $10 \%$ post consumer waste. 